RENATA ARGOLO LACERDA

MODELAGEM MATEMÁTICA DE PROCESSO DE PRODUÇÃO DE PVC POR POLIMERIZAÇÃO EM SUSPENSÃO EM REATOR DE BATELADA 
RENATA ARGOLO LACERDA

MODELAGEM MATEMÁTICA DE PROCESSO DE PRODUÇÃO DE PVC POR POLIMERIZAÇÃO EM SUSPENSÃO EM REATOR DE BATELADA

Dissertação apresentada à Escola Politécnica da Universidade de São Paulo para obtenção do título de Mestre em Engenharia 
RENATA ARGOLO LACERDA

\section{MODELAGEM MATEMÁTICA DE PROCESSO DE PRODUÇÃO DE PVC POR POLIMERIZAÇÃO EM SUSPENSÃO EM REATOR DE BATELADA}

Dissertação apresentada à Escola Politécnica da Universidade de São Paulo para obtenção do título de Mestre em Engenharia

Área de concentração:

Engenharia Química

Orientador:

Prof. Dr. Reinaldo Giudici 
Este exemplar foi revisado e alterado em relação à versão original, sob responsabilidade única do autor e com anuência de seu orientador.

São Paulo, 17 de abril de 2009.

Assinatura do autor:

Assinatura do orientador:

FICHA CATALOGRÁFICA

Lacerda, Renata Argolo

Modelagem matemática de processo de produção de

PVC por polimerização em suspensão em reatores batelada /

R.A. Lacerda. -- São Paulo, 2009.

$100 \mathrm{p}$.

Dissertação (Mestrado) - Escola Politécnica da Universidade de São Paulo. Departamento de Engenharia Química.

1. Polimerização 2. Cinética (Modelagem matemática) I.Uni versidade de São Paulo. Escola Politécnica. Departamento de Engenharia Química II.t. 


\section{DEDICATÓRIA}

Dedico este trabalho, primeiramente a

Deus, pois sem a Sua vontade nada seria possível, e a meus pais, pelo amor e confiança em mim depositada. 


\section{AGRADECIMENTOS}

Neste momento gostaria de expressar minha gratidão pelas pessoas que contribuíram para a realização deste projeto.

À minha família, pela acolhida e em especial a meus pais, pela compreensão e amor incondicional.

Ao Prof. Dr. Reinaldo Giudici, pela oportunidade oferecida assim como pelos ensinamentos e orientação para o desenvolvimento deste trabalho.

Aos meus amigos e ao meu namorado que contribuíram de maneira especial com apoio e companheirismo.

A Capes e ao LSCP pelo incentivo.

A todos que, direta ou indiretamente, colaboraram na concretização deste projeto. 


\section{RESUMO}

O poli(cloreto de vinila) - PVC - é o segundo termoplástico mais consumido no mundo devido a sua versatilidade e seu amplo espectro de utilização. $O$ desenvolvimento de modelos matemáticos representativos é de grande importância para o projeto, análise e otimização de processos de polimerização. A determinação das condições de operação ótimas para um reator de polimerização levando em conta as restrições operacionais e de qualidade do polímero produzido poderia, em princípio, ser realizada de maneira empírica. Entretanto, pode ser feita de maneira muito mais eficiente, econômica e segura através da solução de um problema de otimização. Para tanto, é imprescindível dispor de um modelo matemático representativo do processo de polimerização, confiável e validado experimentalmente em condições tão amplas quanto possível. Dentro deste panorama, o presente trabalho buscou desenvolver, a partir de modelos previamente descritos na literatura, um modelo matemático do processo de polimerização em suspensão de cloreto de vinila. Parâmetros do modelo referentes às limitações difusionais das constantes de terminação e propagação foram ajustados. As previsões do modelo foram comparadas com dados experimentais obtidos na literatura, referentes a diferentes tipos de iniciador, e diferentes condições operacionais. Verificou-se que o modelo desenvolvido foi capaz de representar adequadamente todos os dados experimentais testados quando ajustado individualmente para cada ensaio. Quando aplicada uma correlação generalizada para os parâmetros ajustáveis, o modelo representou de forma satisfatória, tanto qualitativa como quantitativamente, a maioria dos dados experimentais. As possíveis causas para as discrepâncias encontradas em alguns casos foram discutidas e recomendações para melhoramento do modelo foram apresentadas.

Palavras-chave: Polimerização em suspensão. PVC. Modelos matemáticos. Cinética. 


\section{ABSTRACT}

Poly (vinyl chloride) - PVC - is the second-largest thermoplastic that is consumed in the world because of its versatility and comprehensive series of application. The development of representative mathematical models is important for the design, analysis and optimization of polymerization processes. The determination of the optimal operational conditions for a polymerization reactor taking into account operational constraints and quality of the polymer produced could be, in principle, achieved by empirical trial-and-error procedure. However, this can be made in a much more efficient, economic, and safe way through the solution of an optimization problem for which it is required a representative mathematical model of the polymerization process. Such model should be reliable and validated over as wide a range of experimental conditions as possible. In this scenario, the objective of the present work was to develop a mathematical model for suspension polymerization of vinyl chloride, with the abovementioned features, from the models previously described in literature. Model parameters for the diffusion-controlled termination and propagation rate constant were estimated. The model predictions were compared with experimental data taken from the literature, covering different kinds of initiators and different operational conditions. It was found that the model was able to suitably represent all the experimental data tested when fitted for each run. When a general correlation for the adjustable parameters was obtained and included in the model, the model predictions reproduced satisfactorily most of the experimental data in both qualitative and quantitative fashions. Possible causes for the discrepancies found in some cases were discussed and recommendations for model improvement were suggested.

Keywords: Suspension polymerization. PVC. Mathematical models. Kinetics. 


\section{LISTA DE FIGURAS}

Figura 1 - Fluxograma simplificado do processo de produção do PVC (Instituto do PVC).

Figura 2 - Diagrama de fases da mistura PVC/VCM.

.28

Figura 3 - Modelo ajustado com os dados experimentais utilizando como iniciador o

Perkadox $(0,175 \%)$, a diferentes temperaturas.

Figura 4 - Modelo ajustado com os dados experimentais utilizando como iniciador o AIBN $(0,25 \%)$, a diferentes temperaturas .59

Figura 5 - Resultado do ajuste dos parâmetros A e B tendo como base os dados obtidos com os ajustes individuais feitos com o Perkadox $(0,175 \%)$ e o $\operatorname{AIBN}(0,25)$.

Figura 6 - Modelo ajustado com os dados experimentais utilizando como iniciador o TBPD a $45^{\circ} \mathrm{C}$, a diferentes concentrações.

Figura 7 - Modelo ajustado com os dados experimentais utilizando como iniciador o TBPD a $55^{\circ} \mathrm{C}$, a diferentes concentrações 62

Figura 8 - Modelo ajustado com os dados experimentais utilizando como iniciador o TBPD a $65^{\circ} \mathrm{C}$, a diferentes concentrações.

Figura 9 - Modelo ajustado com os dados experimentais utilizando como iniciador o LPO a $50^{\circ} \mathrm{C}$, a diferentes concentrações.

Figura 10 - Resultado do ajuste dos parâmetros A e B tendo como base os dados obtidos em todos os ajustes. 64

Figura 11 - Evolução da conversão do monômero ao longo da polimerização em suspensão do VCM com Perkadox como iniciador $(0,175 \%)$, a diferentes temperaturas. .66

Figura 12 - Evolução da pressão ao longo da polimerização em suspensão do VCM com Perkadox como iniciador $(0,175 \%)$, a $50^{\circ} \mathrm{C}$.

Figura 13 - Evolução da conversão do monômero ao longo da polimerização em suspensão do VCM com AIBN como iniciador (0,25\%), a diferentes temperaturas. 
Figura 14 - Evolução da conversão do monômero ao longo da polimerização em suspensão do VCM com AIBN como iniciador (0,16\%), a diferentes temperaturas.

Figura 15 - Evolução da conversão do monômero ao longo da polimerização em suspensão do cloreto de vinila com AIBN como iniciador a $60^{\circ} \mathrm{C}$, a diferentes concentrações.

Figura 16 - Evolução da conversão do monômero ao longo da polimerização em suspensão do VCM com TBPD como iniciador (0,0785\%), a diferentes temperaturas. .68

Figura 17 - Evolução da conversão do monômero ao longo da polimerização em suspensão do VCM com TBPD como iniciador a $45^{\circ} \mathrm{C}$, a diferentes concentrações.

Figura 18 - Evolução da conversão do monômero ao longo da polimerização em suspensão do VCM com TBPD como iniciador a $55^{\circ} \mathrm{C}$, a diferentes concentrações.

Figura 19 - Evolução da conversão do monômero ao longo da polimerização em suspensão do VCM com TBPD como iniciador a $65^{\circ} \mathrm{C}$, a diferentes concentrações.

Figura 20 - Evolução da conversão do monômero ao longo da polimerização em suspensão do VCM com LPO como iniciador a $50^{\circ} \mathrm{C}$, a diferentes concentrações.

Figura 21 - Evolução da conversão do monômero ao longo da polimerização em suspensão do VCM com LUP como iniciador a $56,5^{\circ} \mathrm{C}$, a diferentes concentrações.

Figura 22 - Evolução da conversão do monômero ao longo da polimerização em suspensão do VCM com PDEH como iniciador (0,606 g/kg de VCM), a diferentes temperaturas.

Figura 23 - Evolução da pressão ao longo da polimerização em suspensão do VCM com PDEH como iniciador $(0,606 \mathrm{~g} / \mathrm{kg}$ de VCM), a diferentes temperaturas..........72

Figura 24 - Comparação entre as constantes cinéticas de decomposição do LPO. ......76 Figura 25 - Comparação entre as constantes cinéticas de decomposição do PDEH.....76 
Figura 26 - Simulação do modelo utilizando diferentes valores de constante de

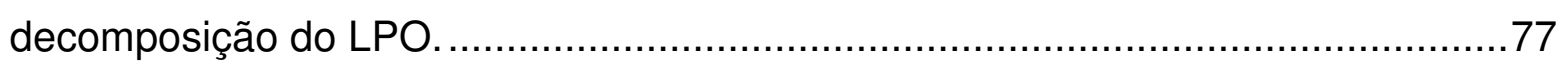

Figura 27 - Simulação do modelo utilizando diferentes valores de constante de

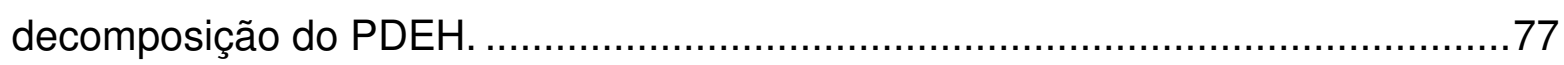

Figura 28 - Comparação entre as constantes cinéticas de propagação reportadas por

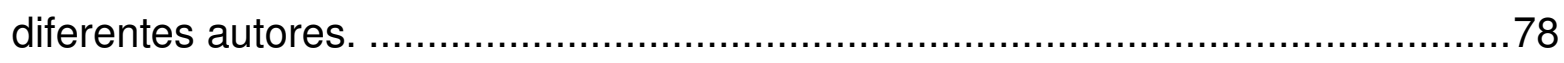

Figura 29 - Comparação entre as constantes cinéticas de terminação reportadas por

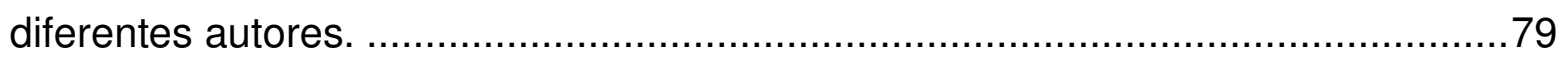

Figura 30 - Comparação entre o grupo de constantes cinéticas $\mathrm{k}_{\mathrm{po}} /\left(\mathrm{k}_{\mathrm{to}}\right)^{1 / 2}$ reportados por

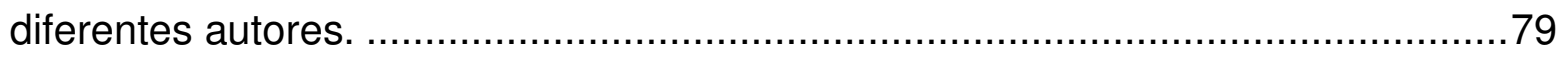




\section{LISTA DE TABELAS}

Tabela 1 - Esquematização das estruturas das espécies presentes no meio reativo. ...36 Tabela 2 - Parâmetros usados nos cálculos da fração de volume livre (Krallis et al.,

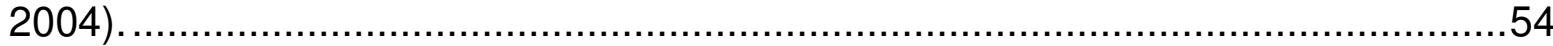

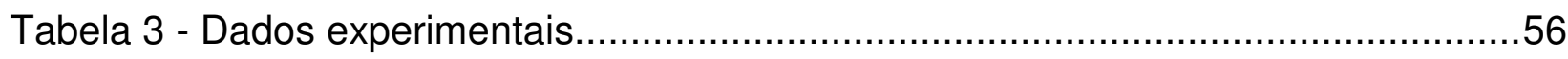

Tabela 4 - Dados e parâmetros cinéticos de decomposição dos iniciadores.................57

Tabela 5 - Valores dos parâmetros ajustados a cada ensaio realizado com o Perkadox e

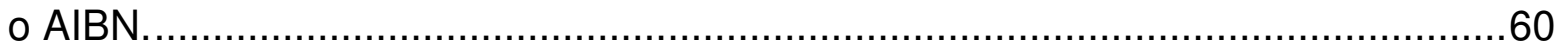

Tabela 6 - Valores dos parâmetros ajustados a cada ensaio realizado com o TBPD e o

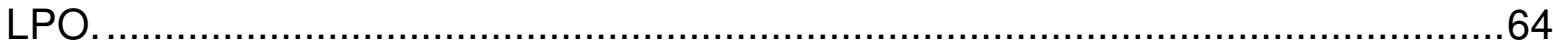

Tabela 7 - Constantes cinéticas de decomposição dos iniciadores. .............................75 


\section{LISTA DE SÍMBOLOS}

A parâmetro ajustável, definido na equação 38

$A_{i} \quad$ parâmetro ajustável, definido na equação 49

$A_{p} \quad$ parâmetro ajustável, definido nas equações 45 e 46

$A_{t} \quad$ parâmetro ajustável, definido nas equações 47 e 48

$B \quad$ parâmetro ajustável, definido na equação 41

$D_{n} \quad$ cadeia de polímero morto de tamanho $n$

f eficiência do iniciador

$f_{0} \quad$ eficiência do iniciador na ausência de limitações difusionais

$f_{b} \quad$ eficiência do iniciador bifuncional

$f_{b A} \quad$ eficiência do iniciador associada à iniciação de cadeias de polímeros ativas pela decomposição de $R_{A}$

$f_{b B} \quad$ eficiência do iniciador associada à iniciação de cadeias de polímeros ativas pela decomposição de $R_{B}$

$f_{i r} \quad$ fração de novos macroradicais formados pela decomposição de espécies moleculares do tipo $Q_{n}, S_{n}, U_{n}, U_{n}^{\prime}, V_{n}, V_{n}^{\prime}$ e $W_{n}$

F $\quad$ função objetivo

$[I]_{j} \quad$ concentração de iniciador na fase $\mathrm{j},\left[\mathrm{mol} \mathrm{L}^{-1}\right]$

j índice indicativo da fase ( 1 = rica em monômero e 2 = rica em polímero)

$k_{d} \quad$ taxa de decomposição do iniciador, $\left[\mathrm{s}^{-1}\right]$ 
$k_{d, i}^{j} \quad$ taxa de decomposição do iniciador monofuncional na fase $\mathrm{j},\left[\mathrm{s}^{-1}\right]$

$k_{d A}^{j} \quad$ taxa de decomposição associada ao peróxido do tipo A na fase j, [ $\left.\mathrm{s}^{-1}\right]$

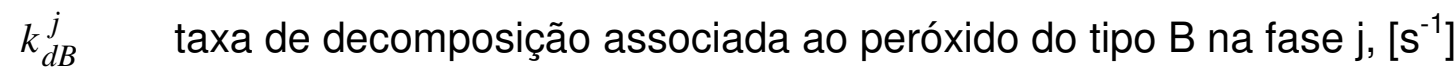

$k_{I}^{j} \quad$ taxa de iniciação na fase $\mathrm{j},\left[\mathrm{L} \mathrm{mol}^{-1} \mathrm{~s}^{-1}\right]$

$k_{p}^{j} \quad$ taxa de propagação na fase $\mathrm{j},\left[\mathrm{L} \mathrm{mol}^{-1} \mathrm{~s}^{-1}\right]$

$k_{f m}^{j} \quad$ taxa de transferência de cadeia para monômero na fase j, [ $\left.\mathrm{L} \mathrm{mol}^{-1} \mathrm{~s}^{-1}\right]$

$k_{b}^{j} \quad$ taxa de transferência intramolecular na fase $\mathrm{j},\left[\mathrm{L} \mathrm{mol}^{-1} \mathrm{~s}^{-1}\right]$

$k_{t c}^{j} \quad$ taxa de terminação por combinação na fase $\mathrm{j},\left[\mathrm{L} \mathrm{mol}^{-1} \mathrm{~s}^{-1}\right]$

$k_{t d}^{j} \quad$ taxa de terminação por desproporcionamento na fase $\mathrm{j},\left[\mathrm{L} \mathrm{mol}{ }^{-1} \mathrm{~s}^{-1}\right]$

$k_{z}^{j} \quad$ taxa de inibição na fase $\mathrm{j},\left[\mathrm{L} \mathrm{mol}^{-1} \mathrm{~s}^{-1}\right]$

$k_{p 0} \quad$ constante de propagação na ausência de limitações difusionais, [ $\mathrm{L} \mathrm{mol}^{-1} \mathrm{~s}^{-1}$ ]

$k_{p 1} \quad$ constante de propagação na fase rica em monômero, [L mol $\left.{ }^{-1} \mathrm{~s}^{-1}\right]$

$k_{p 2} \quad$ constante de propagação na fase rica em polímero considerando o efeito da difusão sobre as cadeias poliméricas, $\left[\mathrm{L} \mathrm{mol}^{-1} \mathrm{~s}^{-1}\right]$

$k_{t 0} \quad$ constante de terminação na ausência de limitações difusionais, [ $\mathrm{L} \mathrm{mol}^{-1} \mathrm{~s}^{-1}$ ]

$k_{t 1} \quad$ constante de terminação na fase rica em monômero, $\left[\mathrm{L} \mathrm{mol}^{-1} \mathrm{~s}^{-1}\right]$

$k_{t 2} \quad$ constante de terminação na fase rica em polímero considerando o efeito da difusão sobre as cadeias poliméricas, $\left[\mathrm{L} \mathrm{mol}^{-1} \mathrm{~s}^{-1}\right]$

$K \quad$ constante de solubilidade do cloreto de vinila na fase aquosa

KI coeficiente de partição do iniciador 
$M_{0} \quad$ massa inicial de cloreto de vinila, [g]

$M_{n} \quad$ massa molecular média numérica, [ $\left.\mathrm{g} \mathrm{mol}^{-1}\right]$

$M_{w} \quad$ massa molecular média mássica, $\left[\mathrm{g} \mathrm{mol}^{-1}\right]$

$M_{1} \quad$ massa de cloreto de vinila na fase rica em monômero, [g]

$M_{2} \quad$ massa de cloreto de vinila na fase rica em polímero, [g]

$M_{a} \quad$ massa de cloreto de vinila na fase aquosa, [g]

$M_{g} \quad$ massa de cloreto de vinila na fase gasosa, [g]

$M_{g\left(X_{f}\right)} \quad$ massa de cloreto de vinila na fase gasosa, na conversão crítica, [g]

$\left\lfloor M_{j}\right\rfloor \quad$ concentração de monômero na fase j, [g L-1]

$M W_{i} \quad$ massa molecular do iniciador, $\left[\mathrm{g} \mathrm{mol}^{-1}\right]$

$M W_{m} \quad$ massa molecular do cloreto de vinila, [ $\mathrm{g} \mathrm{mol}^{-1}$ ]

$N_{o} \quad$ número de mols inicial do monômero, [mol]

$N_{I o} \quad$ número de mols inicial de iniciador, [mol]

$N_{I} \quad$ número de mols de iniciador no instante t, [mol]

$N_{m} \quad$ número de iniciadores monofuncionais

$P_{n} \quad$ cadeia de polímero ativa de tamanho $\mathrm{n}$

$P D \quad$ índice de polidispersidade

$P_{m} \quad$ pressão parcial do monômero, [atm]

$P_{m}^{o} \quad$ pressão de saturação do monômero, [atm]

PVC poli(cloreto de vinila) 
$Q_{n} \quad$ cadeia de polímero vivo de tamanho n contendo um grupo peróxido do tipo A

$R \quad$ constante universal dos gases, [atm $\left.\mathrm{L} \mathrm{mol}^{-1} \mathrm{~K}^{-1}\right]$

$R^{j} \quad$ radical primário que não contém grupo peróxido na fase j

$r_{\lambda, x} \quad$ função momento do polímero de espécie $\mathrm{x}$

$R_{A}^{j} \quad$ radical primário contendo um grupo peróxido do tipo A na fase j

$R_{B}^{j} \quad$ radical primário contendo um grupo peróxido do tipo $\mathrm{B}$ na fase $\mathrm{j}$

$R^{. j} \quad$ diradical primário na fase $\mathrm{j}$

$\left\lfloor R_{j}\right\rfloor \quad$ concentração total de radicais na fase $\mathrm{j}$, $\left[\mathrm{mol} \mathrm{L}^{-1}\right]$

$R D$ parâmetro de difusão por reação

$S_{n} \quad$ cadeia de polímero vivo de tamanho n, contendo um grupo peróxido do tipo B

$t \quad$ tempo, [s]

$T \quad$ temperatura do reator, $[\mathrm{K}]$

$T_{g M} \quad$ temperatura de transição vítrea do monômero, $[\mathrm{K}]$

$T_{g P} \quad$ temperatura de transição vítrea do polímero, [K]

$T_{n} \quad$ cadeia de polímero vivo de tamanho $\mathrm{n}$ contendo dois radicais

$U_{n} \quad$ cadeia de polímero inativo de tamanho $\mathrm{n}$, contendo um grupo peróxido do tipo A

$U_{n}^{\prime} \quad$ cadeia de polímero inativo de tamanho $\mathrm{n}$, contendo dois grupos peróxidos do tipo A

V volume da fase dispersa, [L] 
VCM monômero cloreto de vinila

$V_{f} \quad$ fração de volume livre da mistura

$V_{f}^{*} \quad$ fração de volume livre da mistura na conversão crítica

$V_{f m} \quad$ fração de volume livre do monômero

$V_{f p} \quad$ fração de volume livre do polímero

$V_{j} \quad$ volume da fase $j,[L]$

$V_{n} \quad$ cadeia de polímero inativo de tamanho n, contendo um grupo peróxido do tipo B

$V_{n}^{\prime} \quad$ cadeia de polímero inativo de tamanho $\mathrm{n}$, contendo dois grupos peróxidos do tipo B

$V_{r} \quad$ volume total do reator, [L]

$W_{i} \quad$ fração do volume do reator preenchida inicialmente com líquido

$W_{n} \quad$ cadeia de polímero inativo de tamanho $\mathrm{n}$, contendo dois grupos peróxidos, $\mathrm{A}$ e B

$W_{w} \quad$ massa de água introduzida no reator, [g]

X conversão do monômero

$X_{f} \quad$ conversão crítica

$y_{i} \quad$ valores de conversão obtidos da literatura

$\hat{y}_{i} \quad$ valores de conversão calculados pelo modelo

Z inibidor 


\section{Letras gregas}

$\alpha_{M} \quad$ fator de dilatação térmica do monômero, $\left[\mathrm{K}^{-1}\right]$

$\alpha_{P} \quad$ fator de dilatação térmica do polímero, $\left[\mathrm{K}^{-1}\right]$

$\phi_{2} \quad$ fração volumétrica de polímero na fase polimérica

$\phi_{2, c} \quad$ fração volumétrica crítica de polímero na fase polimérica

$\phi_{m j} \quad$ fração volumétrica do monômero na fase j

$\rho_{m} \quad$ densidade do monômero, $\left[\mathrm{g} \mathrm{L}^{-1}\right]$

$\rho_{p} \quad$ densidade do polímero, $\left[\mathrm{g} \mathrm{L}^{-1}\right]$

$\rho_{w} \quad$ densidade da água, $\left[\mathrm{g} \mathrm{L}^{-1}\right]$

$\rho_{g o} \quad$ densidade nas condições de gás ideal, [g L $\left.{ }^{-1}\right]$

x parâmetro de interação de Flory-Huggins

$\theta \quad$ temperatura, $\left[{ }^{\circ} \mathrm{C}\right]$

$\theta_{p} \quad$ parâmetro ajustável, definido na equação 51

$\theta_{t} \quad$ parâmetro ajustável, definido na equação 50

$\lambda_{\xi, k} \quad$ função momento de ordem $\mathrm{k}$, associada a cadeias de polímero vivos

$\lambda_{\theta, k} \quad$ função momento de ordem $\mathrm{k}$, associada a cadeias de polímeros inativos

$\mu_{k} \quad$ função momento de ordem $\mathrm{k}$, associada a cadeias de polímeros mortos 


\section{SUMÁRIO}

1 INTRODUÇÃO

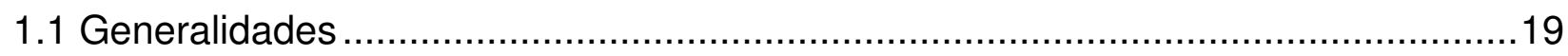

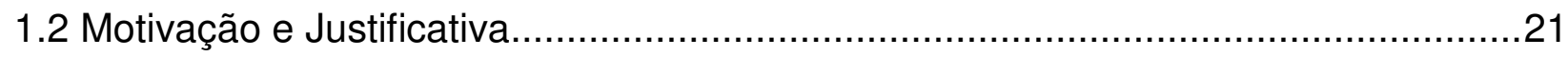

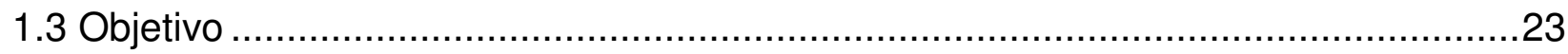

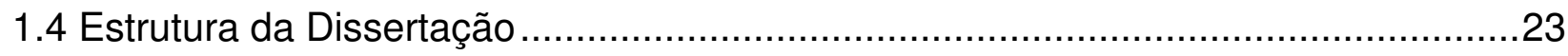

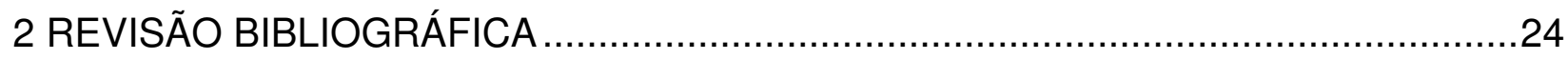

2.1 Descrição do Processo de Polimerização em Suspensão de VCM ………..............24

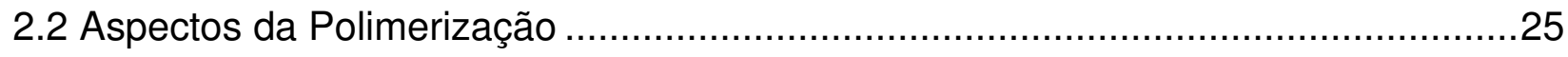

2. 3 Modelos Cinéticos do Processo de Polimerização de VCM ……............................29

2.4 Efeito da Difusão nas Reações na Fase Polimérica..................................................32

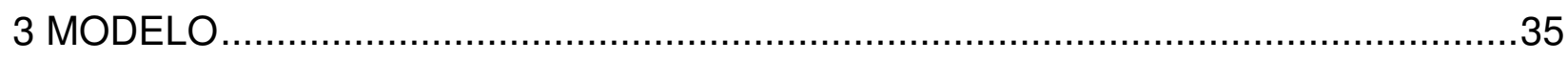

3.1 Hipóteses Adotadas no Desenvolvimento do Modelo .........................................42

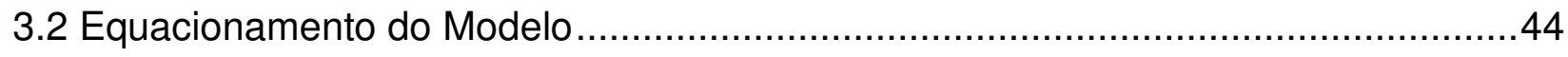

3.2.1 Conversão de monômero (balanço de monômero) .........................................44

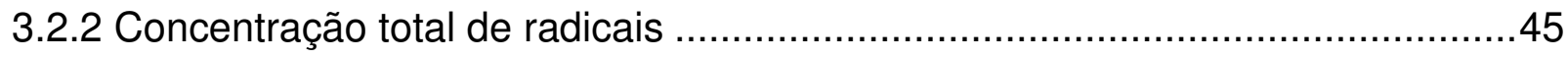

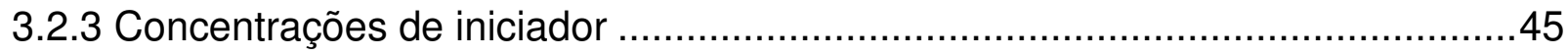

3.2.4 Distribuição do monômero entre as fases...................................................4

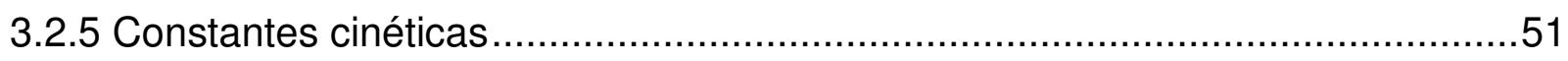

3.2.6 Constantes cinéticas limitadas por difusão .................................................52

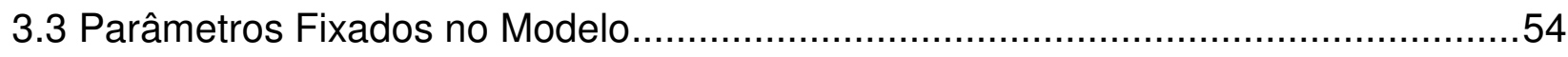


3.4 Método de Solução das Equações do Modelo .54

4 RESULTADOS E DISCUSSÃO .56

4.1 Dados Experimentais .56

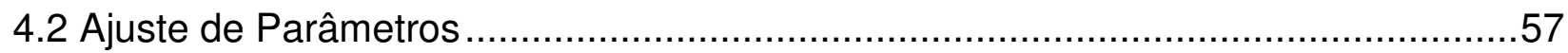

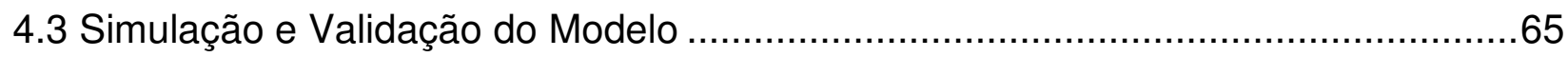

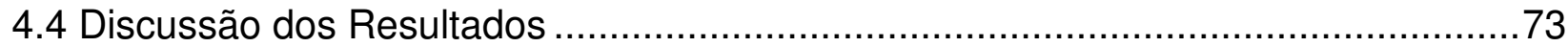

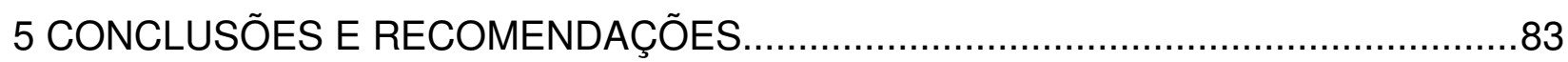

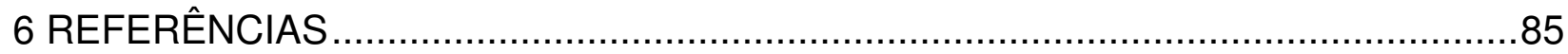

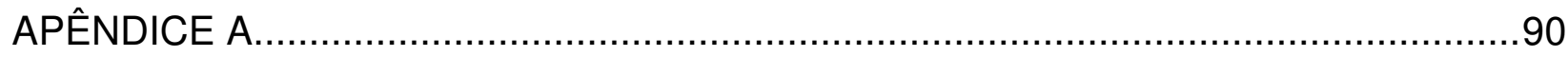

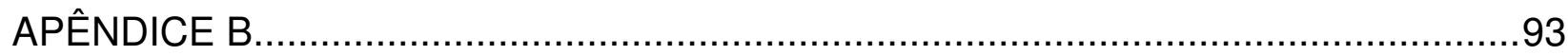




\section{INTRODUÇÃO}

\subsection{Generalidades}

O poli(cloreto de vinila) - PVC - é o segundo termoplástico mais consumido no mundo com grande potencial de crescimento de demanda graças a sua versatilidade, tanto nos diferentes tipos de processos de transformação (injeção, extrusão, calandragem, entre outros) como também no que se refere a sua utilização. Pode ser empregado na fabricação de tubos e perfis rígidos, laminados, embalagens, calçados, brinquedos e até equipamentos médico-hospitalares, por ser uma resina atóxica e inerte que ainda pode ser formulada mediante a incorporação de aditivos dos mais diversos (Rodolfo Jr., Nunes e Ormanji, 2006) e cuja capacidade de absorção depende essencialmente das condições da polimerização, assim como suas propriedades mecânicas (Cebollada, 1989).

No que diz respeito ao consumo mundial de PVC, $80 \%$ deste é produzido pelo processo em suspensão, 10 a $15 \%$ via emulsão e micro-suspensão. Os processos de solução e massa têm pouca representatividade (Rodolfo Jr., Nunes e Ormanji, 2006).

Em sua produção, $57 \%$ dos insumos são provenientes do sal marinho ou da terra (sal-gema) e 43\% de fontes não-renováveis (petróleo e gás natural). A Figura 1 apresenta o fluxograma simplificado do processo de produção de PVC.

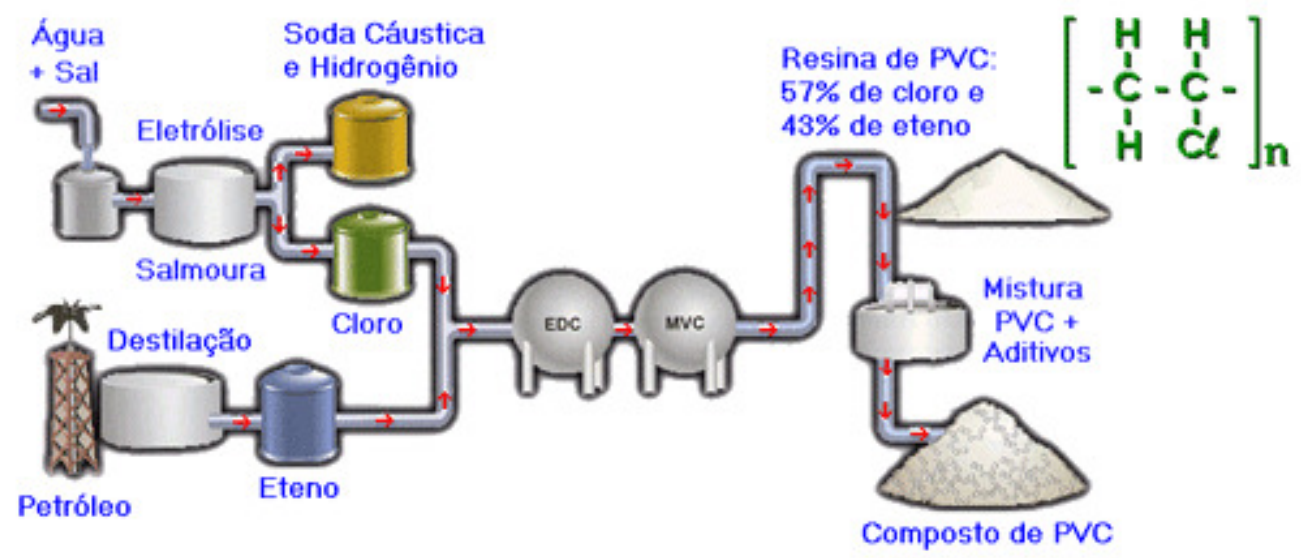

Figura 1 - Fluxograma simplificado do processo de produção do PVC (Instituto do PVC). 
O cloro é obtido através da eletrólise do cloreto de sódio. Como as ligações entre átomos de cloro e carbono são polares, o PVC tem maior afinidade com os aditivos e separação automatizada mais eficaz na reciclagem mecânica, química ou energética.

Incorporam-se ao PVC aditivos em proporções suficientes com o intuito de se obter propriedades específicas, tais como rigidez ou flexibilidade, transparência ou opacidade, ou ainda apresentar resistência à exposição ao intemperismo. São classificados em diversos tipos, como por exemplo estabilizantes, lubrificantes, pigmentos, etc. Um dos tipos mais utilizados na produção de compostos de PVC são os plastificantes, que promovem redução da dureza e aumento da flexibilidade.

Dentre os plastificantes, os ftalatos são os mais comumente adicionados às resinas de PVC e dentre eles destacam-se o DOP (di-octil ftalato), o BBP (butil benzil ftalato), o DBP (di-butil ftalato), o DINP (di-isononil ftalato), DIDP (di-isodecil ftalato) e o DNOP (di-n-octil ftalato), entre outros.

No entanto, há muitas divergências quanto ao uso dos ftalatos na produção de compostos de PVC e estudos científicos continuam sendo feitos para poder garantir com certeza suficiente se os efeitos causados por estes aditivos representam algum perigo à saúde humana e ao meio ambiente, tendo em vista as consequências para o mercado e o desenvolvimento sustentável. Em razão deste fato, algumas restrições ao uso (e à produção) de PVC têm surgido em países da Europa e nos Estados Unidos. No entanto, a análise do ciclo de vida do PVC tem indicado que seus produtos não causam mais impactos ambientais que seus concorrentes. A gestão de resíduos dos compostos de PVC é um importante aspecto a ser analisado, sendo válido estudar a possibilidade de se desenvolver novas técnicas que permitam reduzir a utilização de estabilizantes contendo metais pesados, por exemplo.

Trata-se do único material plástico, dentre os mais comuns, que não é completamente derivado do petróleo (consome apenas $0,3 \%$ do petróleo extraído no mundo) e tem por principal matéria-prima um recurso natural renovável, o sal marinho (56,8\% da massa do PVC é cloro). O Brasil está entre os países detentores de reservas de matérias-primas para produzir PVC. Para a obtenção do cloro, destacam-se o sal marinho produzido em escala industrial na região do Rio Grande do Norte e no Rio de Janeiro, e o sal-gema cujas reservas se concentram em grandes faixas litorâneas, 
seguindo da Bahia a Alagoas. Fica assim assegurada a auto-suficiência na produção de cloro e PVC (Revista Plástico Moderno). Há previsão de crescimento da demanda pelo produto no mercado interno (16\% em 2007), ligados principalmente a investimentos em infra-estrutura e no setor imobiliário, e projetos de expansão da capacidade de produção do PVC pelas indústrias produtoras (Andrade, 2008).

\subsection{Motivação e Justificativa}

A crescente demanda da produção de polímeros faz com que se aumente a importância de estudos que possibilitem que a produção fique mais eficiente, segura e econômica. Os processos industriais de polimerização em suspensão, categoria em que se enquadra a produção do PVC, são realizados tipicamente em reatores em batelada. $O$ aumento da produtividade de processos em batelada passa pela redução do tempo necessário para completar cada batelada, aumentando-se o máximo possível a taxa de reação. Uma restrição importante que precisa ser considerada está relacionada com a qualidade do polímero produzido: as alterações de processo visando aumentar a velocidade de polimerização não podem causar alterações significativas nas propriedades do polímero a ser produzido, por exempo a massa molar média e a distribuição de massas molares. Estas propriedades estão em geral restritas a faixas de especificação definidas pela aplicação/utilização do produto final, que definem os chamados "grades" do polímero.

A limitação típica dos processos de polimerização para o aumento da produtividade é a capacidade do sistema de resfriamento do reator, responsável pela dissipação do calor gerado pela reação exotérmica de polimerização. $O$ aumento de velocidade de polimerização deve, portanto, respeitar esta restrição operacional.

A determinação das condições de operação ótimas para um reator de polimerização levando em conta as restrições operacionais e de qualidade do polímero produzido poderia, em princípio, ser realizada de maneira empírica, por tentativas gradativas na unidade industrial ou em processo em escala piloto. Entretanto, frente aos custos de experimentação excessiva, e os riscos envolvidos em experimentar 
condições que possam ultrapassar os limites operacionais da unidade, a maneira mais eficiente de otimizar as condições de operação de maneira sistemática é através da solução de um problema de otimização. Para tanto, é imprescindível dispor de um modelo matemático representativo do processo de polimerização, confiável e validado experimentalmente em condições tão amplas quanto possível.

Em princípio, variáveis tais como a temperatura e as concentrações de iniciador e de monômero poderiam ser manipuladas, com o objetivo de otimizar o processo. No caso do processo de polimerização de cloreto de vinila, é bem conhecido que o processo de produção das cadeias de polímero é dominado principalmente pelas reações de transferência de cadeia ao monômero, de modo que o peso molecular médio do polímero depende apenas da temperatura. Neste caso é possível manusear a taxa de iniciação de modo a acelerar o processo sem efeitos significativos sobre o peso molecular. Para evitar sistemas bem controlados de dosagem de reagentes requeridos em sistemas semi-batelada, uma alternativa interessante (e efetivamente usada em processos industriais de produção de PVC) é usar misturas de iniciadores ("coquetel") carregados no início da batelada. A mistura de diferentes tipos de iniciadores pode, se bem projetada, modular a taxa de geração de radicais livres de modo a manter, durante a batelada, a taxa de polimerização constante e igual (dentro de uma tolerância de segurança) à máxima taxa de polimerização permitida pelo sistema de resfriamento instalado (Pinto e Giudici, 2001).

Para a adequada otimização do coquetel, é necessário um modelo que não apenas seja bem representativo do processo de polimerização, mas que funcione bem para diferentes tipos de iniciadores sob amplas faixas de concentrações.

A idéia originalmente planejada para o presente trabalho era a de trabalhar com a otimização de misturas de iniciadores, usando algum modelo dentre os disponíveis na literatura. No entanto, durante as etapas preliminares de testes destes modelos, verificou-se que os modelos testados não tinham generalidade satisfatória (embora funcionassem muito bem em casos específicos, falhavam em outras situações). Este fato motivou readequar o foco do trabalho para o desenvolvimento do modelo, deixando o estudo de otimização para etapas seguintes. 


\subsection{Objetivo}

Dentro do panorama descrito no item anterior, o presente trabalho buscou desenvolver, a partir de modelos previamente descritos na literatura, um modelo matemático do processo de polimerização de cloreto de vinila suficientemente representativo, e testar o modelo para diferentes situações usando dados experimentais disponíveis na literatura.

\subsection{Estrutura da Dissertação}

O texto da presente dissertação está assim estruturado. No Capítulo 2 apresenta-se uma revisão da literatura sobre os principais assuntos de interesse para o desenvolvimento do trabalho. No Capítulo 3 é apresentado o desenvolvimento do modelo, as hipóteses adotadas, as equações utilizadas e método de solução. No Capítulo 4 são apresentados os resultados da simulação do modelo, os parâmetros ajustados e os parâmetros adotados, e a comparação das previsões do modelo com dados experimentais de diferentes origens. Finalmente, no Capítulo 5, são sumarizadas as principais conclusões e recomendações decorrentes do trabalho realizado. 


\section{REVISÃO BIBLIOGRÁFICA}

Neste capítulo são apresentadas de maneira sucinta as informações básicas encontradas na literatura que foram de utilidade para o desenvolvimento do trabalho.

\subsection{Descrição do Processo de Polimerização em Suspensão de VCM}

Um processo industrial típico de polimerização em suspensão para a produção de PVC pode ser descrito pelas seguintes etapas. ${ }^{1}$

A carga do reator inclui água desmineralizada, aditivos de polimerização, dispersantes (solução), iniciadores (solúveis no monômero) e monômero. O cloreto de

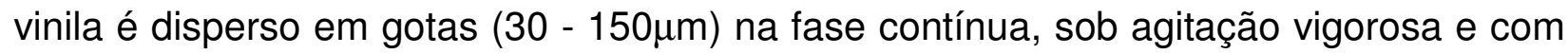
a presença de um colóide protetor (agente de suspensão).

Previamente à adição de monômero, o reator é fechado e emprega-se alto vácuo a fim de se eliminar o oxigênio que poderia causar efeitos adversos no processo, tais como o aumento do tempo de reação e alteração nas propriedades do produto final.

Aquece-se a camisa com vapor sob pressão e a partir do momento que a reação de polimerização (exotérmica) se inicia, o reator passa a ser resfriado. A temperatura da reação varia de 50 a $70^{\circ} \mathrm{C}$ e este é o principal parâmetro para controle do peso molecular da resina.

A reação é extremamente exotérmica o que faz com que a capacidade de remover calor do sistema reativo seja um fator limitante para redução dos tempos de batelada. $O$ aumento do volume dos reatores agravou esse problema de resfriamento devido à diminuição da relação superfície/volume. Estudo sobre esta questão pode ser encontrado no trabalho de Saeki e Emura (2002).

\footnotetext{
${ }^{1}$ No decorrer do trabalho, foi realizada uma visita técnica à fábrica da Braskem S. A., em São Paulo, com o objetivo de conhecer a unidade industrial e observar as etapas de produção do PVC.
} 
Ao se atingir uma conversão de 75 a $95 \%$, o polímero que sai do reator em forma de lama passa por uma etapa de recuperação do monômero remanescente através de um processo de "stripping" com a passagem de vapor sob pressão em contracorrente.

A lama então é centrifugada e encaminhada para secadores de leito fluidizado. A resina seca é peneirada para retenção de partículas extremamente grosseiras e armazenada em silos para posteriormente serem empacotadas em sacos de $25 \mathrm{~kg}$, "big bags" de 1,2 t ou ainda em caminhões-silo.

As plantas comerciais operam com reatores do tipo batelada cujo volume varia de 50 a $200 \mathrm{~m}^{3}$, chegando a produzir até $25 \mathrm{t}$ de resina seca por batelada (Rodolfo Jr., Nunes e Ormanji, 2006). Como efluentes do processo resultam cloro, etileno, 1,2dicloroetano, cloreto de hidrogênio e cloreto de vinila, além de outros subprodutos como dioxinas. Os processos de produção devem seguir medidas rigorosas de controle dessas emissões.

\subsection{Aspectos da Polimerização}

A polimerização do cloreto de vinila é radicalar e seu mecanismo consiste em quatro etapas elementares: iniciação, propagação, terminação e transferência de cadeia (Hamielec e Tobita, 1992).

$\mathrm{Na}$ etapa de iniciação acontece a decomposição do iniciador que produz radicais continuamente durante a reação, sendo estes chamados de radicais primários.

A propagação é a etapa de crescimento através da adição de moléculas de monômero ao radical da cadeia.

A terminação é chamada bimolecular quando ocorre a reação entre dois radicais, podendo ser ainda classificada como terminação por desproporcionamento ou combinação. Nesta última, dois radicais poliméricos se ligam gerando uma única cadeia de polímero morto; no outro caso, formam-se duas cadeias de polímero morto com os mesmos tamanhos dos dois radicais poliméricos. No caso da polimerização de VCM, há evidências experimentais (Park, 1970, apud Xie et al., 1999a) de que a terminação por despropocionamento é responsável por cerca de $75 \%$ dos eventos de terminação 
bimolecular, sendo $25 \%$ via terminação por combinação.

A transferência de cadeia a monômero acontece quando um radical "migra" para uma molécula de monômero, cessando o crescimento da cadeia enquanto transforma o monômero em um novo radical. No caso da polimerização de VCM, a transferência de cadeia a monômero é o principal evento de transformação dos radicais em moléculas de polímero "morto"; há evidências experimentais de que apenas 19 a 40\% das moléculas de polímero são produzidas via terminação bimolecular (Razuvayev et al., 1963 apud Xie et al., 1991a).

As reações de transferência de cadeia para polímero (abstração de hidrogênio) e de transferência de cadeia intramolecular ("backbiting") são responsáveis pela formação de ramificações longas e de ramificações curtas, respectivamente, porém este fato não interfere no número total de cadeias de polímeros vivos e, portanto, a taxa de polimerização não é afetada (Sidiropoulou e Kiparissides, 1990).

Processos de polimerização podem ser classificados ainda como homogêneos ou heterogêneos (Kiparissides, 1996). O que os diferencia é o fato de os primeiros serem realizados em uma única fase.

A polimerização em suspensão é uma polimerização heterogênea, sendo que os monômeros, insolúveis no meio aquoso, ficam neste dispersos em forma de pequenas gotas, juntamente com o iniciador, com o auxílio de agentes de dispersão como, por exemplo, tensoativos, que agem de forma a diminuir a tensão interfacial entre as gotas do monômero e a água. Estes agentes formam uma fina camada ao serem adsorvidos na superfície das gotas, evitando a coalescência entre elas que poderia levar à desestabilização da suspensão. Agindo desta maneira, eles auxiliam no controle da dimensão e da estrutura das partículas durante a reação (Cebollada, 1989).

Com o progresso da reação, as gotas transformam-se em partículas "pegajosas" e viscosas para enfim ficarem mais rígidas com o aumento da conversão (Kiparissides, 1996).

Os mecanismos de formação e crescimento das partículas bem como cálculos de distribuição de seus tamanhos podem ser vistos em estudos de Kuchanov e Bort (1973), Cebollada et al. (1989), Xie et al. (1991c), Saeki e Emura (2002) e Alexopoulos e Kiparissides (2007). 
Como a polimerização do cloreto de vinila ocorre dentro de cada gota onde estão contidos o monômero e o iniciador, ela pode ser vista como uma polimerização em massa. Em comparação com a polimerização em massa, a reação em suspensão apresenta a vantagem de a temperatura poder ser mais facilmente controlada, já que no primeiro caso há um aumento considerável da viscosidade, provocando dificuldades na agitação o que acaba gerando pontos de superaquecimento no reator. $O$ resfriamento necessário ao controle da taxa de liberação de calor na reação em suspensão é feito, em parte, pelo próprio meio dispersante (água). Além disso, a taxa de geração de calor por unidade de volume do reator é menor na polimerização em suspensão, já que a água ocupa uma parte considerável do volume do reator.

A agitação é um importante fator a ser controlado pois além de facilitar a dissipação do calor do reator para a camisa de resfriamento, também ajuda a evitar a coalescência das gotas, fato este que pode interferir na característica do produto final (Kiparissides, 1996).

Como o polímero formado (PVC) não é completamente miscível com o respectivo monômero (VCM), sob condições típicas de polimerização formam-se duas fases dentro da gota: uma fase rica em polímero, contendo monômero dissolvido, e uma fase rica em monômero, com praticamente nenhum polímero nela dissolvido. $\mathrm{O}$ diagrama de fases da mistura PVC/VCM ilustra a existência destas duas fases e os valores das composições das fases em equilíbrio. Partindo-se de monômero puro (conversão $0 \%$ ), a polimerização se inicia em uma única fase (rica em monômero), mas após uma conversão de $0,1 \%$ passa a existir uma segunda fase rica em polímero, cuja composição é fixa até a conversão $X_{f}$. Para conversões acima de $X_{f}$, o sistema volta a ter apenas uma fase, rica em polímero. 


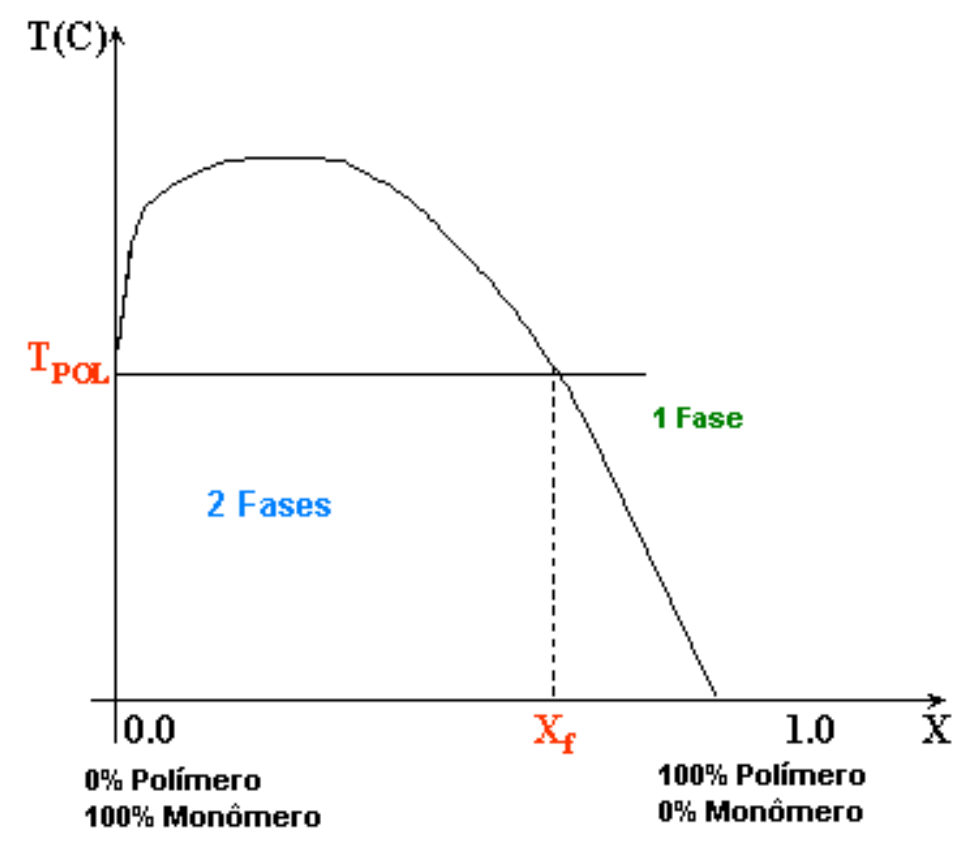

Figura 2 - Diagrama de fases da mistura PVC/VCM.

Tendo em vista esta particularidade na polimerização do VCM, para questões de cinética, o modelo pode ser separado em três estágios:

- Primeiro estágio ( $X<0,1 \%$ ): ocorre a decomposição do iniciador e formação de radicais primários que reagem rapidamente com as moléculas de monômero. Neste período, a concentração do polímero no meio é muito baixa (abaixo de seu limite de solubilidade no monômero) e, portanto, a mistura contém praticamente apenas monômero puro.

- Segundo estágio $\left(0,1 \% \leq X \leq X_{f}\right)$ : a concentração do polímero vai crescendo com o tempo e começa a surgir uma fase polimérica. A reação ocorre nas fases rica em monômero e rica em polímero a diferentes taxas. Ocorre ainda transferência de monômero para a fase polimérica, que assim é mantida saturada neste componente. Este estágio se prolonga até o momento de desaparecimento da fase monomérica, fato este que ocasiona uma diminuição da pressão no interior do reator, devido à transferência de monômero da fase gasosa para a fase polimérica, uma vez que esta fica então subsaturada. 
- Terceiro estágio $\left(X>X_{f}\right)$ : acontece para altos valores de conversão, para os quais somente a fase rica em polímero existe. A concentração de monômero vai decrescendo com o decorrer do tempo até sua conversão limite.

\section{3 Modelos Cinéticos do Processo de Polimerização de VCM}

Encontram-se na literatura diversos modelos que descrevem a polimerização via radicais livres do cloreto de vinila. A seguir apresenta-se uma rápida análise dos modelos pesquisados.

O primeiro modelo desenvolvido para a polimerização do VCM em duas fases foi proposto por Crosato-Arnaldi, Gasparini e Talamini (1968). Foi admitido que a concentração de iniciador permanece constante ao longo da reação e que não há transferências de radicais entre as fases reativas (rica em monômero e rica em polímero). Abdel-Alim e Hamielec (1972) tomaram por base este modelo e o aplicaram à polimerização em massa de cloreto de vinila, considerando desta vez variações nos volumes das fases e na concentração do iniciador, além de variações nas constantes cinéticas de propagação e terminação por razões de limitações difusionais ao se atingir altos valores de conversão.

Kuchanov e Bort (1973) desenvolveram um modelo cinético envolvendo a transferência de radicais entre as fases monomérica e polimérica, sendo esta migração expressa em função do número de partículas e de seus diâmetros, de seus coeficientes de difusão e da concentração de radicais em cada fase. Foi ainda considerada que a dessorção de radicais da fase polimérica só seria possível para uma pequena quantidade de radicais de pequeno tamanho uma vez que a solubilidade destes na fase

monomérica diminui com o aumento da cadeia e sendo assim, a transferência de radicais para a fase rica em monômero foi desprezada.

Kelsall e Maitland (1983) propuseram um modelo considerando que ocorre transferência de massa de iniciador, monômero e polímero, além da possibilidade de distribuição heterogênea de iniciador e diferença nos valores de eficiência entre as 
fases reativas. O modelo faz a previsão da taxa de polimerização, distribuição de massa molecular e outras propriedades estruturais como porosidade e tamanho de partícula. $\mathrm{O}$ modelo possui parâmetros ajustáveis (cujos valores, entretanto, não foram reportados) relacionados às características da reação de polimerização, iniciador, estabilidade e agitação do sistema. A validade do modelo não foi verificada experimentalmente.

As expressões que representam a dinâmica da reação de polimerização são obtidas pela aplicação das equações de conservação de massa para as diferentes espécies químicas envolvidas, apresentando-se como um sistema de infinitas equações diferenciais. Nestes casos, é comum o emprego do método dos momentos às equações dos balanços a fim de reduzir a quantidade de equações diferenciais a serem avaliadas e assim facilitar o cálculo das massas moleculares médias (Ray, 1972) e a determinação de características estruturais do polímero citadas acima, como concentrações de ramificações curtas e de duplas ligações terminais (que podem surgir, respectivamente, das reações de transferência de cadeia e terminação por desproporcionamento) (Sidiropoulou e Kiparissides, 1990).

Os momentos de ordem 0 e 1 admitem interpretação física: o momento de ordem zero corresponde à concentração total da espécie e o momento de ordem um indica o número de unidades monoméricas presentes no polímero.

A massa molecular média numérica $\left(M_{n}\right)$ expressa a massa molar média ponderada pelo número de cadeias e seu valor típico para o PVC encontra-se em um intervalo que varia de 20000 a $150000 \mathrm{~g} / \mathrm{mol}$. É calculada por uma relação entre os momentos de ordem 1 e os de ordem zero e proporcional à massa molecular do monômero.

A massa molecular média mássica $\left(M_{w}\right)$ denota a massa molar média ponderada pelo peso das cadeias e está entre 40000 e 400000 g/mol (Rodolfo Jr., Nunes e Ormaji, 2006). É calculada de forma análoga, com a ressalva da relação, que neste caso é entre os momentos de ordem dois e os de ordem um.

O índice de polidispersidade $(P D)$ que mede a largura da distribuição da massa molecular é dado pela razão entre a massa molecular média mássica $\left(M_{w}\right)$ e a massa molecular média numérica $\left(M_{n}\right)$ e, em geral, o PVC apresenta uma distribuição estreita, cujo valor de $P D$ apresenta algumas variações em torno de 2. 
Xie et al. (1987) estudaram alguns aspectos da reação como temperatura, pressão, conversão e distribuição de monômeros entre as fases, inclusive para altos valores de conversão, além de obter uma correlação de solubilidade do VCM em água e o parâmetro de interação de Flory-Huggins da mistura VCM-PVC.

O trabalho de Sidiropoulou e Kiparissides (1990) apresenta um modelo capaz de prever além da conversão e da taxa de polimerização, algumas características como quantidade de ramificações curtas e longas e a quantidade de ligações terminais insaturadas. São levadas em conta reações de transferência de cadeia para monômero e para polímero, além de transferências intramoleculares. Foi ainda por eles estudado a validade da hipótese de princípio pseudo-estacionário (PSSA) para as cadeias de macroradicais em crescimento. Dados de conversão e de massa molecular foram comparados e não foram verificadas diferenças significantes entre os resultados obtidos através de soluções algébricas (adotada a hipótese) e os conseguidos pelas resoluções das equações diferenciais descritas para o balanço de massa desses radicais.

Xie et al. (1991a) elaboraram um modelo de polimerização em batelada que prediz a concentração do monômero nas fases aquosa, gasosa e polimérica, a conversão global do monômero e a taxa de polimerização. Em um outro estudo do mesmo grupo (Xie et al., 1991b) apresenta a modelagem de uma reação de polimerização em um reator semi-batelada com adição de monômero, permitindo que a pressão no reator continue constante, sem ser observada a queda de pressão característica quando do desaparecimento da fase rica em monômero que ocorreria logo após atingida a conversão crítica. Em comparação com o processo em batelada, o produto obtido no processo semi-batelada apresenta uma distribuição de massa molecular mais estreita e uma maior produtividade.

O modelo de Kiparissides et al. (1997) considera que há um equilíbrio na partição do iniciador e monômero entre as fases durante todo o período da reação. O modelo é capaz de calcular a concentração do monômero nas fases gasosa, aquosa, rica em monômero e rica em polímero, além de algumas características estruturais da cadeia polimérica, por exemplo, massas moleculares médias numérica e mássica, quantidade de ramificações curtas e longas, concentração de duplas ligações terminais e polidispersidade. Este modelo ainda apresenta equações que representam dinâmica 
do reator, como a pressão do sistema e as temperaturas do interior do reator bem como de entrada e saída da camisa de resfriamento.

O modelo proposto por Wieme et al. (2007), assim como o do Kiparissides et al. (1997), também inclui em seu desenvolvimento as trocas de energia no reator e na camisa, com controle de temperatura e de vazão do agente de refrigeração.

O modelo proposto por Krallis et al. (2004) foi elaborado a partir do modelo proposto anteriormente por Kiparissides et al. (1997) e considera a possibilidade da utilização de iniciadores bifuncionais, cuja estrutura química apresenta dois grupos peróxidos, podendo esta molécula apresentar-se de maneira simétrica ou assimétrica.

Poucos estudos com iniciadores do tipo bifuncional foram reportados durante os anos, embora estes tenham sido elaborados para reações em meio homogêneo ("bulk"), como nos casos das polimerizações do estireno (Kim e Choi, 1989; Villalobos, Hamielec e Wood, 1991 e 1993; Estenoz et al., 1996; González, Meira e Oliva, 1996) e do etileno (Dhib e Al-Nidawy, 2002). O modelo de Krallis et al. (2004) foi o primeiro a ser formulado para reação com esses tipos de iniciadores em meio heterogêneo para polimerização de cloreto de vinila e seu equacionamento pode ser visto no Apêndice B.

\subsection{Efeito da Difusão nas Reações na Fase Polimérica}

Para meios reacionais muito viscosos, em decorrência da presença de polímero, as reações envolvidas nos processos de polimerização tendem a ser afetadas por limitações difusionais em diferentes graus, tornando-se controladas pela difusão. Por exemplo, as reações de iniciação, de propagação e de terminação são afetadas pelos chamados efeitos gaiola, vítreo e gel, respectivamente (Achilias e Kiparissides, 1992).

O efeito gel, também conhecido como efeito Trommsdorff-Norrish, é atribuído à diminuição da constante cinética de terminação provocada pela queda na mobilidade das cadeias poliméricas e dos radicais poliméricos. Este fenômeno afeta as propriedades finais do polímero pois acarreta numa distribuição larga de peso molecular. Também afeta a velocidade de polimerização (auto-aceleração), pois a 
terminação limitada por difusão provoca um aumento na concentração de radicais livres no meio reacional.

O efeito vítreo está relacionado à redução da constante cinética de propagação (na verdade, de todas as reações), também devido à menor mobilidade das moléculas que ocorre quando a temperatura da reação encontra-se abaixo da temperatura de transição vítrea do polímero. Em consequência deste fenômeno pode acontecer o "congelamento" da mistura reacional (transição vítreo) antes mesmo de se alcançar conversões de $100 \%$.

A eficiência do iniciador é definida pela fração de radicais, produzidos pela decomposição, que efetivamente irão iniciar a propagação de uma cadeia e admite valores entre 0 (zero) e 1. Para que isso aconteça, esses radicais devem se difundir rapidamente para longe de outros radicais a fim de evitar uma recombinação que pode regenerar a molécula de iniciador ou formar uma outra molécula diferente incapaz de gerar outros radicais. Esta situação é o que se conhece como efeito gaiola.

As consequências desses efeitos nas constantes cinéticas podem ser descritas quantitativamente através de expressões empíricas. As tentativas mais bem sucedidas de descrição fenomenológica dos efeitos difusionais são baseadas na chamada teoria do volume livre, que considera que quanto maiores os espaçamentos entre as moléculas (maior a fração de volume livre do meio), mais facilmente ocorrerá a movimentação das cadeias e das moléculas em geral, pois menor será o cisalhamento entre elas. Assim sendo, quanto menor a fração de volume livre da mistura reacional, menores serão as constantes cinéticas das reações naquele meio.

O modelo proposto por Xie et al. (1991a) faz a correção das constantes cinéticas pela teoria do volume livre, explicitando parâmetros através de equações expressas em função da temperatura e ajustadas a partir de dados experimentais. A forma matemática das equações para as limitações difusionais inclui um fator multiplicativo da constante cinética (modelo tipo Marten-Hamielec, 1979). Neste modelo admite-se que a constante de terminação na fase rica em polímero já é limitada por difusão tão logo o surgimento desta fase (desde o início do estágio 2). No entanto, foi considerado que a constante de propagação desta mesma fase (rica em polímero) começa a ser afetada por limitações difusionais apenas após o desaparecimento da fase rica em monômero 
(estágio 3). Os autores consideraram correção na eficiência do iniciador para iniciador AIBN (do tipo azo-composto), mas para iniciador Perkadox (do tipo peróxido) a eficiência é mantida inalterada e é feita uma correção de sua constante cinética de decomposição a partir do início do estágio 3 (quando o meio se torna mais viscoso).

Krallis et al. (2004) também fazem uso deste mesmo recurso, porém não explicitam os valores dos parâmetros ajustados das equações relacionadas às limitações difusionais, e não deixam claro essas particularidades para os tipos de iniciadores.

Kiparissides et al. (1997), baseado em estudos anteriores feitos com Achilias (1992) para a polimerização do estireno e do metacrilato de metila, propõem uma correção das constantes cinéticas de terminação e propagação, na forma de combinação de resistências à reação e à difusão combinadas em série (modelo de limitação difusional do tipo proposto por Chiu, Carrat e Soong, 1983).

Wieme et al. (2007) também propuseram correções desse tipo referindo-se ao estudo sobre a obtenção das equações das constantes cinéticas intrínsecas feito anteriormente por De Roo et al. (2005) que promoveu uma estimativa dos parâmetros de Arrhenius (fatores pré-exponenciais e energias de ativação) para algumas dessas constantes, por meio de regressões de dados experimentais, utilizando o TBPD como iniciador. 


\section{MODELO}

Vários mecanismos cinéticos que descrevem as possíveis reações que ocorrem na polimerização via radicais livres do cloreto de vinila são encontrados na literatura (Xie et al., 1991a, Starnes et al., 1998; Starnes, 2002).

O mecanismo proposto por Krallis et al. (2004) considera as variações de produção e consumo de cadeias ativas, inativas e "mortas" nas fases monomérica e polimérica, incluindo a eventual presença de inibidores além de iniciadores tanto monofuncionais como bifuncionais.

Os iniciadores monofuncionais são aqueles cuja estrutura apresenta apenas um grupo peróxido, caracterizado pela ligação $\mathrm{O}-\mathrm{O}$ (ou apenas uma ligação azo $\mathrm{N}=\mathrm{N}$, no caso de azo compostos), passível de ser decomposto e originar radicais ativos que darão início à propagação da cadeia. Como o próprio nome sugere, os bifuncionais contêm dois grupos peróxidos em sua estrutura química, podendo esta molécula apresentar-se de maneira simétrica ou assimétrica.

As cadeias ativas correspondem àquelas que apresentam em sua estrutura um ou mais radicais livres. As inativas são assim denominadas por possuírem em suas cadeias pelo menos um grupo peróxido passível de sofrer decomposição e gerar radicais. Já as cadeias "mortas" não apresentam nenhuma das condições expostas acima.

As descrições das diversas estruturas dos polímeros que podem ser encontrados no meio reativo, considerando-se a presença de iniciadores bifuncionais do tipo peróxido, podem ser vistas na Tabela 1 (Krallis et al., 2004). 
Tabela 1 - Esquematização das estruturas das espécies presentes no meio reativo.

\begin{tabular}{|c|c|c|}
\hline Esp & écies & Descrições \\
\hline$P_{n}$ & $\bullet-----]$ & Cadeia de polímero vivo \\
\hline$Q_{n}$ & $\bullet-----R_{A}$ & $\begin{array}{l}\text { Cadeia de polímero vivo com um grupo } \\
\text { peróxido terminal tipo A }\end{array}$ \\
\hline & $\bullet-----R_{B}$ & $\begin{array}{l}\text { Cadeia de polímero vivo com um grupo } \\
\text { peróxido terminal tipo B }\end{array}$ \\
\hline$T_{n}$ & $\bullet-----\bullet$ & Cadeia de polímero vivo com diradical \\
\hline$U_{n}$ & {$\left[-------R_{A}\right.$} & $\begin{array}{l}\text { Cadeia de polímero inativo com um grupo } \\
\text { peróxido terminal tipo } \mathrm{A}\end{array}$ \\
\hline$V_{n}$ & {$\left[-------R_{B}\right.$} & $\begin{array}{l}\text { Cadeia de polímero inativo com um grupo } \\
\text { peróxido terminal tipo B }\end{array}$ \\
\hline & $R_{A}-------R_{B}$ & $\begin{array}{l}\text { Cadeia de polímero inativo com dois } \\
\text { grupos peróxido terminais tipos } \mathrm{A} \text { e B }\end{array}$ \\
\hline$U_{n}^{\prime}$ & $R_{A}-------R_{A}$ & $\begin{array}{l}\text { Cadeia de polímero inativo com dois } \\
\text { grupos peróxido terminais tipo A }\end{array}$ \\
\hline$V_{n}^{\prime}$ & $R_{B}-------R_{B}$ & $\begin{array}{l}\text { Cadeia de polímero inativo com dois } \\
\text { grupos peróxido terminais tipo } B\end{array}$ \\
\hline$D_{n}$ & {$[---------]$} & Cadeia de polímero morto \\
\hline
\end{tabular}

em que $\mathrm{n}$ representa o número de meros na cadeia.

De acordo com as denominações das cadeias feitas anteriormente e ainda com a descrição de que os símbolos $\mathrm{M}$ e $\mathrm{Z}$ indicam as moléculas de monômero e de inibidor, respectivamente, as possíveis reações que acontecem na fase $\mathrm{j}$ (rica em monômero, $\mathrm{j}$ = 1 e rica em polímero, $\mathrm{j}=2$ ) podem ser descritas conforme o mecanismo abaixo: 
- Decomposição de Iniciadores Monofuncionais

$$
I_{m, i}^{j} \stackrel{k_{d, i}^{j}}{\longrightarrow} 2 R^{j} \quad i=1,2, \ldots, N m
$$

sendo $\mathrm{Nm}$ o número de iniciadores monofuncionais utilizados na reação de polimerização e $k_{d, i}^{j}$ a taxa de decomposição do iniciador do tipo i na fase j.

- Decomposição de Iniciadores Bifuncionais Assimétricos

$$
\begin{aligned}
& I_{b}^{j} \stackrel{k_{d A}^{j}}{\longrightarrow} R_{B}^{j}+R^{j} \\
& I_{b}^{j} \stackrel{k_{d B}^{j}}{\longrightarrow} R_{A}^{j}+R^{j} \\
& R_{A}^{j} \stackrel{k_{d A}^{j}}{\longrightarrow} R^{j}+R^{\prime j} \\
& R_{B}^{j} \stackrel{k_{d B}^{j}}{\longrightarrow} R^{j}+R^{j}
\end{aligned}
$$

em que $k_{d A}^{j}$ representa a taxa de decomposição associada ao peróxido do tipo $\mathrm{A}$ na fase j. De forma análoga, para o peróxido do tipo $B$.

- Iniciação

$$
\begin{aligned}
& R^{j}+M^{j} \stackrel{k_{I}^{j} \longrightarrow}{\longrightarrow} P_{1}^{j} \\
& R_{A}^{j}+M^{j} \stackrel{k_{I}^{j}}{\longrightarrow} Q_{1}^{j} \\
& R_{B}^{j}+M^{j} \stackrel{k_{I}^{j}}{\longrightarrow} S_{1}^{j} \\
& R^{\prime j}+M^{j} \stackrel{2 k_{I}^{j}}{\longrightarrow} T_{1}^{j}
\end{aligned}
$$


sendo $k_{I}^{j}$ a taxa de iniciação na fase $\mathrm{j}$, com probabilidade duas vezes maior para o caso do diradical $R^{\prime}$.

- Reiniciação de cadeias vivas e inativas

$$
\begin{array}{ll}
Q_{n}^{j} \stackrel{k_{d A}^{j}}{\longrightarrow} R^{j}+T_{n}^{j} & \\
S_{n}^{j} \stackrel{k_{d B}^{j}}{\longrightarrow} R^{j}+T_{n}^{j} & \\
U_{n}^{j} \stackrel{k_{d A}^{j}}{\longrightarrow} R^{j}+P_{n}^{j} & \text { para } j=2 \\
V_{n}^{j} \stackrel{k_{d B}^{j}}{\longrightarrow} R^{j}+P_{n}^{j} & \text { para } j=2 \\
W_{n}^{j} \stackrel{k_{d A}^{j}}{\longrightarrow} R^{j}+S_{n}^{j} & \text { para } j=2 \\
W_{n}^{j} \stackrel{k_{d B}^{j}}{\longrightarrow} R^{j}+Q_{n}^{j} & \text { para } j=2 \\
U_{n}^{\prime j} \stackrel{2 k_{d A}^{j}}{\longrightarrow} R^{j}+Q_{n}^{j} & \text { para } j=2 \\
V_{n}^{\prime j} \stackrel{2 k_{d B}^{j}}{\longrightarrow} R^{j}+S_{n}^{j} & \text { para } j=2
\end{array}
$$

Pode-se observar que, para os casos de cadeias inativas e mortas, as reações ocorrem somente na fase rica em polímero $(j=2)$ uma vez adotada a hipótese de que estas cadeias estão presentes exclusivamente na fase rica em polímero, devido à baixa solubilidade deste no próprio monômero.

- Propagação

$$
\begin{aligned}
& P_{n}^{j}+M^{j} \stackrel{k_{p}^{j}}{\longrightarrow} P_{n+1}^{j} \\
& Q_{n}^{j}+M^{j} \stackrel{k_{p}^{j}}{\longrightarrow} Q_{n+1}^{j}
\end{aligned}
$$




$$
\begin{aligned}
& S_{n}^{j}+M^{j} \stackrel{k_{p}^{j}}{\longrightarrow} S_{n+1}^{j} \\
& T_{n}^{j}+M^{j} \stackrel{2 k_{p}^{j}}{\longrightarrow} T_{n+1}^{j}
\end{aligned}
$$

em que $k_{p}^{j}$ refere-se à constante cinética de propagação na fase j.

- Transferência de cadeia para Monômero

$$
\begin{aligned}
& P_{n}^{j}+M^{j} \stackrel{k_{f m}^{j}}{\longrightarrow} D_{n}+P_{1}^{j} \\
& Q_{n}^{j}+M^{j} \stackrel{k_{f m}^{j}}{\longrightarrow} U_{n}+P_{1}^{j} \\
& S_{n}^{j}+M^{j} \stackrel{k_{f m}^{j}}{\longrightarrow} V_{n}+P_{1}^{j} \\
& T_{n}^{j}+M^{j} \stackrel{2 k_{f m}^{j}}{\longrightarrow} P_{n}^{j}+P_{1}^{j}
\end{aligned}
$$

em que $k_{f m}^{j}$ refere-se à constante cinética de transferência de cadeia para monômero na fase $j$.

- Transferência intramolecular ("backbiting")

$$
\begin{aligned}
& P_{n}^{j} \stackrel{k_{b}^{j}}{\longrightarrow} P_{n}^{j} \\
& Q_{n}^{j} \stackrel{k_{b}^{j}}{\longrightarrow} Q_{n}^{j} \\
& S_{n}^{j} \stackrel{k_{b}^{j}}{\longrightarrow} S_{n}^{j} \\
& T_{n}^{j} \stackrel{2 k_{b}^{j}}{\longrightarrow} T_{n}^{j}
\end{aligned}
$$

sendo $k_{b}^{j}$ a taxa de transferência intramolecular na fase j. 
- Terminação por combinação

$$
\begin{aligned}
& P_{n}^{j}+P_{m}^{j} \stackrel{k_{t c}^{j}}{\longrightarrow} D_{n+m} \\
& P_{n}^{j}+Q_{m}^{j} \stackrel{k_{t c}^{j}}{\longrightarrow} U_{n+m} \\
& P_{n}^{j}+S_{m}^{j} \stackrel{k_{t c}^{j}}{\longrightarrow} V_{n+m} \\
& P_{n}^{j}+T_{m}^{j} \stackrel{2 k_{t c}^{j}}{\longrightarrow} P_{n+m}^{j} \\
& Q_{n}^{j}+Q_{m}^{j} \stackrel{k_{t c}^{j}}{\longrightarrow} U_{n+m}^{\prime} \\
& Q_{n}^{j}+S_{m}^{j} \stackrel{k_{t c}^{j}}{\longrightarrow} W_{n+m} \\
& Q_{n}^{j}+T_{m}^{j} \stackrel{2 k_{t c}^{j}}{\longrightarrow} Q_{n+m}^{j} \\
& S_{n}^{j}+S_{m}^{j} \stackrel{2 k_{t c}^{j}}{\longrightarrow} V_{n+m}^{\prime} \\
& S_{n}^{j}+T_{m}^{j} \stackrel{2 k_{t c}^{j}}{\longrightarrow} S_{n+m}^{j} \\
& T_{n}^{j}+T_{m}^{j} \stackrel{4 k_{t c}^{j}}{\longrightarrow} T_{n+m}^{j}
\end{aligned}
$$

em que $k_{t c}^{j}$ representa a constante cinética de terminação por combinação na fase j, com probabilidade duas vezes maior para o caso de reações com o diradical e quatro vezes maior quando da reação entre dois radicais deste tipo.

\section{- Terminação por desproporcionamento}

$$
\begin{aligned}
& P_{n}^{j}+P_{m}^{j} \stackrel{k_{t d}^{j}}{\longrightarrow} D_{n}+D_{m} \\
& P_{n}^{j}+Q_{m}^{j} \stackrel{k_{t d}^{j}}{\longrightarrow} D_{n}+U_{m} \\
& P_{n}^{j}+S_{m}^{j} \stackrel{k_{t d}^{j}}{\longrightarrow} D_{n}+V_{m} \\
& P_{n}^{j}+T_{m}^{j} \stackrel{2 k_{t d}^{j}}{\longrightarrow} D_{n}+P_{m}^{j}
\end{aligned}
$$




$$
\begin{aligned}
& Q_{n}^{j}+Q_{m}^{j} \stackrel{k_{t d}^{j}}{\longrightarrow} U_{n}+U_{m} \\
& Q_{n}^{j}+S_{m}^{j} \stackrel{k_{t d}^{j}}{\longrightarrow} U_{n}+V_{m} \\
& Q_{n}^{j}+T_{m}^{j} \stackrel{2 k_{t d}^{j}}{\longrightarrow} U_{n}+P_{m}^{j} \\
& S_{n}^{j}+S_{m}^{j} \stackrel{k_{t d}^{j}}{\longrightarrow} V_{n}+V_{m} \\
& S_{n}^{j}+T_{m}^{j} \stackrel{2 k_{t d}^{j}}{\longrightarrow} V_{n}+P_{m}^{j} \\
& T_{n}^{j}+T_{m}^{j} \stackrel{4 k_{t d}^{j}}{\longrightarrow} P_{n}^{j}+P_{m}^{j}
\end{aligned}
$$

em que $k_{t d}^{j}$ representa a constante cinética de terminação por desproporcionamento na fase j, em situação análoga à descrita no caso anterior de terminação por combinação com relação às probabilidades de reações.

- Inibição

$$
\begin{aligned}
& P_{n}^{j}+Z^{j} \stackrel{k_{z}^{j}}{\longrightarrow} D_{n}+Z^{\bullet j} \\
& Q_{n}^{j}+Z^{j} \stackrel{k_{z}^{j}}{\longrightarrow} U_{n}+Z^{\bullet j} \\
& S_{n}^{j}+Z^{j} \stackrel{k_{z}^{j}}{\longrightarrow} V_{n}+Z^{\bullet j} \\
& T_{n}^{j}+Z^{j} \stackrel{2 k_{z}^{j}}{\longrightarrow} P_{n}^{j}+Z^{\bullet j} \\
& Z^{\bullet j}+Z^{\bullet j} \stackrel{k_{z}^{j}}{\longrightarrow} Z^{j}+\text { produtos inativos }
\end{aligned}
$$

sendo $k_{z}^{j}$ a representação da taxa de inibição na fase j. 


\subsection{Hipóteses Adotadas no Desenvolvimento do Modelo}

O presente trabalho foi desenvolvido com base no modelo de Xie et al. (1991a) e para tal algumas hipóteses foram adotadas:

(I) a polimerização do monômero nas fases aquosa e gasosa é negligenciável (a qauntidade de monômero presente nestas fases é muito menor que a quantidade de monômero nas fases rica em monômero e rica em polímero);

(II) a polimerização heterogênea do cloreto de vinila ocorre conforme o mecanismo cinético descrito anteriormente, em reator de batelada, com a ocorrência de três estágios: o primeiro estágio, para conversões menores que $0,1 \%$, durante o qual nas gotas somente existe a fase rica em monômero; o segundo estágio, para conversões entre $0,1 \%$ e $X_{f}$, durante a qual existem, nas gotas, duas fases: a fase rica em monômero e a fase rica em polímero; e o terceiro estágio, durante o qual existe nas gotas somente a fase rica em polímero.

(III) durante o segundo estágio, não há transferência de radicais entre as fases reativas, rica em monômero (1) e rica em polímero (2) (estudos prévios feitos com o modelo de Xie et al. (1991a) que inclue explicitamente esta transferência de radicais mostraram que este efeito é pequeno, nas situações testadas);

(IV) as concentrações do monômero nas quatro fases (fase gasosa, fase aquosa, fase rica em monômero e fase rica em polímero) encontram-se em equilíbrio termodinâmico (esta é uma hipótese usualmente empregada nos modelos de polimerização em suspensão);

(V) as concentrações do(s) iniciador(es) nas fases rica em monômero e rica em polímero encontram-se em equilíbrio termodinâmico (esta também é uma hipótese usualmente empregada nos modelos de polimerização em suspensão); 
(VI) as constantes cinéticas são independentes do tamanho da cadeia do radical polimérico (esta hipótese é largamente empregada nos modelos de polimerização e se apoia em farta evidência experimental de estudos cinéticos de reações entre compostos de séries homólogas);

(VII) para os radicais, aplica-se o princípio de estado pseudo-estacionário (PSSA), no qual os radicais produzidos são quase que instantaneamente consumidos logo após se formarem, isto é, a taxa de formação e a taxa de consumo dos radicais são consideradas iguais (esta hipótese é classicamente adotada em modelos cinéticos de reações em cadeia envolvendo radicais livres, devido à sua elevada reatividade);

(VIII) para o balanço do monômero, adota-se a hipótese de aproximação de cadeia longa (LCA, "long chain aproximation"), segundo a qual a cadeia polimérica é formada principalmente por propagação e é deste modo que a maioria dos monômeros são consumidos (ou seja, no balanço de monômero, o consumo de monômero é considerado ocorrer apenas pela reação de propagação, desconsiderando-se, portanto, a quantidade de monômero consumida pelas outras reações do mecanismo);

(IX) apesar de desempenhar uma função importante no controle da massa molecular do polímero, a transferência de cadeia para monômero não é considerada no estudo da conversão (as reações de transferência de cadeia não afetam a cinética da polimerização pois não afetam a concentração de radicais livres poliméricos no meio reacional). 


\subsection{Equacionamento do Modelo}

\subsubsection{Conversão de monômero (balanço de monômero)}

O balanço de monômero, expresso em termos de conversão de monômero $X$ (fração do monômero inicial que foi convertido em polímero), para cada um dos três estágios, é descrito por:

$$
\begin{aligned}
& \text { estágio 1: } \quad \frac{d X}{d t}=\frac{k_{p_{1}}\left[R_{1}\right] M_{1}}{N_{o} M W_{m}} \\
& \text { estágio 2: } \quad \frac{d X}{d t}=\frac{k_{p_{1}}\left[R_{1}\right] M_{1}+k_{p_{2}}\left[R_{2}\right] M_{2}}{N_{o} M W_{m}} \\
& \text { estágio 3: } \quad \frac{d X}{d t}=\frac{k_{p_{2}}\left[R_{2}\right] M_{2}}{N_{o} M W_{m}}
\end{aligned}
$$

em que:

$N_{o}$ é o número de mols inicial de monômero alimentado ao reator;

$M W_{m}$ é a massa molar do monômero $(62,5 \mathrm{~g} / \mathrm{mol})$;

$k_{p 1}$ e $k_{p 2}$ são a constante de propagação na fase rica em monômero e na fase rica em polímero, respectivamente;

$M_{1}$ e $M_{2}$ são a massa de monômero na fase rica em monômero e na fase rica em polímero, respectivamente;

$\left[R_{1}\right]$ e $\left[R_{2}\right]$ são a concentração total de radicais na fase rica em monômero e na fase rica em polímero, respectivamente. 


\subsubsection{Concentração total de radicais}

As concentrações de radicais em cada uma das fases (rica em monômero e rica em polímero) são determinadas por:

$$
\begin{aligned}
& {\left[R_{1}\right]=\sqrt{\frac{2 f_{1} k_{d}[I]_{1}}{k_{t 1}}}} \\
& {\left[R_{2}\right]=\sqrt{\frac{2 f_{2} k_{d}[I]_{2}}{k_{t 2}}}}
\end{aligned}
$$

em que

$k_{t j}$ representa a constante cinética de terminação (L/mol.s) na fase $\mathrm{j}$ ( $\mathrm{j}=1$ fase rica em monômero, j = 2 fase rica em polímero);

$k_{d}$ representa a constante cinética de decomposição do iniciador $\left(\mathrm{s}^{-1}\right)$;

$[I]_{j}$ é a concentração de iniciador na fase j;

$f_{j}$ é a eficiência do iniciador na fase j. No presente modelo, seguindo a proposta de Xie et al. (1991a), foram considerados iguais os valores de eficiência $f_{1}=f_{2}=f$.

\subsubsection{Concentrações de iniciador}

As concentrações dos iniciadores nas fases rica em monômero (1) e rica em polímero (2) estão relacionadas pelo coeficiente de partição: 


$$
K_{I}=\frac{[I]_{2}}{[I]_{1}}
$$

cujo valor adotado foi $K_{I}=0,77$ conforme estudos feitos por Xie et al. (1991a). O balanço de iniciador pode ser escrito na forma:

$$
\frac{d N_{I}}{d t}=-k_{d} N_{I}
$$

e para uma polimerização ocorrendo isotermicamente $\left(k_{d}\right.$ constante), pode ser integrada analiticamente:

$$
N_{I}=N_{I o} \exp \left(-k_{d} t\right)
$$

em que $N_{I o}$ é o número de mols inicial de iniciador. Considerando a partição do iniciador entre as fases, a concentração de iniciador em cada fase pode ser calculada por:

$$
\begin{aligned}
& {[I]_{1}=\frac{N_{I}}{V_{1}+K_{I} V_{2}}} \\
& {[I]_{2}=K_{I} \frac{N_{I}}{V_{1}+K_{I} V_{2}}}
\end{aligned}
$$

em que $V_{1}$ e $V_{2}$ são os volumes das fases 1 e 2 , respectivamente. 


\subsubsection{Distribuição do monômero entre as fases}

A quantidade total de monômero presente dentro do reator em cada instante está distribuída entre as quatro fases existentes (aquosa, gasosa, rica em monômero e rica em polímero):

$$
M_{0}(1-X)=M_{1}+M_{2}+M_{a}+M_{g}
$$

em que os símbolos $M_{0}, M_{1}, M_{2}, M_{a}$ e $M_{g}$ denotam, respectivamente, a massa total de monômero introduzida inicialmente no reator, e as massas de monômero presente nas fases monomérica (1), polimérica (2), aquosa (a) e gasosa(g). Considera-se que as fases encontram-se em equilíbrio termodinâmico.

A massa de VCM na fase aquosa é dada por:

$$
M_{a}=K W_{w}
$$

em que $W_{w}$ é a massa inicial de água (g) e $K$ é a constante de solubilidade do VCM na fase aquosa e conforme Xie et al. (1987) é calculada em função da temperatura pela seguinte expressão:

$$
K=0,0472-\frac{11.6}{T}
$$

\section{- Estágio 1}

Durante o primeiro estágio, cujo intervalo de conversão vai de 0 (zero) a 0,1\% ainda não há fase polimérica e, portanto, $M_{2}$ vale zero. Dessa forma, a equação (11) pode ser usada para calcular a massa de monômero na fase rica em monômero: 


$$
M_{2}=0
$$

$$
M_{1}=M_{0}(1-X)-M_{a}-M_{g}
$$

A massa do VCM na fase gasosa é determinada da seguinte forma:

$$
M_{g}=\frac{M W_{m} P_{m}^{o}}{R T}\left[\left(1-W_{i}\right) V_{r}+\frac{X M_{0}\left(1 / \rho_{m}-1 / \rho_{p}\right)}{1-\rho_{g o} / \rho_{m}}\right]
$$

em que:

$V_{r}$ é o volume total do reator;

$P_{m}^{o}$ é a pressão de vapor do monômero (atm);

$\rho_{g o}$ é a densidade da fase gasosa ( $\mathrm{g} / \mathrm{L}$ ) calculada para condições de gás ideal:

$$
\rho_{g o}=\frac{P_{m}^{o} M W_{m}}{R T}
$$

$W_{i}$ é a fração do volume do reator preenchida inicialmente com líquido, calculado por:

$$
W_{i}=\frac{\left(W_{w} / \rho_{w}+M_{0} / \rho_{m}-\rho_{g o} V_{r} / \rho_{m}\right)}{V_{r}\left(1-\rho_{g o} / \rho_{m}\right)}
$$

- Estágio 2

Durante o estágio dois, as massas de monômero na fase rica em monômero e na fase rica em polímero são obtidas por:

$$
M_{1}=M_{0}(1-X)-M_{2}-M_{a}-M_{g}
$$




$$
M_{2}=\frac{X}{X_{f}}\left[M_{0}\left(1-X_{f}\right)-M_{g\left(X_{f}\right)}-M_{a}\right]
$$

em que $M_{g\left(x_{f}\right)}$ é a massa de monômero na fase gasosa, determinada na conversão crítica $\left(X_{f}\right)$ :

$$
M_{g\left(X_{f}\right)}=\frac{M W_{m} P_{m}^{o}}{R T}\left[\left(1-W_{i}\right) V_{r}+\frac{X_{f} M_{0}\left(1 / \rho_{m}-1 / \rho_{p}\right)}{1-\rho_{g o} / \rho_{m}}\right]
$$

A conversão crítica $X_{f}$ (conversão na qual termina o estágio 2 e inicia o estágio 3 com o desaparecimento da fase rica em monômero) é obtida pela seguinte expressão:

$$
X_{f}=\frac{M_{0}-\left\lfloor\rho_{g o}\left(1-W_{i}\right) V_{r}+K W_{w}\right\rfloor}{M_{0}\left[\left(1+\rho_{g o} \frac{\left(1 / \rho_{m}-1 / \rho_{p}\right)}{1-\rho_{g o} / \rho_{m}}+\rho_{m} \frac{1-\phi_{2}}{\phi_{2, c} \rho_{p}}\right)\right]}
$$

sendo $\phi_{2, c}$ representa a fração volumétrica de polímero na fase rica em polímero durante o estágio 2.

Esta fração volumétrica permanece inalterada durante todo o segundo estágio. Isto se deve à existência de um equilíbrio termodinâmico entre a fase rica em monômero (praticamente monômero puro) e a fase rica em polímero (polímero saturado com monômero). Durante o segundo estágio (conversão menores que a conversão crítica $\left.X_{f}\right)$, a fração volumétrica de monômero na fase $2\left(\phi_{2, c}\right)$ é calculada admitindo o equilíbrio de solubilidade entre monômero e polímero, expresso pela equação de FloryHuggins:

$$
\ln \left(1-\phi_{2, c}\right)+\phi_{2, c}+\chi \phi_{2, c}{ }^{2}=0
$$


em que $\chi$ é chamado de parâmetro de interação de Flory-Huggins, e neste trabalho foi calculado pela seguinte expressão obtida por Xie et al. (1987):

$$
\chi=\frac{1286,4}{T}-3,02
$$

As concentrações do monômero nas fases monomérica (1) e polimérica (2) são assim calculadas:

$$
\begin{aligned}
& {\left[M_{1}\right]=\frac{\rho_{m}}{M W_{m}}} \\
& {\left[M_{2}\right]=\frac{M_{2}}{\left(M W_{m} V_{2}\right)}}
\end{aligned}
$$

e o volume de cada fase será:

$$
\begin{aligned}
& V_{1}=\frac{M_{1}}{\rho_{m}} \\
& V_{2}=\left(\frac{M_{2}}{\rho_{m}}+\frac{M_{0} X}{\rho_{p}}\right)
\end{aligned}
$$

- Estágio 3

No estágio 3, a fase rica em monômero desaparece e a distribuição do monômero nas fases restantes é calculada pelas seguintes expressões:

$$
M_{1}=0
$$




$$
\begin{aligned}
& M_{2}=M_{0}(1-X)-M_{a}-M_{g} \\
& M_{g}=\frac{M W_{m} P_{m}}{R T}\left[\left(1-W_{i}\right) V_{r}+\frac{M_{0}\left(1 / \rho_{m}-1 / \rho_{p}\right)}{1-\rho_{g o} / \rho_{m}}\left(X+X_{f} \frac{\rho_{g o}}{\rho_{m}-\rho_{g o}}\right)\right] \\
& M_{a}=K W_{w} \frac{P_{m}}{P_{m}^{o}}
\end{aligned}
$$

Neste estágio 3 da polimerização, tanto a pressão parcial do monômero na fase gasosa quanto a fração volumétrica do monômero na fase rica em polímero começam a variar. A pressão do reator começa a diminuir em função da transferência de monômero existente na fase gasosa para a gota de polímero, onde o monômero continua sendo consumido pela polimerização. Neste estágio a equação (23) não vale pois a fase 2 não mais estará saturada de monômero, e a relação de equilíbrio entre a pressão parcial de monômero na fase gasosa $P_{m}$ e a fração volumétrica de monômero na fase 2 passa e ser dada por:

$$
\frac{P_{m}}{P_{m}^{o}}=\exp \left(\ln \left(1-\phi_{2}\right)+\phi_{2}+\chi \phi_{2}^{2}\right)
$$

\subsubsection{Constantes cinéticas}

As constantes cinéticas de terminação e de propagação, na ausência de limitações difusionais, foram calculadas a partir das equações propostas por Xie et al. (1991a), obtidas a partir de dados de conversões muito pequenas: 


$$
\begin{aligned}
& k_{t 0}=1,3 \times 10^{12} \exp \left(-\frac{4200}{1,987 T}\right) \\
& k_{p 0}=\left(k_{t 0}^{1 / 2}\right) 10,4 \exp \left(-\frac{3780}{1,987 T}\right)
\end{aligned}
$$

\subsubsection{Constantes cinéticas limitadas por difusão}

No presente estudo, um modelo simplificado da teoria do volume livre proposto por Xie et al. (1991a) foi empregado para descrever as reações controladas por difusão na polimerização em suspensão do cloreto de vinila.

Para a fase rica em monômero (fase 1), considera-se que as constantes cinéticas permanecem inalteradas e iguais aos valores isentos de limitações difusionais:

$$
\begin{aligned}
& k_{t 1}=k_{t 0} \\
& k_{p 1}=k_{p 0}
\end{aligned}
$$

Contudo, na fase rica em polímero (fase 2) a constante de terminação sofre correção devido às limitações difusionais:

$$
k_{t, 2}=k_{t 0} \exp \left[-A\left(\frac{1}{V_{f}}-\frac{1}{V_{f_{\text {crit }}}}\right)\right]
$$

em que o volume livre da mistura na fase polimérica, $V_{f}$, é dado por: 


$$
V_{f}=\phi_{2} V_{f p}+\left(1-\phi_{2}\right) V_{f m}
$$

em que $V_{f p}$ e $V_{f m}$ são os volumes livres do polímero e do monômero, respectivamente e $\phi_{2}$ é a fração volumétrica do polímero na fase polimérica.

Durante o segundo estágio $\left(0,001 \leq X \leq X_{f}\right)$, a composição da fase 2 permanece constante e $V_{f}=V_{f}^{*}$ que nada mais é do que o próprio $V_{f}$ calculado nas condições críticas $\left(\phi_{2, c}\right)$.

De forma similar, a constante de propagação na fase polimérica, $k_{p 2}$, é expressa por:

$$
\begin{array}{ll}
k_{p 2}=k_{p 0} & \text { para } X<X_{f} \\
k_{p 2}=k_{p 0} \exp \left[-B\left(\frac{1}{V_{f}}-\frac{1}{V_{f}^{*}}\right)\right] & \text { para } X>X_{f}
\end{array}
$$

Neste modelo, considera-se que a propagação passa a ser limitada por difusão apenas após o início do estágio 3, quando deixa de existir a fase rica em monômero, e o meio reacional (fase rica em polímero) passa a se tornar gradativamente mais viscosa pelo consumo do monômero e aumento da fração de polímero na mistura reacional.

Os parâmetros A e B nas equações (38) e (41) foram estimados a partir dos dados experimentais.

Neste modelo, a eficiência do iniciador, $f$, é considerada constante e assume-se que $k_{p}$ torna-se limitado por difusão a partir do início do estágio 3. Sabe-se que a eficiência também decai (torna-se limitada por difusão) quando o meio se torna mais viscoso. Com base apenas em dados de conversão versus tempo, entretanto, não é possível separar estes efeitos. Portanto, a variação de $k_{p}$ com a conversão, expresso pela equação (41), de fato representa a variação no grupo $f^{1 / 2} k_{p}$. 


\subsection{Parâmetros Fixados no Modelo}

Os parâmetros utilizados nestes cálculos para a correção das constantes cinéticas devido ao efeito das limitações impostas pela difusão estão apresentados na Tabela 2.

Tabela 2 - Parâmetros usados nos cálculos da fração de volume livre (Krallis et al., 2004).

\begin{tabular}{|l|l|}
\hline$T_{g_{M}}=70$ & Temperatura de transição vítrea do VCM, (K) \\
\hline$T_{g_{P}}=360,25-0,132 T$ & Temperatura de transição vítrea do PVC, (K) \\
\hline$\alpha_{M}=9,98 \times 10^{-4}$ & Fator de dilatação térmica do VCM, (K $\left.{ }^{-1}\right)$ \\
\hline$\alpha_{P}=5,47 \times 10^{-4}$ & Fator de dilatação térmica do PVC, (K $\left.{ }^{-1}\right)$ \\
\hline$V_{f_{m}}=0,025+\alpha_{M}\left(T-T_{g_{M}}\right)$ & Fração de volume livre do VCM \\
\hline$V_{f_{P}}=0,025+\alpha_{P}\left(T-T_{g_{P}}\right)$ & Fração de volume livre do PVC \\
\hline$V_{f_{c r i t}}=0,8 V_{f_{m}}$ & Fração de volume livre crítica do sistema \\
\hline
\end{tabular}

\subsection{Método de Solução das Equações do Modelo}

Todas essas equações descritas ao longo deste capítulo foram resolvidas com o auxílio do programa MATLAB. A solução das equações diferenciais foi obtida através do uso do algoritmo de Runge-Kutta (função ode45).

A equação algébrica (23) foi resolvida para obter o valor de $\phi_{2, c}$ usando a função fzero do MATLAB.

As equações referentes à distribuição do monômero no estágio 3 formam um conjunto de equações algébricas não-lineares, cuja solução requer um procedimento 
iterativo a cada instante de tempo. Dessa forma, foram determinados os valores de $\phi_{2}$ que satisfaçam a equação (33). O método da bissecção do intervalo foi utilizado com o objetivo de determinar esta fração.

\subsection{Estimativa de Parâmetros do Modelo}

Os parâmetros A e B foram estimados pelo critério de mínimos quadrados utilizando uma rotina de cálculo de parâmetros de regressão não-linear (função nlinfit do MATLAB) a fim de minimizar a função objetivo $F$ :

$$
F=\sum_{i=1}^{N}\left(y_{i}-\hat{y_{i}}\right)^{2}
$$

em que $y_{i}$ e $\hat{y}_{i}$ são os valores de conversão $(X)$ obtidos na literatura e os calculados pelo modelo, respectivamente. 


\section{RESULTADOS E DISCUSSÃO}

\subsection{Dados Experimentais}

Os dados experimentais utilizados neste trabalho para ajuste do modelo e posterior comparação com os resultados das simulações foram obtidos na literatura e estão apresentados na Tabela 3.

Tabela 3 - Dados experimentais.

\begin{tabular}{|c|c|c|c|}
\hline Iniciador & Tempera & $\begin{array}{l}\text { / Quantidade inicial } \\
\text { iniciador * }\end{array}$ & Referência \\
\hline \multirow{4}{*}{$\begin{array}{l}\text { Perkadox } 16 \\
\text { (Peroxidicarbonato de di(4-terc- } \\
\text { butilciclohexila)) }\end{array}$} & $45^{\circ} \mathrm{C}$ & \multirow{4}{*}{$0,175 \%$} & \multirow{4}{*}{ Xie et al. (1991a) } \\
\hline & $50^{\circ} \mathrm{C}$ & & \\
\hline & $55^{\circ} \mathrm{C}$ & & \\
\hline & $60^{\circ} \mathrm{C}$ & & \\
\hline \multirow{8}{*}{$\begin{array}{l}\text { AIBN } \\
\text { (Azobis (isobutironitrila)) }\end{array}$} & $55^{\circ} \mathrm{C}$ & \multirow{4}{*}{$0,25 \%$} & \multirow{8}{*}{ Xie et al. (1991a) } \\
\hline & $60^{\circ} \mathrm{C}$ & & \\
\hline & $65^{\circ} \mathrm{C}$ & & \\
\hline & $70^{\circ} \mathrm{C}$ & & \\
\hline & \multirow{2}{*}{$60^{\circ} \mathrm{C}$} & $0,09 \%$ & \\
\hline & & $0,16 \%$ & \\
\hline & $57^{\circ} \mathrm{C}$ & \multirow{2}{*}{$0,16 \%$} & \\
\hline & $62^{\circ} \mathrm{C}$ & & \\
\hline \multirow{7}{*}{$\begin{array}{l}\text { TBPD } \\
\text { (Peroxineodecanoato de terc-butila) }\end{array}$} & \multirow{2}{*}{$45^{\circ} \mathrm{C}$} & $0,0785 \%$ & \multirow{7}{*}{ De Roo et al. (2005) } \\
\hline & & $0,2354 \%$ & \\
\hline & \multirow{3}{*}{$55^{\circ} \mathrm{C}$} & $0,0392 \%$ & \\
\hline & & $0,0785 \%$ & \\
\hline & & $0,1569 \%$ & \\
\hline & \multirow{2}{*}{$65^{\circ} \mathrm{C}$} & $0,0262 \%$ & \\
\hline & & $0,0785 \%$ & \\
\hline \multirow{4}{*}{$\begin{array}{l}\text { LPO } \\
\text { (Peróxido de lauroíla) }\end{array}$} & \multirow{4}{*}{$50^{\circ} \mathrm{C}$} & $0,53 \%$ & \multirow{4}{*}{$\begin{array}{l}\text { Crosato-Arnaldi et al. } \\
\qquad(1968)\end{array}$} \\
\hline & & $1,00 \%$ & \\
\hline & & $2,16 \%$ & \\
\hline & & $4,21 \%$ & \\
\hline \multirow{3}{*}{$\begin{array}{l}\text { LUP } \\
\text { (Peroxineodecanoato de } \\
\text { ( } 3 \text { - hidroxil }-1,1 \text { - dimetilbutila) }\end{array}$} & \multirow{3}{*}{$56,5^{\circ} \mathrm{C}$} & $1,17 \mathrm{~g} / \mathrm{kg}$ de VCM & \multirow{3}{*}{ Krallis et al. (2004) } \\
\hline & & $1,62 \mathrm{~g} / \mathrm{kg}$ de VCM & \\
\hline & & $2,15 \mathrm{~g} / \mathrm{kg}$ de VCM & \\
\hline \multirow{3}{*}{$\begin{array}{l}\text { PDEH } \\
\text { (Peroxidicarbonato de di(2- } \\
\text { etilhexila)) }\end{array}$} & $56,5^{\circ} \mathrm{C}$ & \multirow{3}{*}{$0,606 \mathrm{~g} / \mathrm{kg}$ de VCM } & \multirow{3}{*}{ Krallis et al. (2004) } \\
\hline & $58,5^{\circ} \mathrm{C}$ & & \\
\hline & $68,5^{\circ} \mathrm{C}$ & & \\
\hline
\end{tabular}

* As porcentagens de iniciador são calculadas em relação à massa inicial de monômero. 
Os dados se referem a ensaios experimentais em reator de batelada, nos quais foram medidos dados de conversão em função do tempo, e em alguns casos, pressão em função do tempo. Os dados selecionados incluem ensaios com diferentes iniciadores, e, para um dado iniciador, ensaios com diferentes temperaturas e diferentes concentrações iniciais de iniciador. Foram, portanto uma base de dados adequada para uma validação ampla do modelo em estudo.

\subsection{Ajuste de Parâmetros}

Na Tabela 4 apresentam-se os dados de constante cinética de decomposição dos iniciadores.

Tabela 4 - Dados e parâmetros cinéticos de decomposição dos iniciadores.

\begin{tabular}{|c|c|c|c|}
\hline Iniciador & $\begin{array}{c}M W_{i} \\
(\mathbf{g} / \mathrm{mol})\end{array}$ & $k_{d}\left(\mathbf{s}^{-1}\right)$ & Referência \\
\hline $\begin{array}{l}\text { Perkadox } 16 \\
\text { (Peroxidicarbonato de } \\
\text { di(4-terc-butilciclohexila)) }\end{array}$ & 398,50 & $k_{d}=2,31 \times 10^{15} \exp \left(-\frac{29100}{1,987 T}\right)$ & Xie et al. (1991a) \\
\hline $\begin{array}{l}\text { AIBN } \\
\text { (Azobis (isobutironitrila)) }\end{array}$ & 164,21 & $k_{d}=2,88 \times 10^{15} \exp \left(-\frac{31200}{1,987 T}\right)$ & Xie et al. (1991a) \\
\hline $\begin{array}{l}\text { TBPD } \\
\text { (Peroxineodecanoato de } \\
\text { terc-butila) }\end{array}$ & 244,00 & $k_{d}=1,52 \times 10^{14} \exp \left(-\frac{115470}{8,314 T}\right)$ & De Roo et al. (2005) \\
\hline $\begin{array}{l}\text { LPO } \\
\text { (Peróxido de lauroíla) }\end{array}$ & 398,70 & $k_{d}=1,20 \times 10^{14} \exp \left(-\frac{120478,12}{8,314 T}\right.$ & Chemicalland21 \\
\hline $\begin{array}{l}\text { LUP } \\
\text { (Peroxineodecanoato de } \\
\text { (3- hidroxil }-1,1- \\
\text { dimetilbutila) }\end{array}$ & 302,41 & $k_{d}=1,054 \times 10^{14} \exp \left(-\frac{26557}{1,987 T}\right)$ & Arkema \\
\hline $\begin{array}{l}\text { PDEH } \\
\text { (Peroxidicarbonato de } \\
\text { di(2-etilhexila)) }\end{array}$ & 346,50 & $k_{d}=1,32 \times 10^{14} \exp \left(-\frac{114176}{8,314 T}\right)$ & $\begin{array}{l}\text { Allsopp e Vianello } \\
\qquad(2002)\end{array}$ \\
\hline
\end{tabular}


Os parâmetros $A$ e $B$ das expressões de correções das constantes cinéticas de terminação e propagação foram escolhidos para serem ajustados (equações 38 e 41, respectivamente). A eficiência de cada iniciador $(f)$ também foi determinada através de ajuste.

A estratégia escolhida foi selecionar inicialmente dois conjuntos de dados, fazer o ajuste dos parâmetros para estes conjuntos, no caso, os dados com o iniciador Perkadox $(0,175 \%)$ e com o iniciador $\operatorname{AIBN}(0,25 \%)$ para as diferentes temperaturas de polimerização. $\mathrm{O}$ ajuste foi feito individualmente para cada ensaio, usando o critério de mínimos quadrados.

Posteriormente, os valores obtidos dos parâmetros $A$ e $B$ foram analisados $e$ verificou-se que variavam com a temperatura. Então, uma correlação $A(T)$ e $B(T)$ na forma da expressão de Arrhenius foi obtida.

Os resultados dos ajustes individuais obtidos para o caso do Perkadox $(0,175 \%)$ e o $\operatorname{AIBN}(0,25 \%)$ para as diferentes temperaturas de polimerização estão expressos nas Figuras 3 e 4 , onde se pode observar que o modelo foi capaz de ajustar adequadamente os dados experimentais, reproduzindo qualitativa e quantitativamente o comportamento das curvas experimentais de conversão versus tempo.

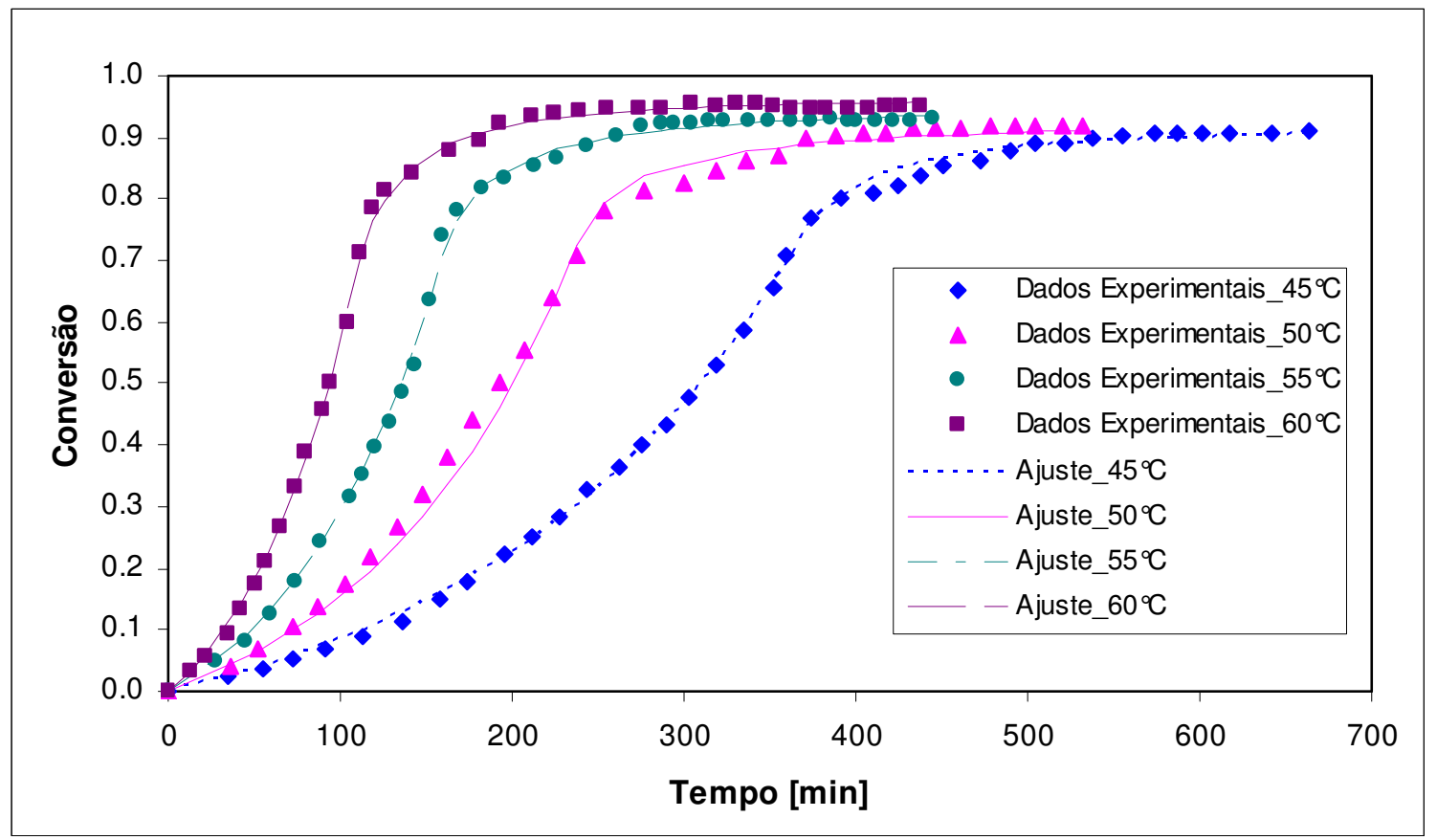

Figura 3 - Modelo ajustado com os dados experimentais utilizando como iniciador o Perkadox (0,175\%), a diferentes temperaturas. 


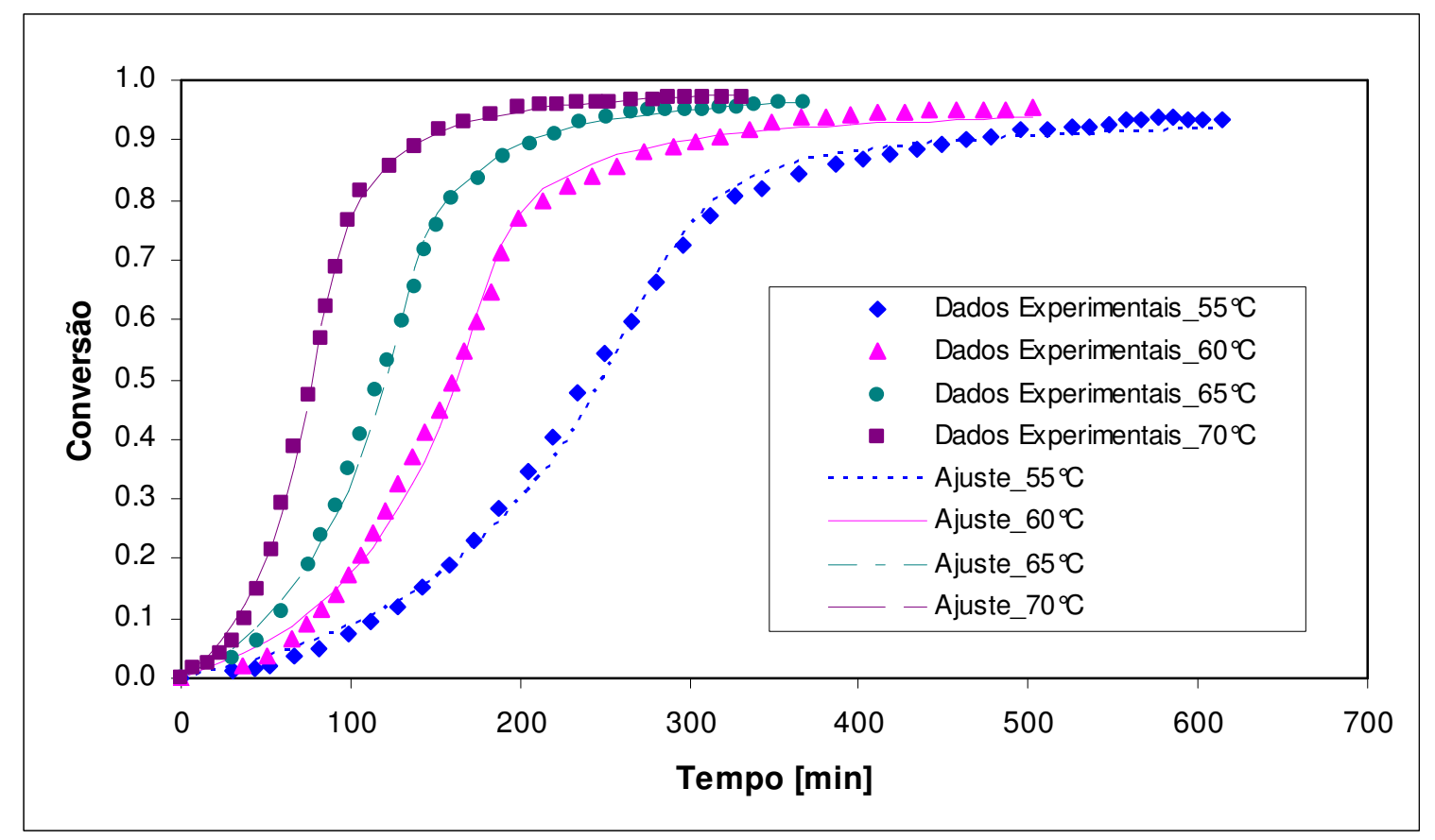

Figura 4 - Modelo ajustado com os dados experimentais utilizando como iniciador o $\operatorname{AIBN}(0,25 \%)$, a diferentes temperaturas.

Os valores dos parâmetros ajustados estão apresentados na Tabela 5 . Na Figura 5 verifica-se que o comportamento dos parâmetros $A$ e B em função da temperatura pode ser representado por uma equação do tipo Arrhenius, como também observado em Xie et al. (1991a). 
Tabela 5 - Valores dos parâmetros ajustados a cada ensaio realizado com o Perkadox e o AIBN.

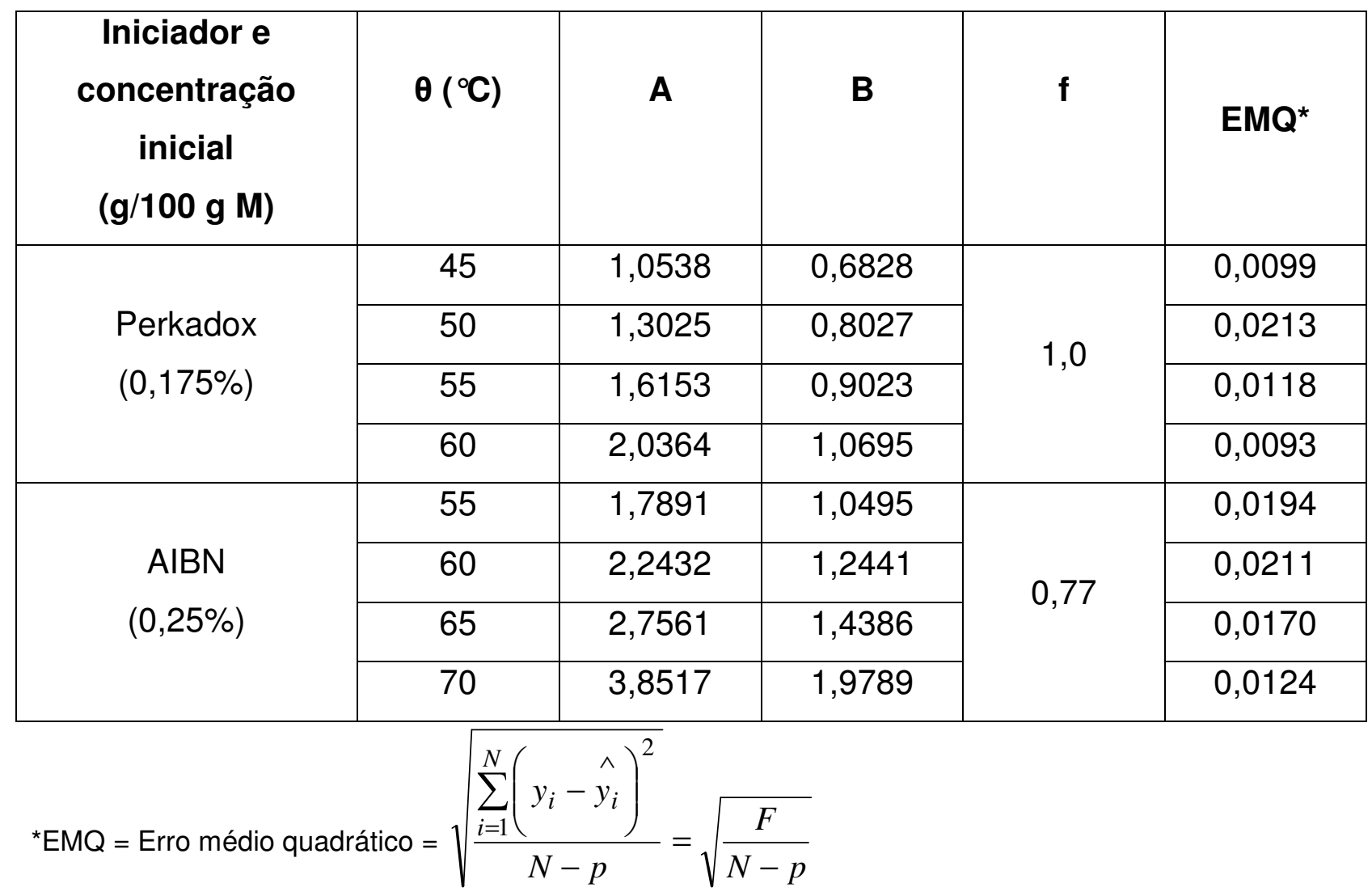
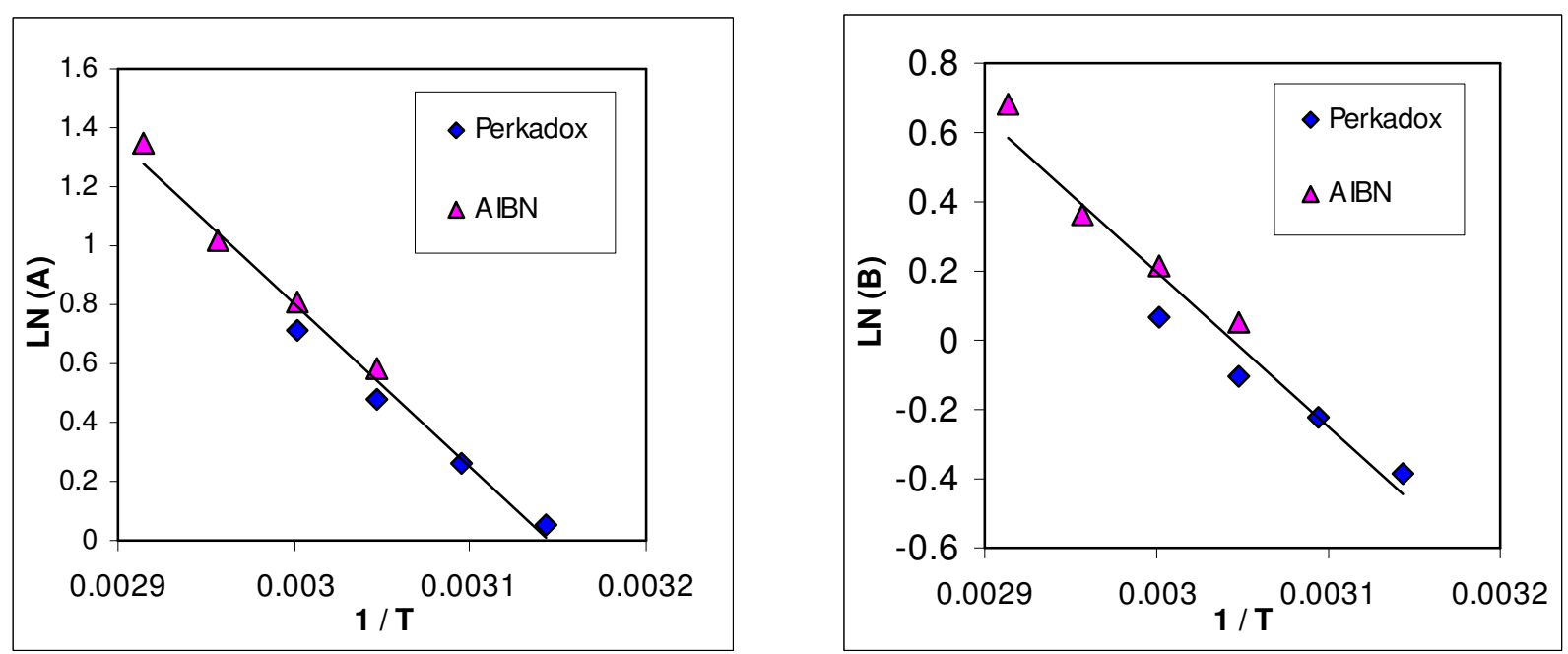

Figura 5 - Resultado do ajuste dos parâmetros A e B tendo como base os dados obtidos com os ajustes individuais feitos com o Perkadox $(0,175 \%)$ e o AIBN $(0,25)$. 
$\mathrm{Na}$ Figura 5 observa-se que, apesar de uma ligeira separação entre os dois conjuntos de pontos (os do Perkadox, e os do AIBN), uma única equação pode representar razoavelmente o comportamento de ambos os conjuntos. As seguintes equações (mostradas na Figura 5 como uma reta) representam a variação de $A$ e $B$ com a temperatura:

$$
\begin{aligned}
& A=\exp \left(17,488-\frac{5562,3}{T(K)}\right) \\
& B=\exp \left(13,641-\frac{4480,1}{T(K)}\right)
\end{aligned}
$$

Além destes ajustes, outros similares foram feitos para os outros tipos de iniciadores mencionados na Tabela 3.

Para as reações iniciadas com o TBPD, o ajuste foi feito simultaneamente para diferentes concentrações a uma mesma temperatura.

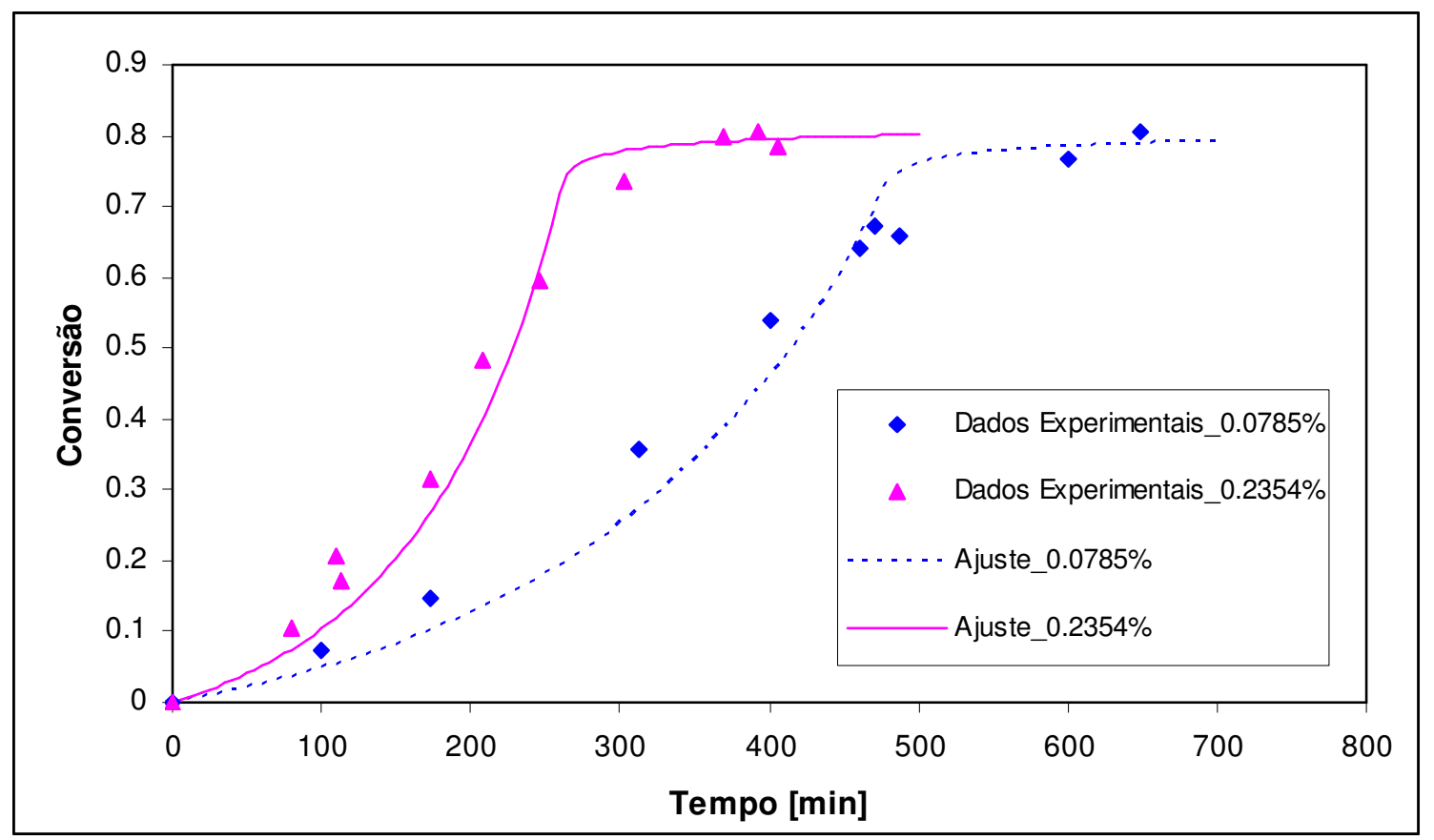

Figura 6 - Modelo ajustado com os dados experimentais utilizando como iniciador o TBPD a $45^{\circ} \mathrm{C}$, a diferentes concentrações. 


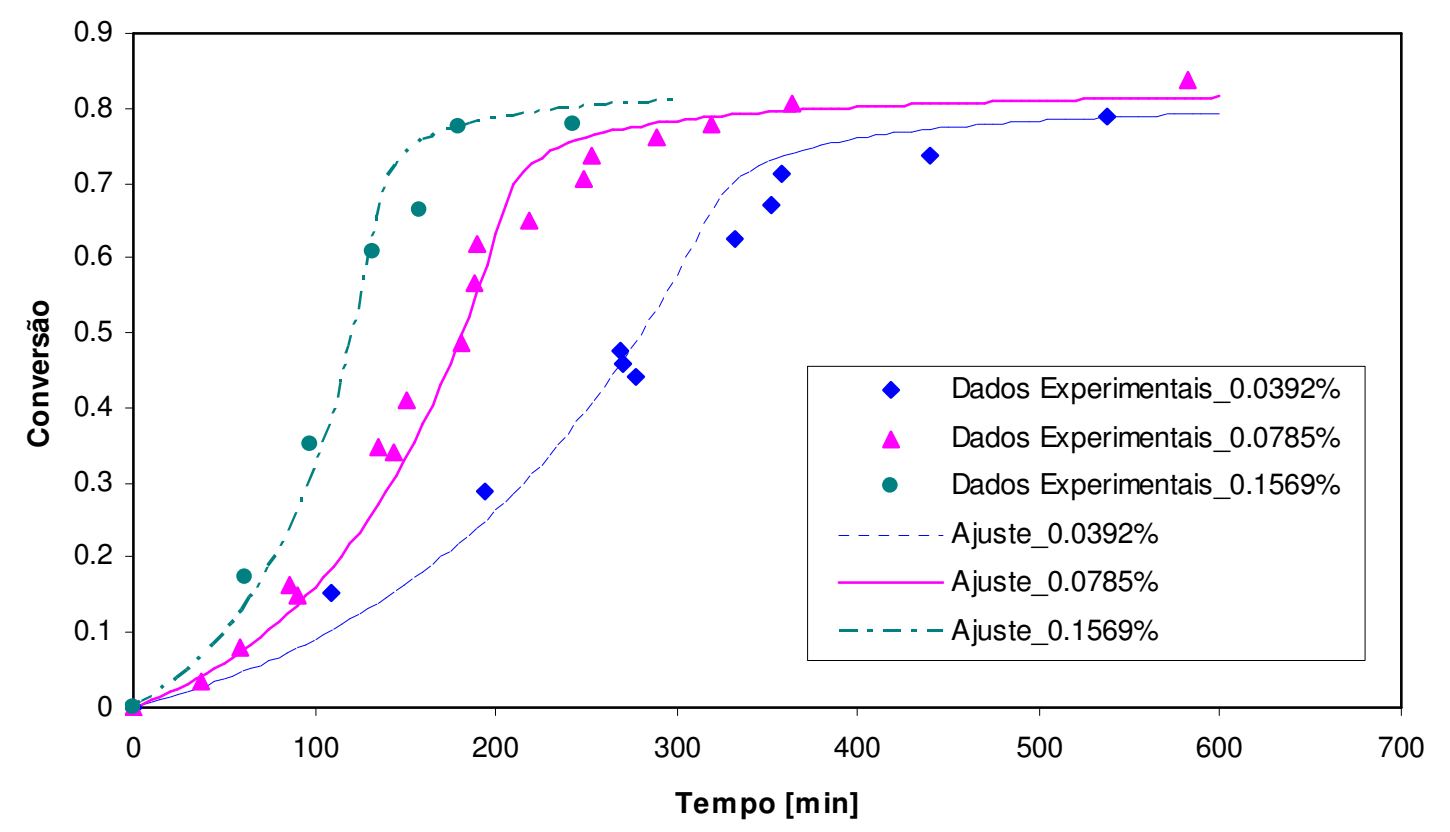

Figura 7 - Modelo ajustado com os dados experimentais utilizando como iniciador o TBPD a $55^{\circ} \mathrm{C}$, a diferentes concentrações.

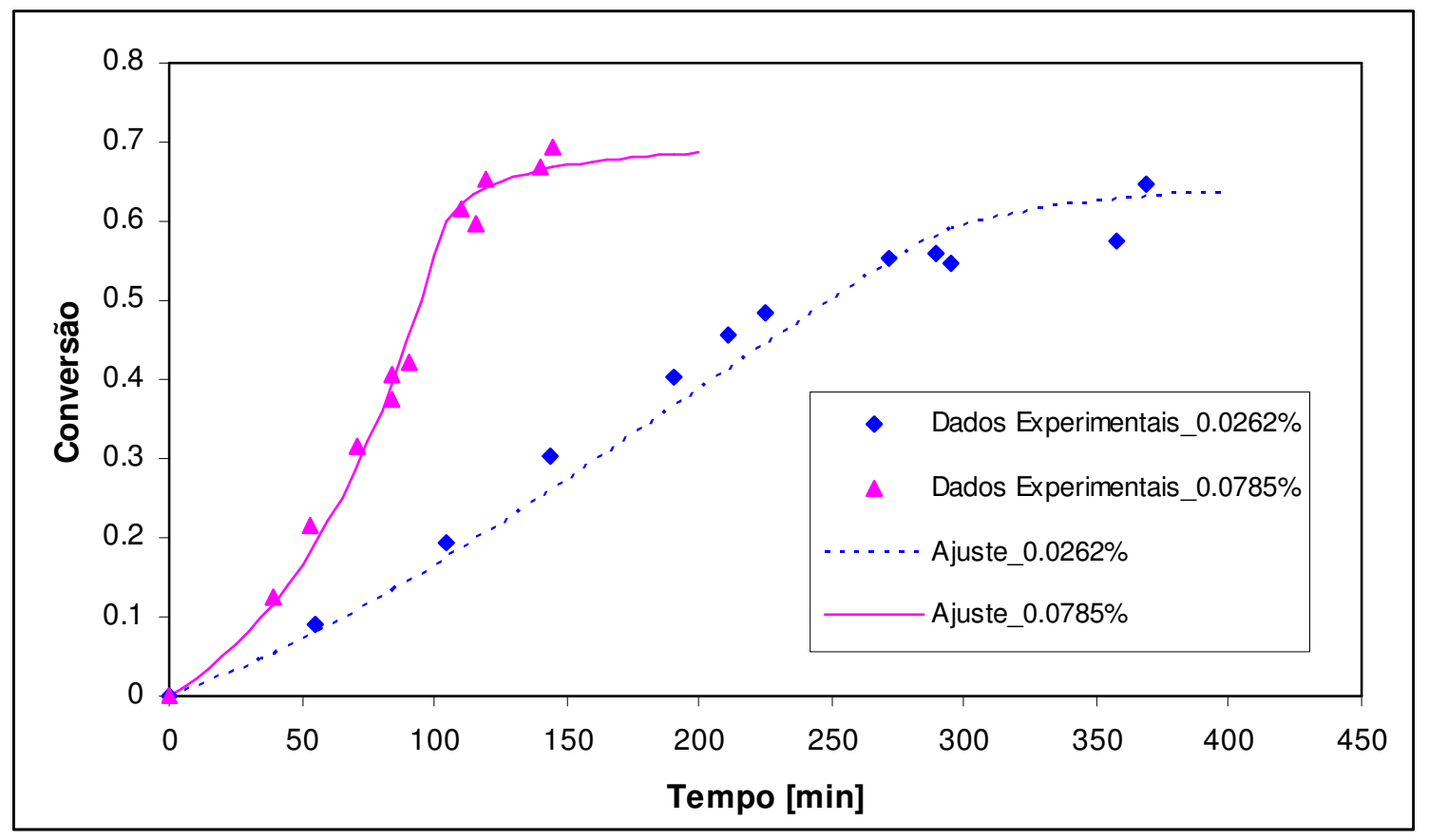

Figura 8 - Modelo ajustado com os dados experimentais utilizando como iniciador o TBPD a $65^{\circ} \mathrm{C}$, a diferentes concentrações. 
Para as reações iniciadas com o LPO, procedeu-se um ajuste individual para cada concentração de iniciador.

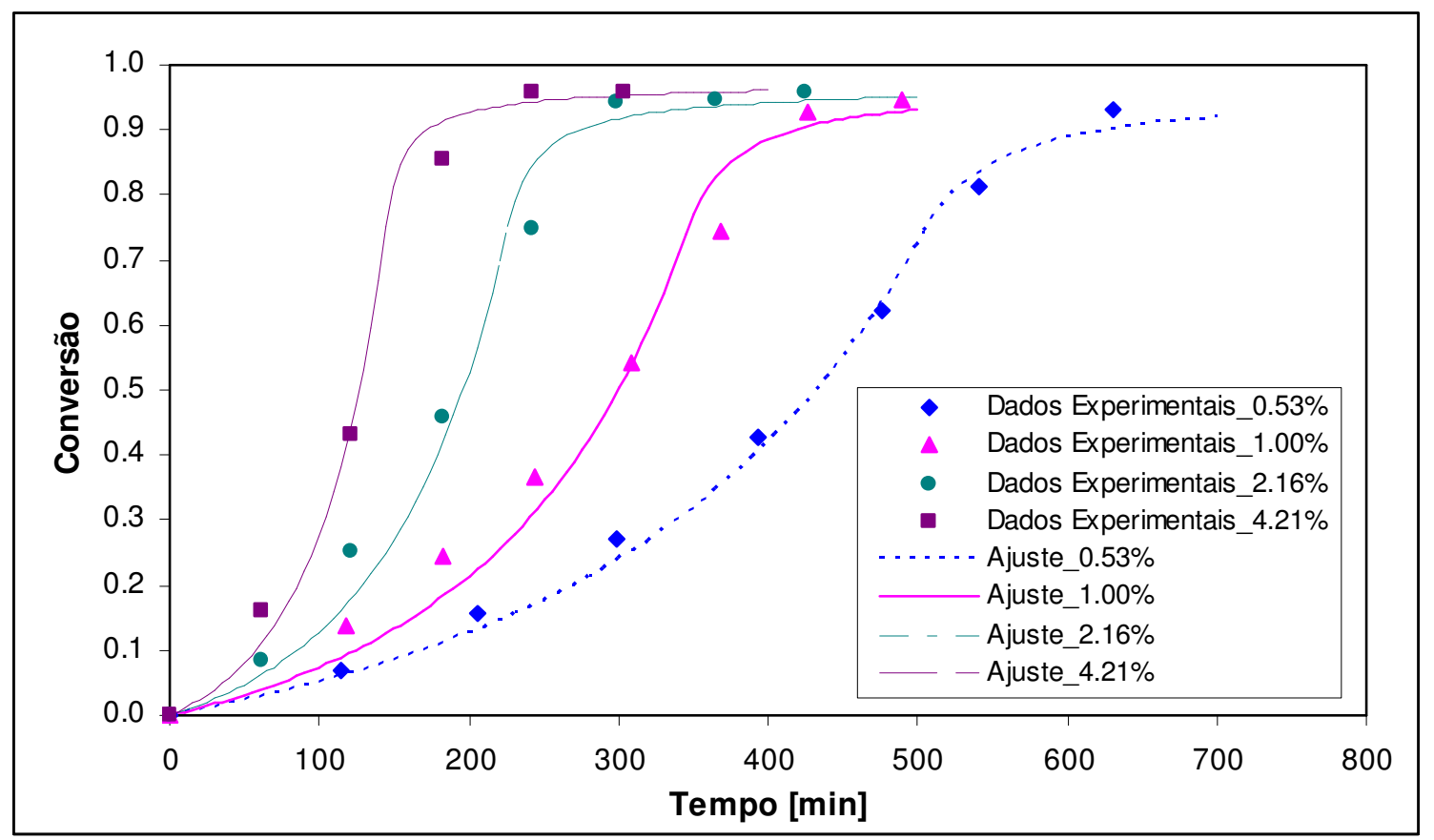

Figura 9 - Modelo ajustado com os dados experimentais utilizando como iniciador o LPO a $50^{\circ} \mathrm{C}$, a diferentes concentrações.

Pode-se observar que os modelos ajustados apresentam-se com boa concordância em relação aos dados experimentais. Os valores dos parâmetros ajustados estão representados na Tabela 6, e na Figura 10 são comparados com os valores de A e de B obtidos para Perkadox e AIBN e com as equações (43) e (44). Observa-se que os valores ajustados de A para todos os casos podem ser razoavelmente bem representados pela equação (43). Por outro lado, os valores do parâmetro B ajustados para 0 iniciador TBPD diferem significativamente daqueles representados pela equação (44). 
Tabela 6 - Valores dos parâmetros ajustados a cada ensaio realizado com o TBPD e o LPO.

\begin{tabular}{|c|c|c|c|c|c|c|}
\hline Iniciador & $\theta\left({ }^{\circ} \mathrm{C}\right)$ & $\begin{array}{c}\text { Concentração } \\
\text { inicial } \\
\text { (g/100 g VCM) }\end{array}$ & A & B & $f$ & EMQ \\
\hline \multirow{7}{*}{ TBPD } & \multirow{2}{*}{45} & 0,0785 & \multirow{2}{*}{1,1683} & \multirow{2}{*}{1,5038} & \multirow{2}{*}{0,65} & \multirow{2}{*}{0,0523} \\
\hline & & 0,2354 & & & & \\
\hline & \multirow{3}{*}{55} & 0,0392 & \multirow{3}{*}{1,7795} & \multirow{3}{*}{1,3931} & \multirow{3}{*}{0,71} & \multirow{3}{*}{0,0413} \\
\hline & & 0,0785 & & & & \\
\hline & & 0,1569 & & & & \\
\hline & \multirow{2}{*}{65} & 0,0262 & \multirow{2}{*}{2,8765} & \multirow{2}{*}{2,6913} & \multirow{2}{*}{0,73} & \multirow{2}{*}{0,0295} \\
\hline & & 0,0785 & & & & \\
\hline \multirow{4}{*}{ LPO } & \multirow{4}{*}{50} & 0,53 & 1,3163 & 0,7638 & 0,94 & 0,0299 \\
\hline & & 1,00 & 1,3876 & 0,7892 & 0,82 & 0,0598 \\
\hline & & 2,16 & 1,4481 & 0,8345 & 0,71 & 0,0615 \\
\hline & & 4,21 & 1,5054 & 0,8557 & 0,71 & 0,0447 \\
\hline
\end{tabular}
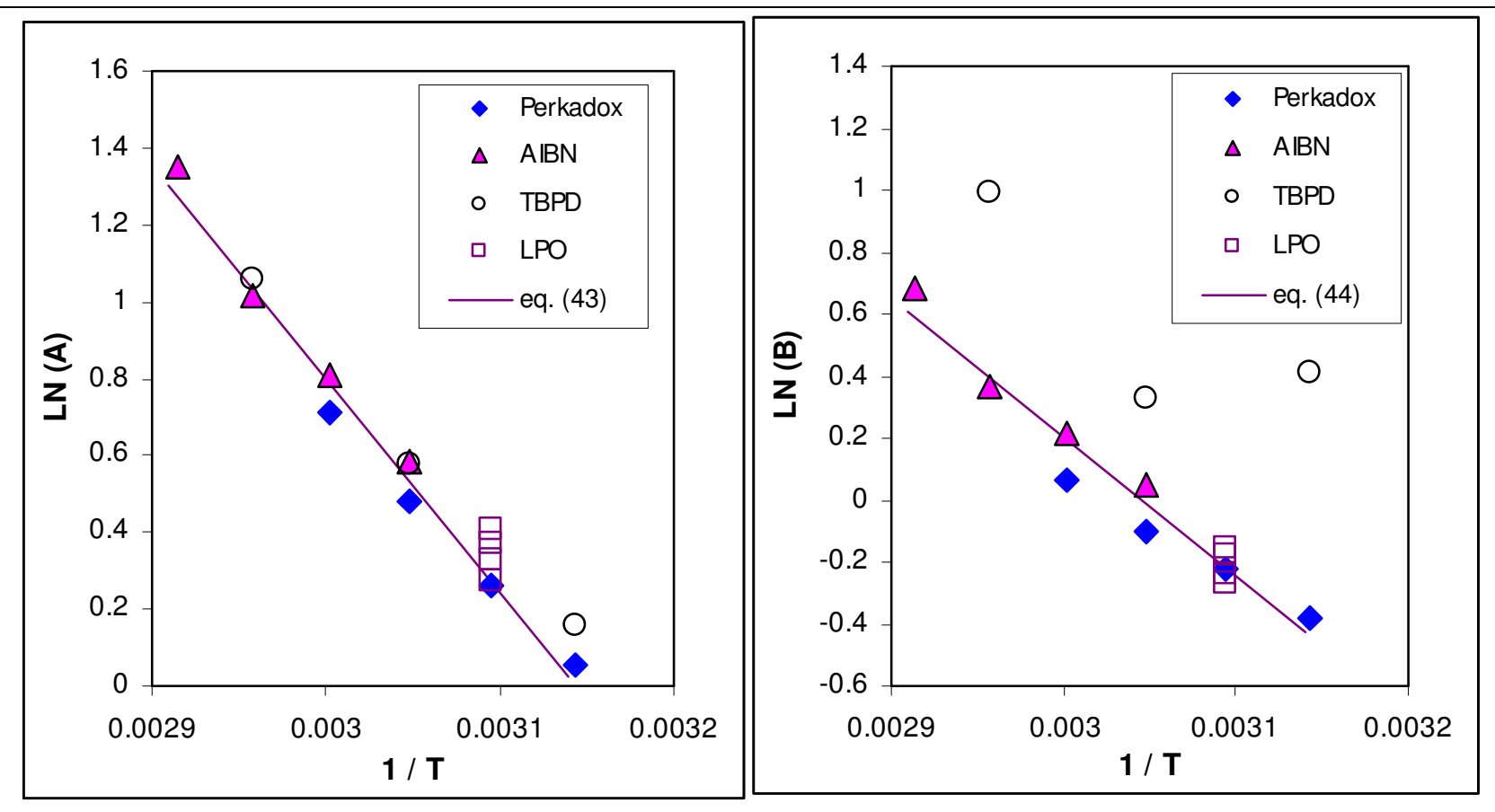

Figura 10 - Resultado do ajuste dos parâmetros A e B tendo como base os dados obtidos em todos os ajustes. 


\subsection{Simulação e Validação do Modelo}

Os resultados da simulação do modelo incorporando as equações (43) e (44) para calcular os parâmetros $\mathrm{A}$ e $\mathrm{B}$, comparados com os dados experimentais dos diferentes ensaios listados na Tabela 3, estão apresentados nas Figuras 11 a 23.

Comparando as Figuras 11 e $13 \mathrm{com}$ as Figuras 3 e 4, respectivamente, observa-se que a generalização imposta pelas equações (43) e (44) fez aumentar as diferenças do modelo em relação aos dados experimentais. Isto seria, até certo ponto, esperado, pois o ajuste individual dos parâmetros A e B para cada ensaio (Figuras 3 e 4) representaria o melhor ajuste possível do modelo. Como existem pequenas diferenças entre os valores individuais de $\mathrm{A}$ e $\mathrm{B}$ e os valores preditos pelas equações (43) e (44), como se pode observar na Figura 5, estas diferenças acabam por causar a ocorrência dos desvios maiores observados nas Figuras 11 e 13 quando comparados com as Figuras 3 e 4.

Na Figura 12 é apresentada a comparação de uma simulação do modelo para uma reação de polimerização iniciada pelo Perkadox $(0,175 \%)$ a $50^{\circ} \mathrm{C}$, mostrando que o modelo reproduz com boa concordância a variação da pressão com a conversão. 


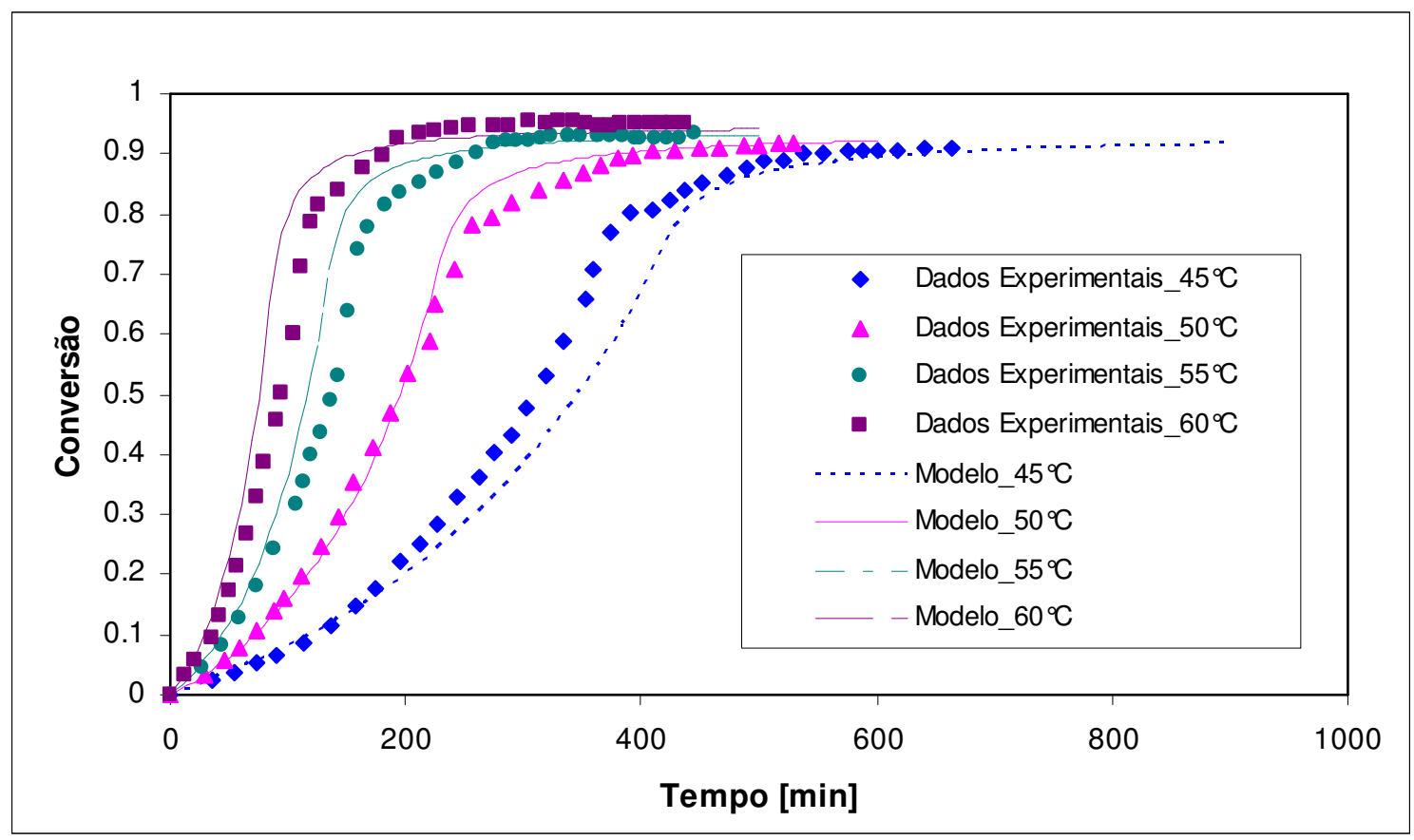

Figura 11 - Evolução da conversão do monômero ao longo da polimerização em suspensão do VCM com Perkadox como iniciador $(0,175 \%)$, a diferentes temperaturas.

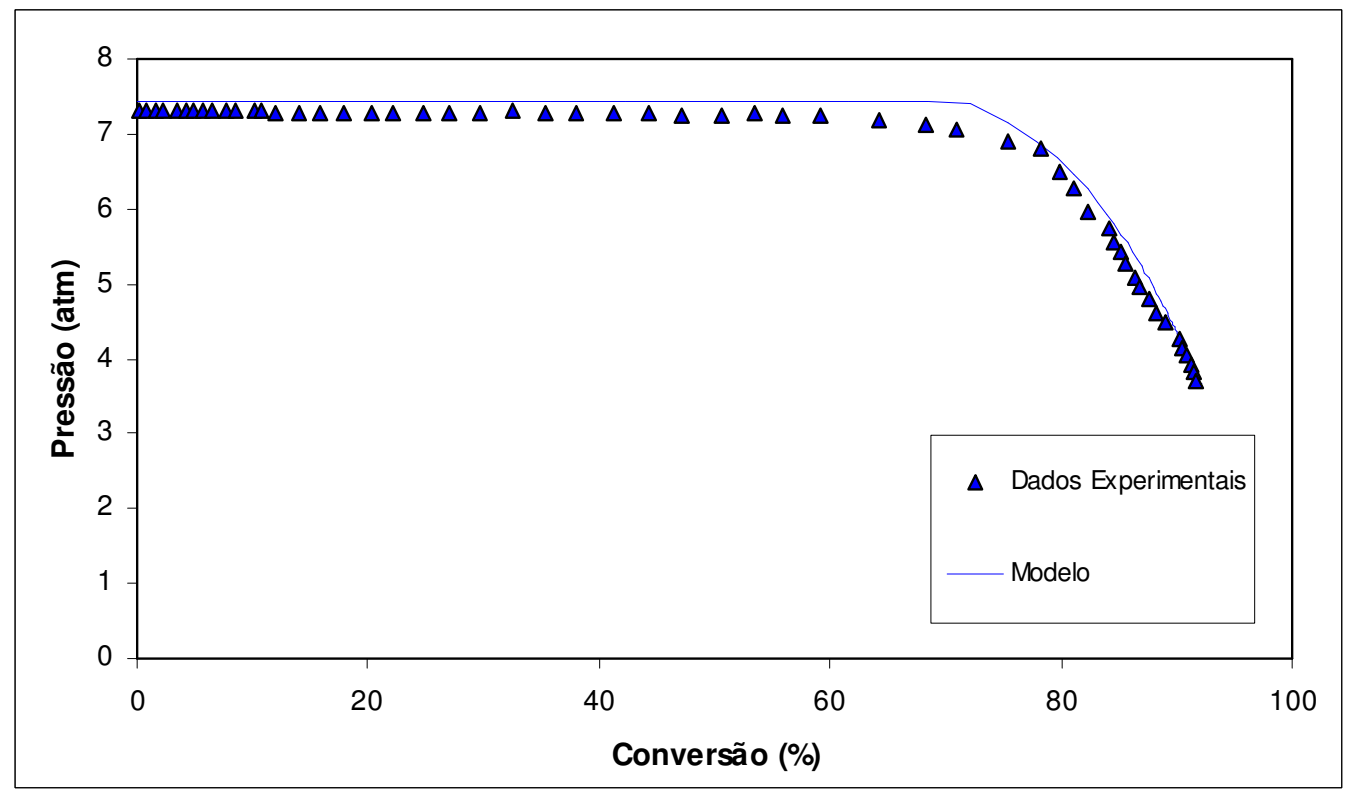

Figura 12 - Evolução da pressão ao longo da polimerização em suspensão do VCM com Perkadox como iniciador $(0,175 \%)$, a $50^{\circ} \mathrm{C}$. 


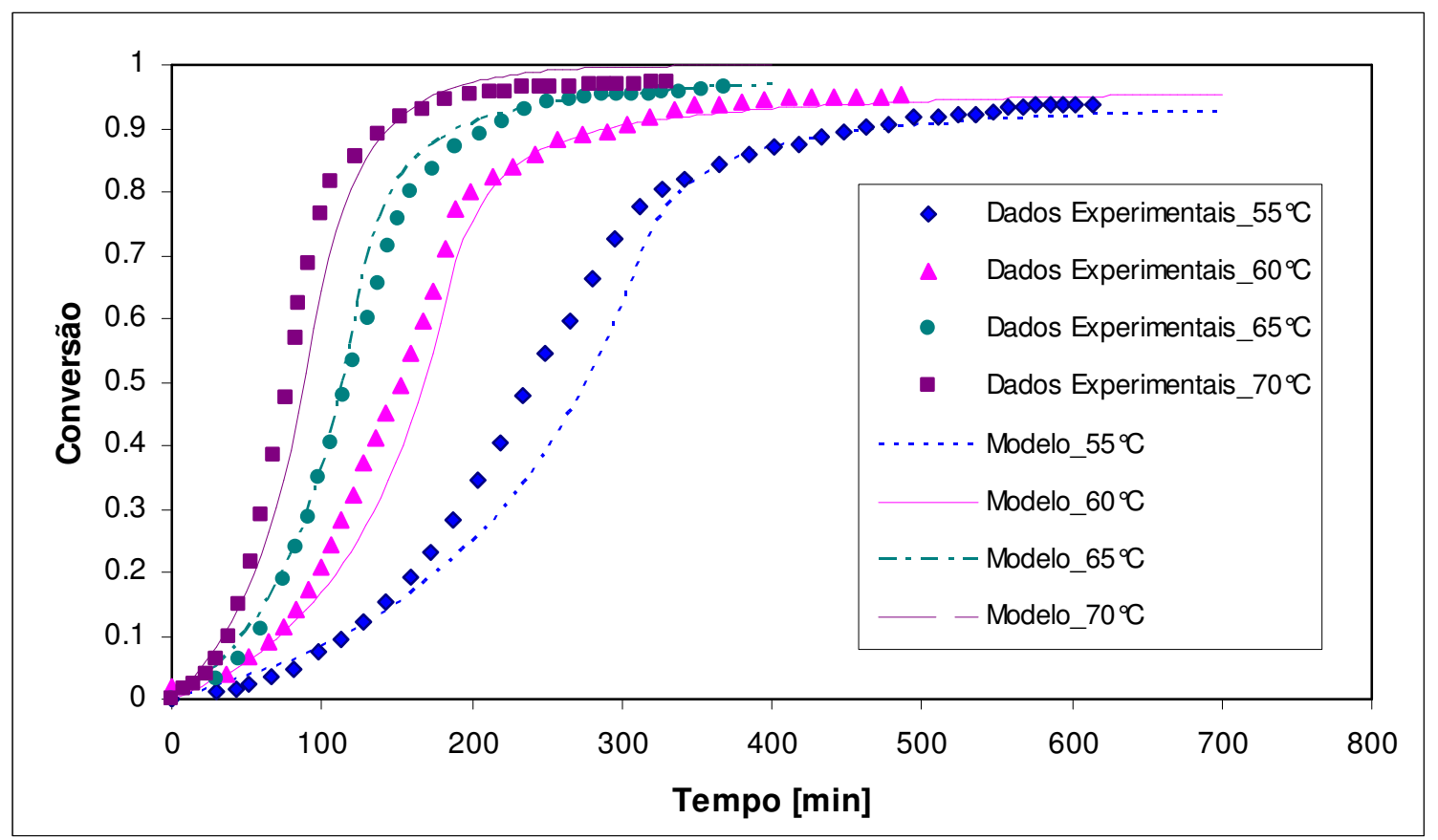

Figura 13 - Evolução da conversão do monômero ao longo da polimerização em suspensão do VCM com AIBN como iniciador $(0,25 \%)$, a diferentes temperaturas.

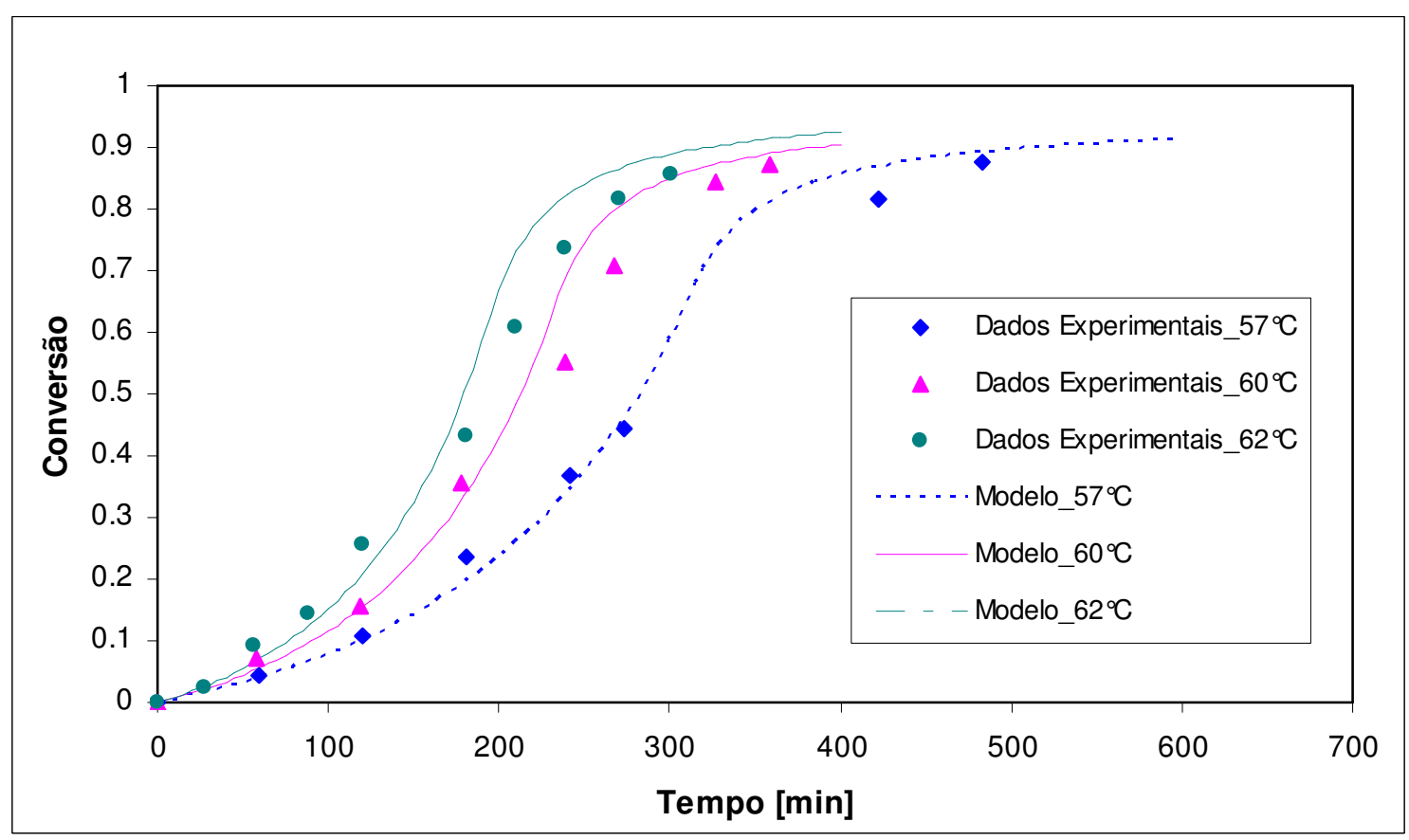

Figura 14 - Evolução da conversão do monômero ao longo da polimerização em suspensão do VCM com AIBN como iniciador $(0,16 \%)$, a diferentes temperaturas. 


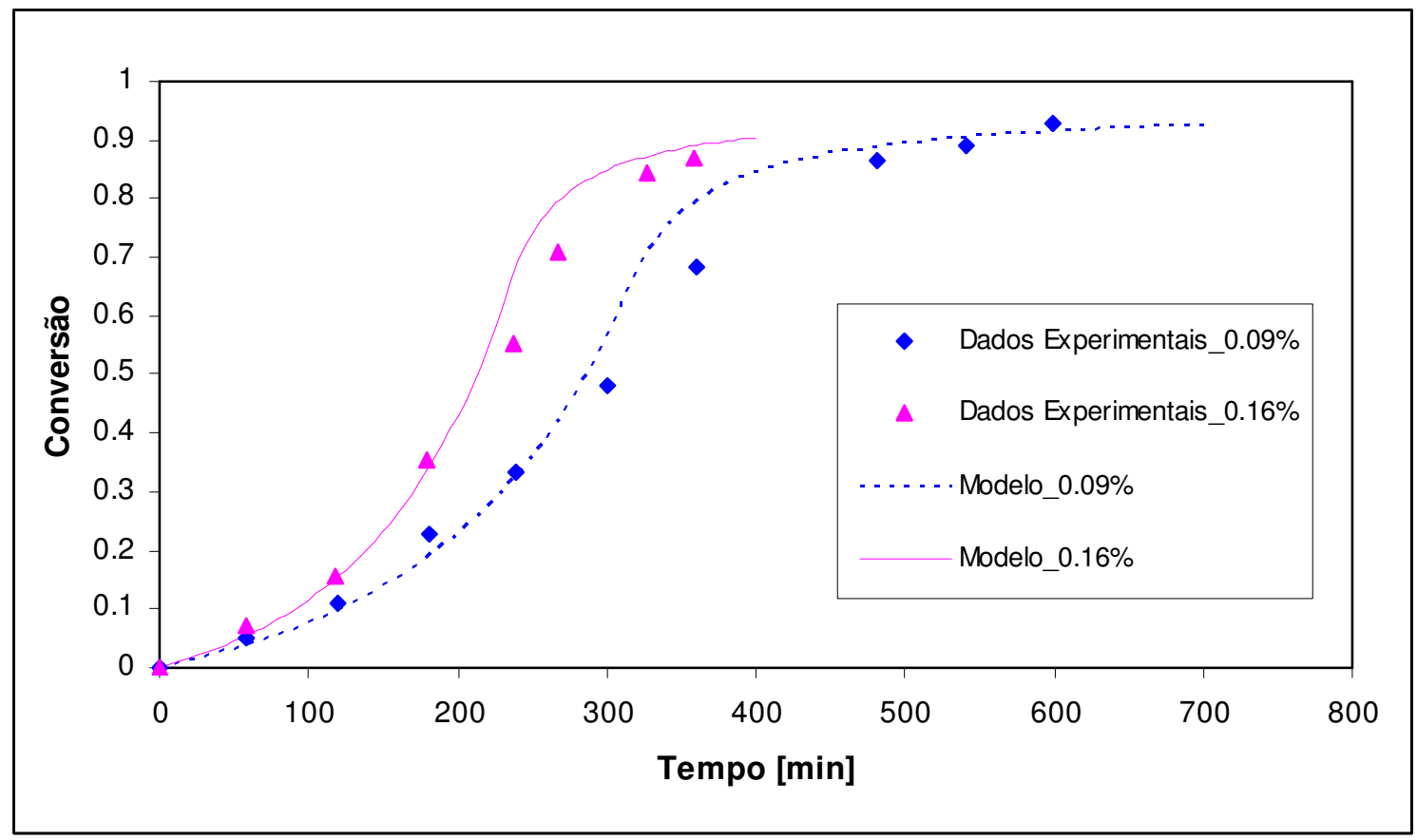

Figura 15 - Evolução da conversão do monômero ao longo da polimerização em suspensão do cloreto de vinila com AIBN como iniciador a $60^{\circ} \mathrm{C}$, a diferentes concentrações.

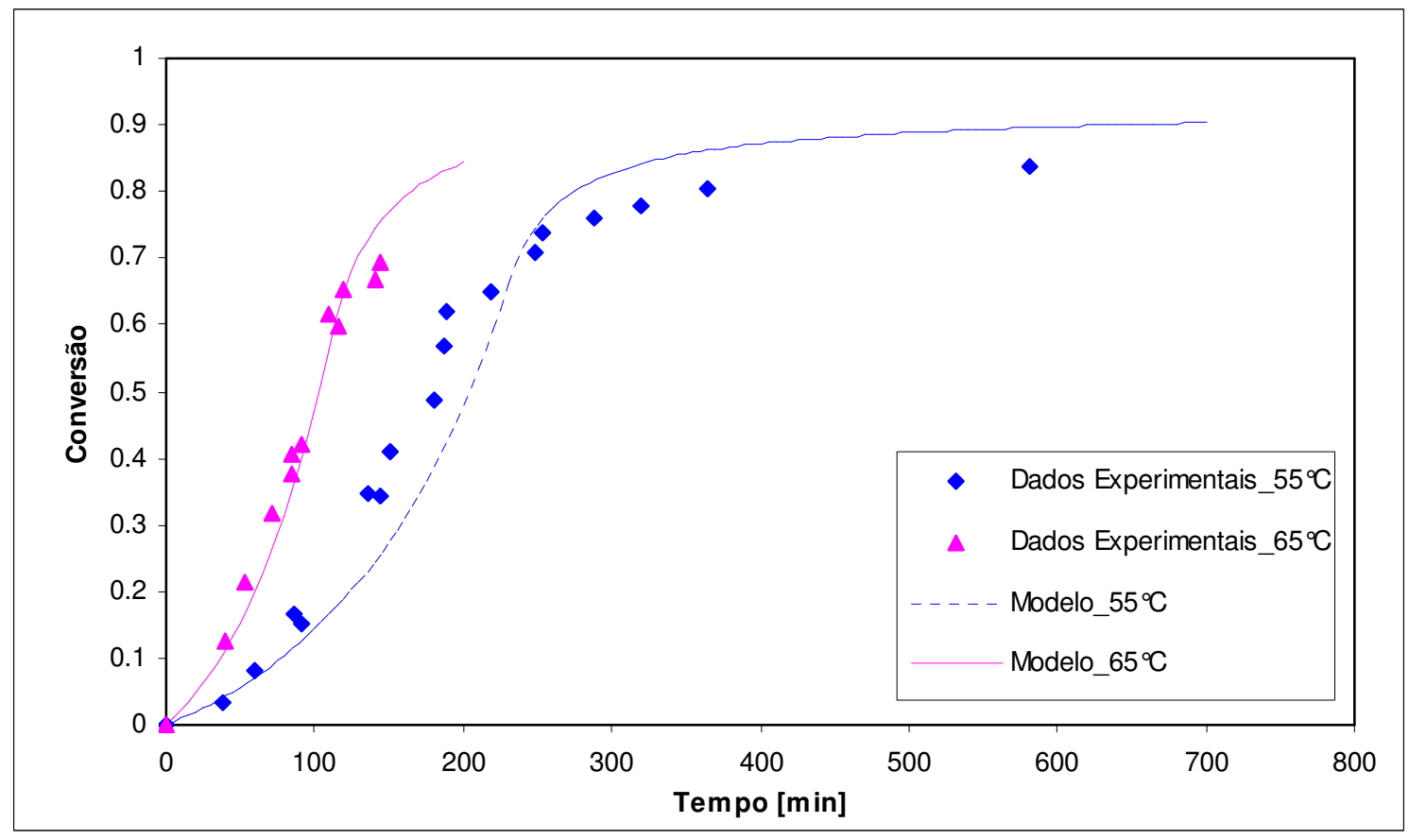

Figura 16 - Evolução da conversão do monômero ao longo da polimerização em suspensão do VCM com TBPD como iniciador $(0,0785 \%)$, a diferentes temperaturas. 


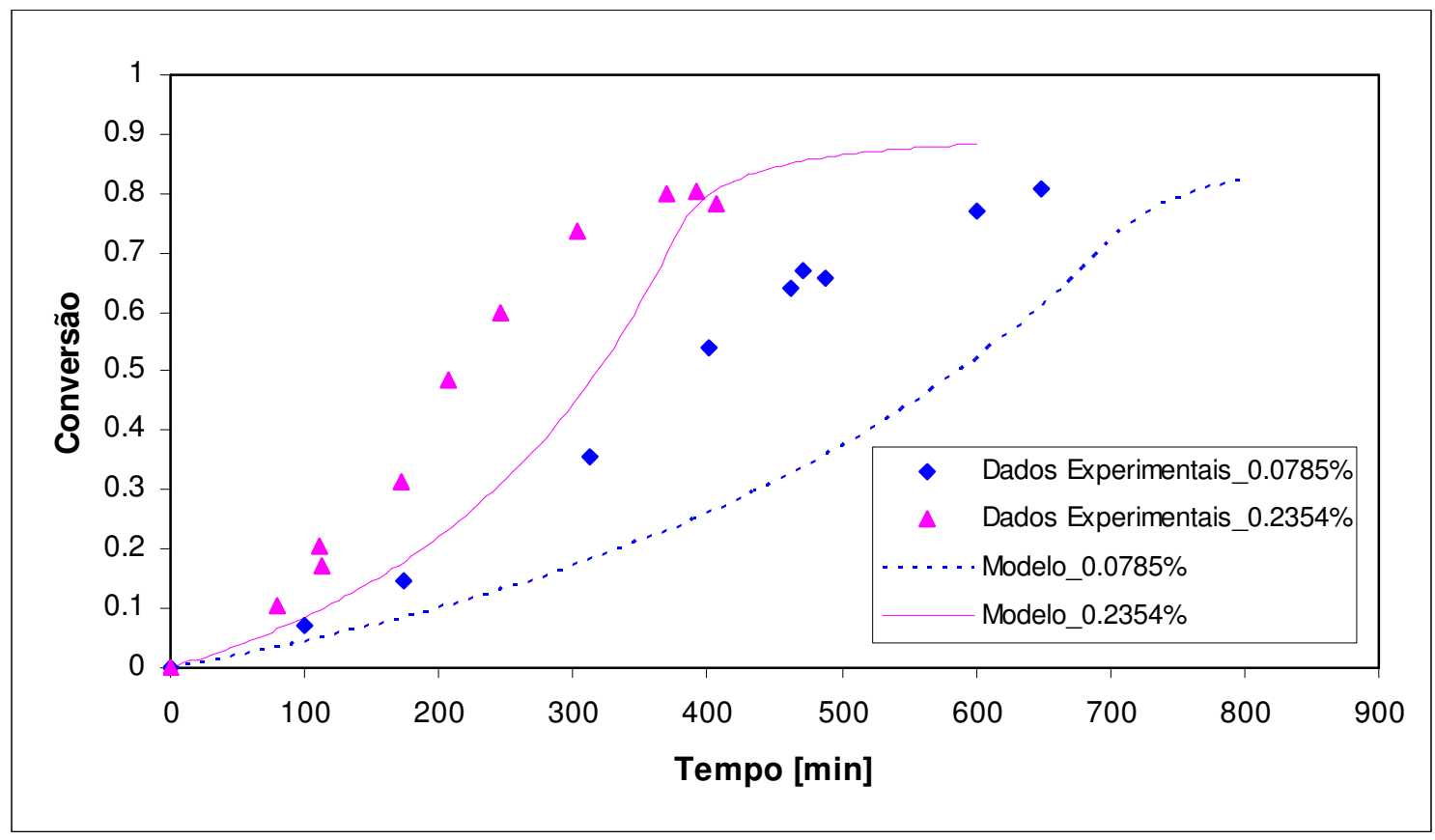

Figura 17 - Evolução da conversão do monômero ao longo da polimerização em suspensão do VCM com TBPD como iniciador a $45^{\circ} \mathrm{C}$, a diferentes concentrações.

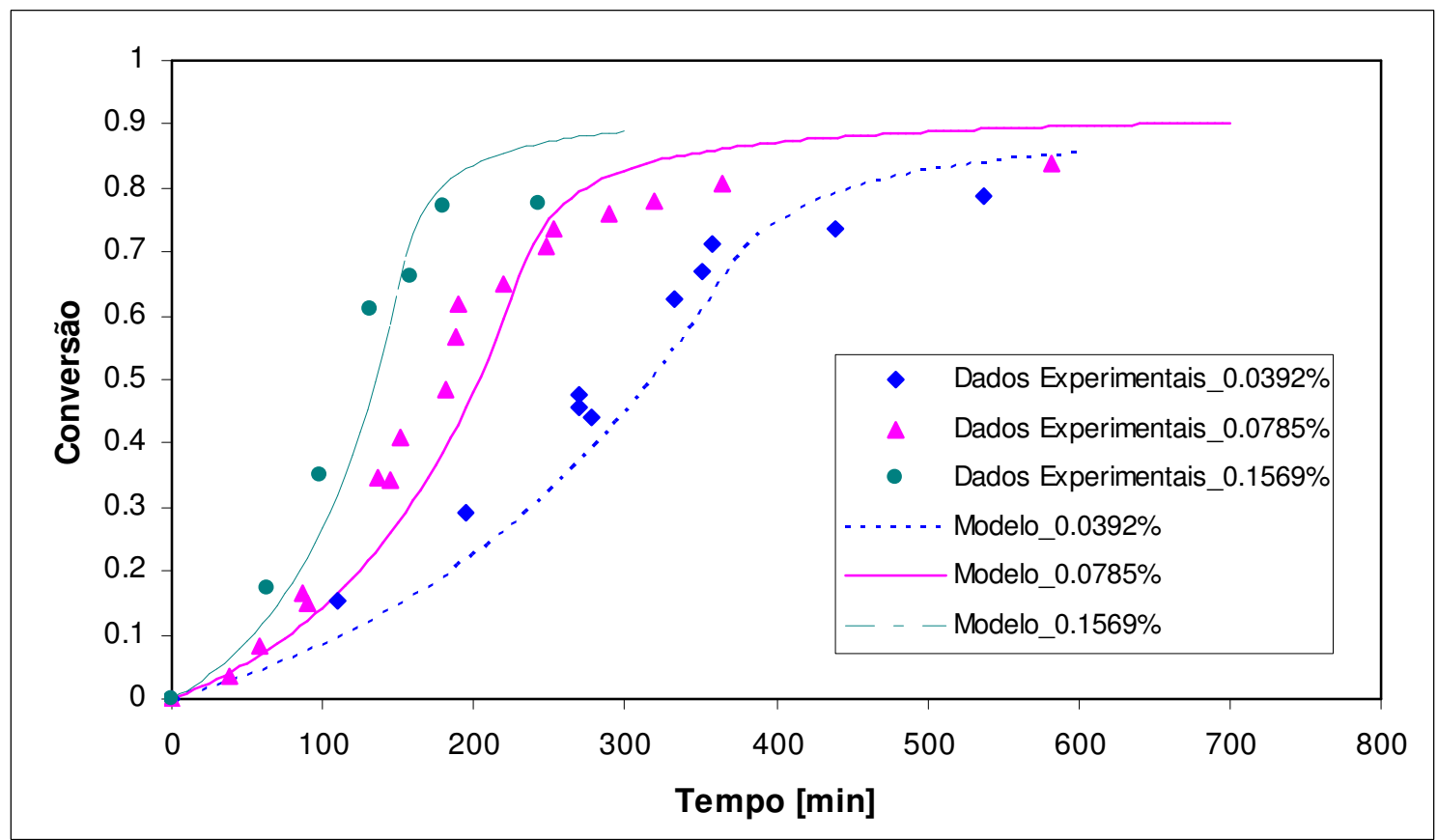

Figura 18 - Evolução da conversão do monômero ao longo da polimerização em suspensão do VCM com TBPD como iniciador a $55^{\circ} \mathrm{C}$, a diferentes concentrações. 


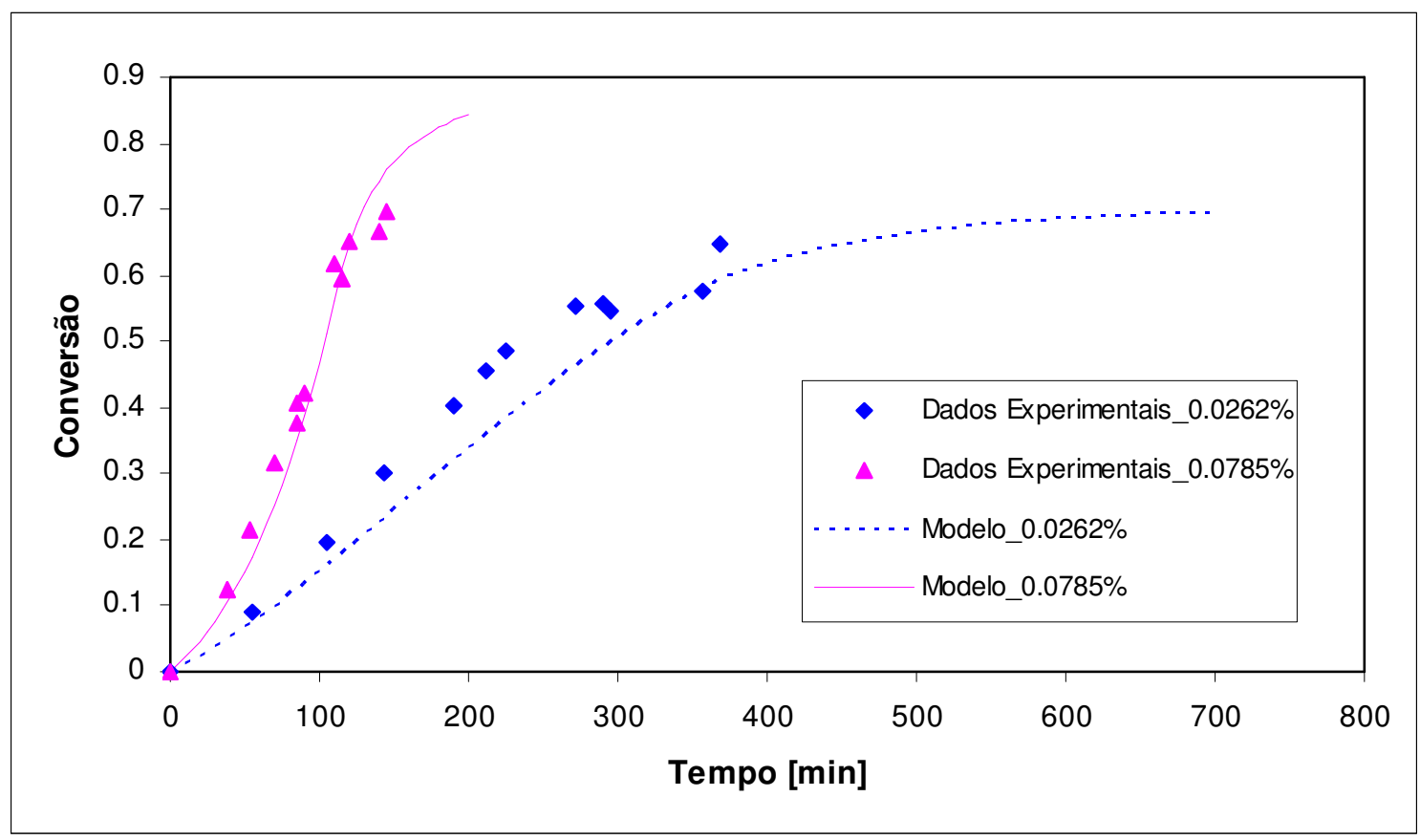

Figura 19 - Evolução da conversão do monômero ao longo da polimerização em suspensão do VCM com TBPD como iniciador a $65^{\circ} \mathrm{C}$, a diferentes concentrações.

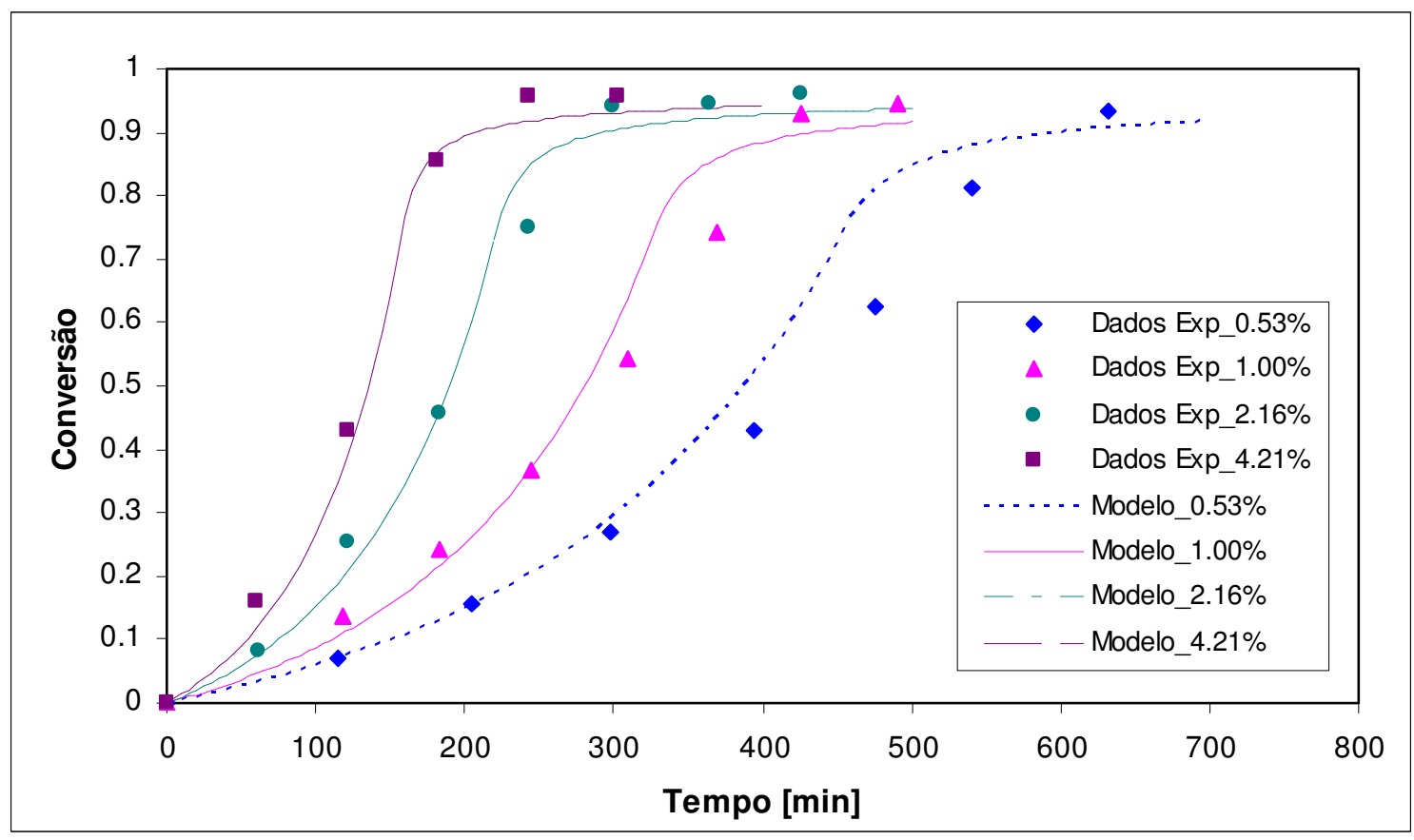

Figura 20 - Evolução da conversão do monômero ao longo da polimerização em suspensão do VCM com LPO como iniciador a $50^{\circ} \mathrm{C}$, a diferentes concentrações. 


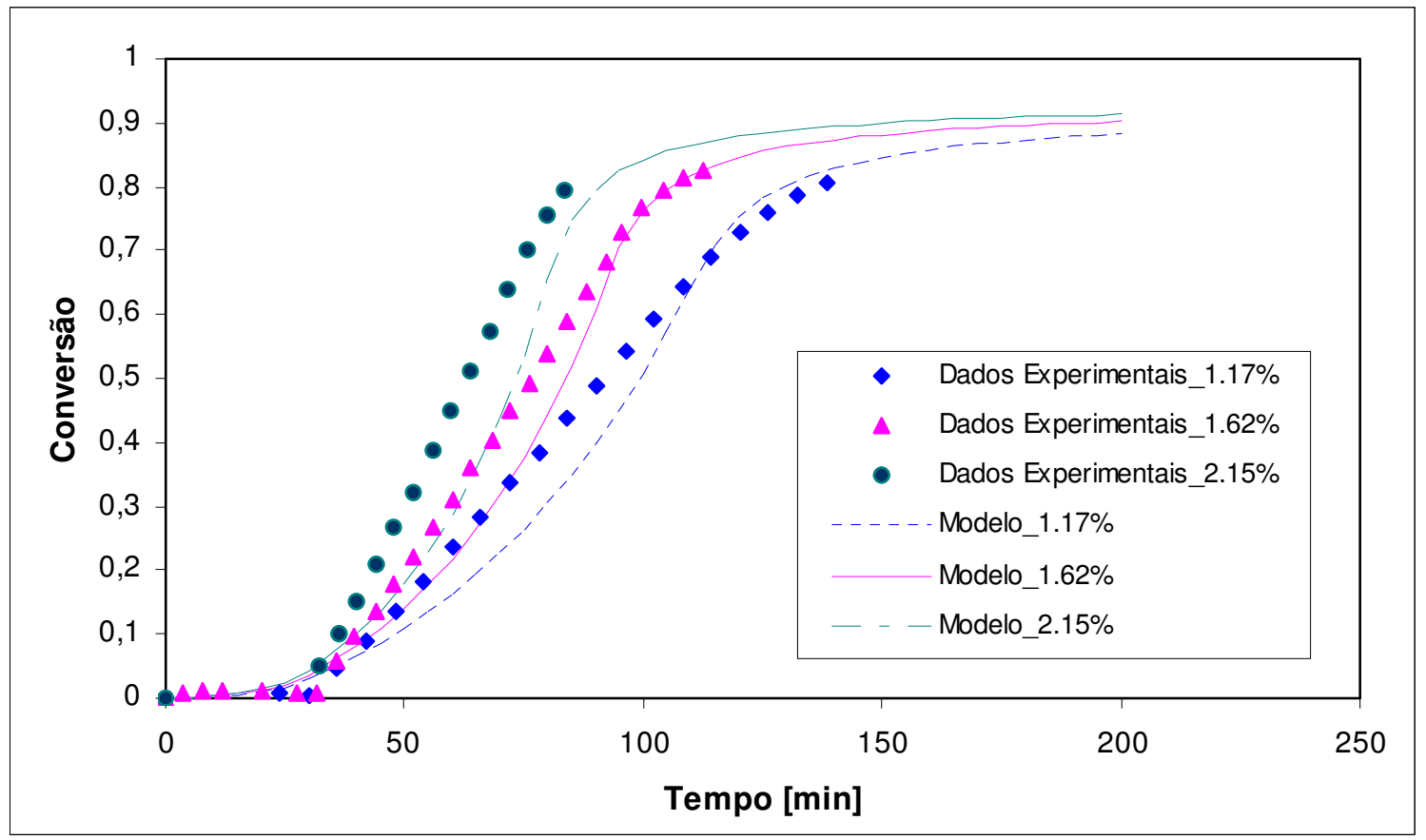

Figura 21 - Evolução da conversão do monômero ao longo da polimerização em suspensão do VCM com LUP como iniciador a $56,5^{\circ} \mathrm{C}$, a diferentes concentrações.

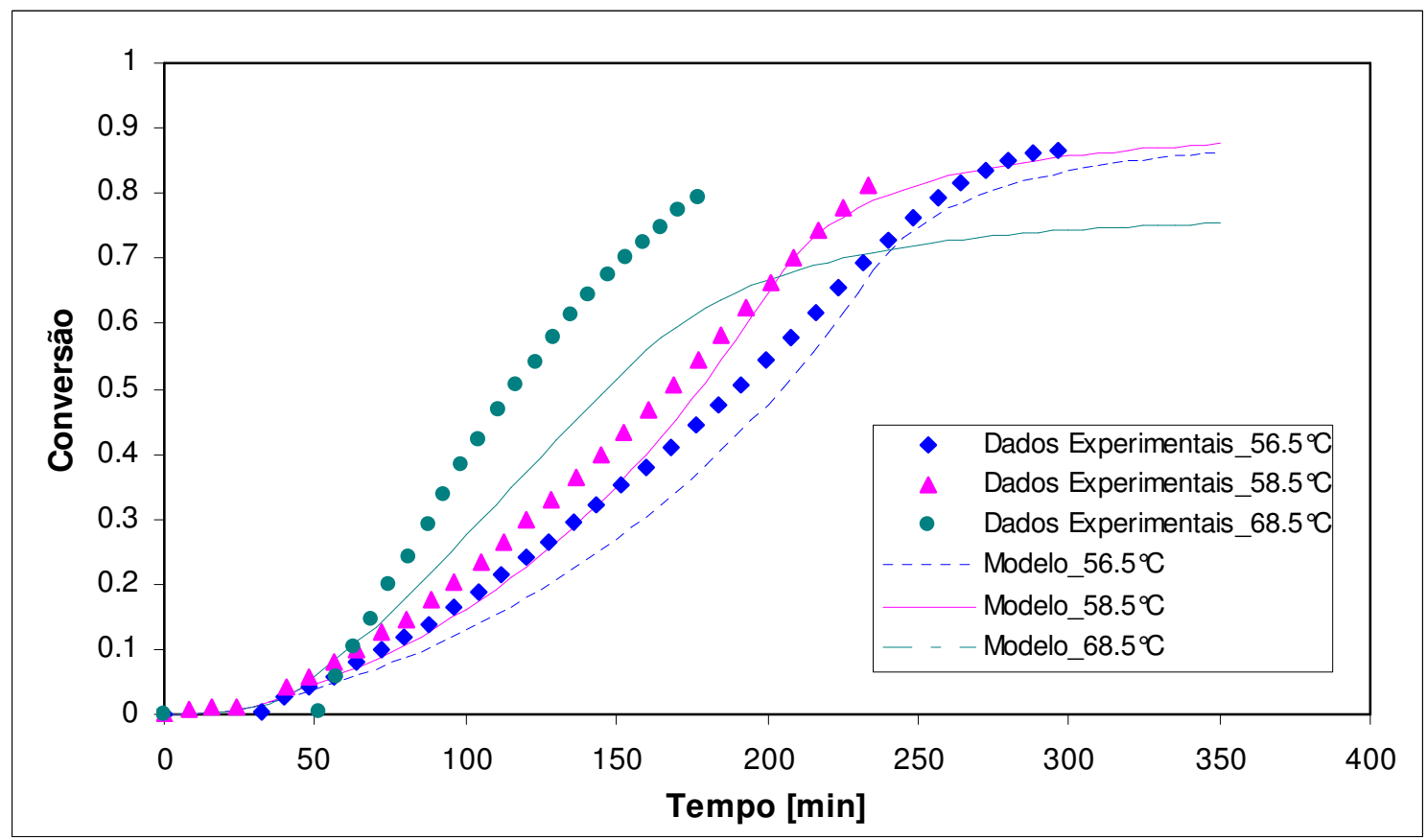

Figura 22 - Evolução da conversão do monômero ao longo da polimerização em suspensão do VCM com PDEH como iniciador (0,606 $\mathrm{g} / \mathrm{kg}$ de VCM), a diferentes temperaturas. 


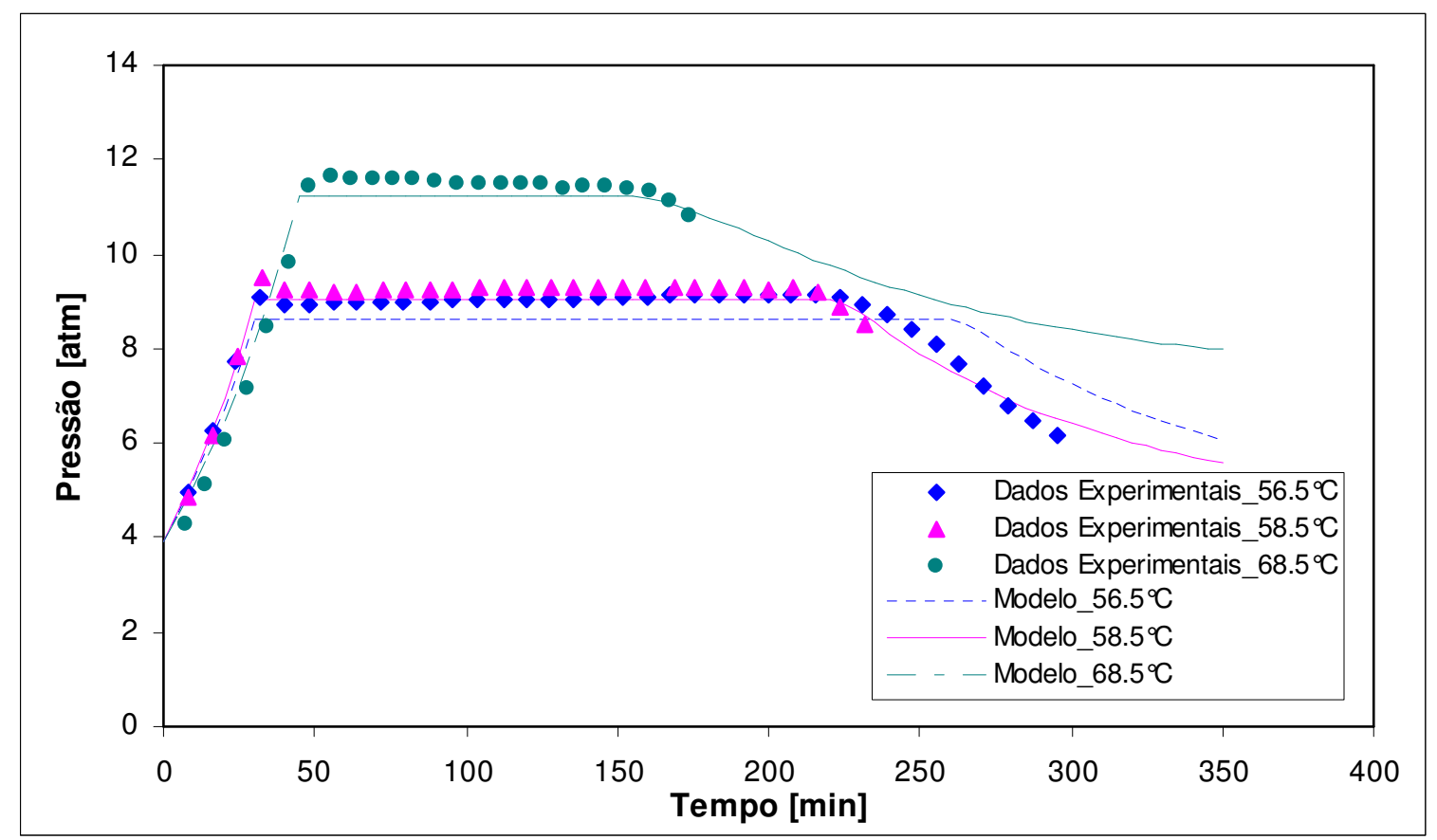

Figura 23 - Evolução da pressão ao longo da polimerização em suspensão do VCM com PDEH como iniciador $(0,606 \mathrm{~g} / \mathrm{kg}$ de VCM), a diferentes temperaturas.

Nas Figuras 21 a 23 são apresentadas comparações das previsões do modelo com conjuntos de dados com iniciadores diferentes, LUP e PDEH, cujos dados não foram usados previamente no ajuste de parâmetros.

No geral, nas Figuras 14 a 23, observa-se que o modelo consegue reproduzir corretamente o comportamento qualitativo dos dados experimentais. Quanto ao comportamento quantitativo, na maioria dos casos o modelo reproduz razoavelmente bem os dados, levando-se em conta que nenhum destes conjuntos de dados (das Figuras 14 a 23) foram usados no ajuste do modelo (ou seja, esta comparação constitui uma validação genuína). Em alguns casos, os desvios foram significativamente maiores (p.ex., as curvas na Figura 17, todas referentes a $45^{\circ} \mathrm{C}$ com iniciador TBPD, e as curvas na Figura 22 com iniciador PDEH, referente à temperatura de $68,5^{\circ} \mathrm{C}$ ).

A variação da pressão total no reator também é satisfatoriamente representada pelo modelo, como se observa na Figura 23. 


\subsection{Discussão dos Resultados}

Previamente ao desenvolvimento do presente modelo, foi testado o modelo de Xie et al. (1991a), com os dados experimentais de diferentes fontes. Entretanto, a qualidade de representação não foi adequada, nem sempre conseguindo reproduzir os próprios dados experimentais reportados no artigo citado. Além disso, quando utilizados outros tipos de iniciadores, os resultados usando o modelo de Xie et al. (1991a) também não foram melhores que os aqui reportados.

Esta foi a motivação para o desenvolvimento do modelo aqui apresentado. A estrutura do modelo de Xie et al. (1991a) foi adotada no presente trabalho (embora simplificada, sem considerar a transferência de radicais entre as fases 1 e 2), e promoveu-se o ajuste dos parâmetros ligados às limitações difusionais das constantes cinéticas ( $\mathrm{A}$ e $\mathrm{B})$, com o intuito de se obter melhores respostas na comparação do modelo com os dados experimentais.

Os resultados dos ajustes individuais feitos com o Perkadox e o AIBN vistos nas Figuras 3 e 4 foram muito bons e ofereceram, através de regressões, novos valores para estes parâmetros.

Ajustes dos parâmetros $A$ e $B$ também foram feitos para os ensaios com outros iniciadores. Estes foram realizados simultaneamente para cada conjunto de dados, mantendo-se fixa a temperatura e variando-se as concentrações iniciais dos iniciadores, e também obtiveram bons resultados. No entanto, fixados os novos parâmetros, as respostas das simulações, embora reproduzam bem as características qualitativas da polimerização, não se apresentaram com a mesma qualidade que nos ajustes individuais, verificando-se ainda alguns desvios em relação aos dados experimentais.

Outras tentativas foram feitas buscando ajustar modelos alternativos de limitações difusionais aos dados experimentais aqui mostrados. Estes modelos estão sucintamente descritos no Apêndice A. No entanto, os resultados obtidos não foram melhores do que os apresentados pelo modelo descrito no Capítulo 3.

A polimerização heterogênea do VCM é um processo muito complexo química e fisicamente. Dados experimentais reportados na literatura contêm tanto resultados consistentes como, em alguns casos, resultados conflitantes. 
Além disso, como os ensaios experimentais são de diferentes fontes e diferentes autores, é difícil inferir se problemas específicos ocorridos nos experimentos podem ter influenciado na qualidade dos dados. Por exemplo, a maioria dos trabalhos experimentais não menciona especificamente se o monômero foi purificado, ou se foi usado monômero comercial nos ensaios. É bem conhecido que monômero comercial contém uma certa quantidade de inibidor, que pode causar um atraso ("tempo morto") no início da polimerização, defasando a curva de conversão versus tempo. Para efeito de modelagem, além do atraso no início da polimerização, o inibidor terá consumido uma parte do iniciador alimentado, de modo que a concentração efetiva do iniciador quando a polimerização efetivamente começa será menor que a concentração inicial nominal.

Outro aspecto experimental que pode influenciar os resultados é a ocorrência de rampas de aquecimento iniciais, ou seja, a temperatura real da polimerização não é exatamente igual à temperatura nominal do ensaio nos instantes iniciais. Sempre que isto foi identificado nos dados, ou explicitamente informado nos trabalhos experimentais, estas variações de temperatura com o tempo foram explicitamente consideradas no modelo. Por exemplo, nas Figuras 22 e 23 ocorreu uma rampa de temperatura partindo da temperatura de $25^{\circ} \mathrm{C} \mathrm{em} \mathrm{t}=0$ até atingir a temperatura nominal do ensaio em tempos maiores ( 35 e $50 \mathrm{~min}$ ). Nos casos em que as medidas de pressão no reator são disponíveis (como no caso da Figura 23), é relativamente fácil perceber que ocorreu esta variação inicial de temperatura. Analogamente, na Figura 21 esta variação na temperatura ocorreu em um intervalo de tempo de aproximadamente 30 minutos.

Outro aspecto a ser considerado é que alguns dos dados experimentais foram obtidos em reatores de laboratório, supostamente em condições melhor controladas, enquanto que outros dados foram obtidos em reatores industriais ou de escala piloto, que em geral possuem instrumentação menos detalhada, maior dificuldade de amostragem, controle de temperatura menos eficiente, etc.

Adicionalmente, podem existir imprecisões nos valores dos parâmetros cinéticos adotados no modelo, que foram tomados da literatura. Variações no valor destes parâmetros também poderiam afetar positiva ou negativamente as previsões do 
modelo, em relação aos dados experimentais. Por exemplo, diferentes valores para a constante cinética de decomposição do iniciador $\left(k_{d}\right)$ foram encontrados na literatura para os iniciadores LPO e PDEH, conforme reportado na Tabela 7. Estas diferenças podem ser atribuídas ao fato de que a constante de decomposição do iniciador pode variar com a natureza do meio reacional (p.ex. o solvente, a presença de solutos, etc.). Para avaliar o impacto destas incertezas sobre as previsões do modelo, foram realizadas simulações usando os diferentes valores reportados para $k_{d}$ e os resultados estão apresentados nas Figuras 26 e 27, junto com os respectivos dados experimentais. Como se pode ver, o valor escolhido de $k_{d}$ a ser usado no modelo pode afetar em algum grau as previsões quantitativas do modelo, embora suas variações com a temperatura, ilustradas nas Figuras 24 e 25, não tenham se apresentado de maneira muito diferente uma em relação às outras.

Tabela 7 - Constantes cinéticas de decomposição dos iniciadores.

\begin{tabular}{|c|c|c|}
\hline \multicolumn{1}{|c|}{ Iniciador } & $k_{d}\left(\mathbf{s}^{-1}\right)$ & Referência \\
\hline \multirow{3}{*}{ LPO } & $k_{d}=3,056 \times 10^{15} \exp \left(-\frac{31123}{1,987 T}\right)$ & Arkema \\
\cline { 2 - 4 } & $k_{d}=1,20 \times 10^{14} \exp \left(-\frac{120478,12}{8,314 T}\right)$ & Chemicalland 21 \\
\cline { 2 - 4 } & $k_{d}=3,92 \times 10^{14} \exp \left(-\frac{123370}{8,314 T}\right)$ & Moad e Solomon (1995) \\
\hline \multirow{3}{*}{ PDEH } & $k_{d}=1,83 \times 10^{15} \exp \left(-\frac{122450}{8,314 T}\right)$ & AKZO NOBEL \\
\cline { 2 - 4 } & $k_{d}=8,80 \times 10^{15} \exp \left(-\frac{30462}{1,987 T}\right)$ & Arkema \\
\hline & $k_{d}=1,32 \times 10^{14} \exp \left(-\frac{114176}{8,314 T}\right)$ & Allsopp e Vianello (2002) \\
\hline
\end{tabular}




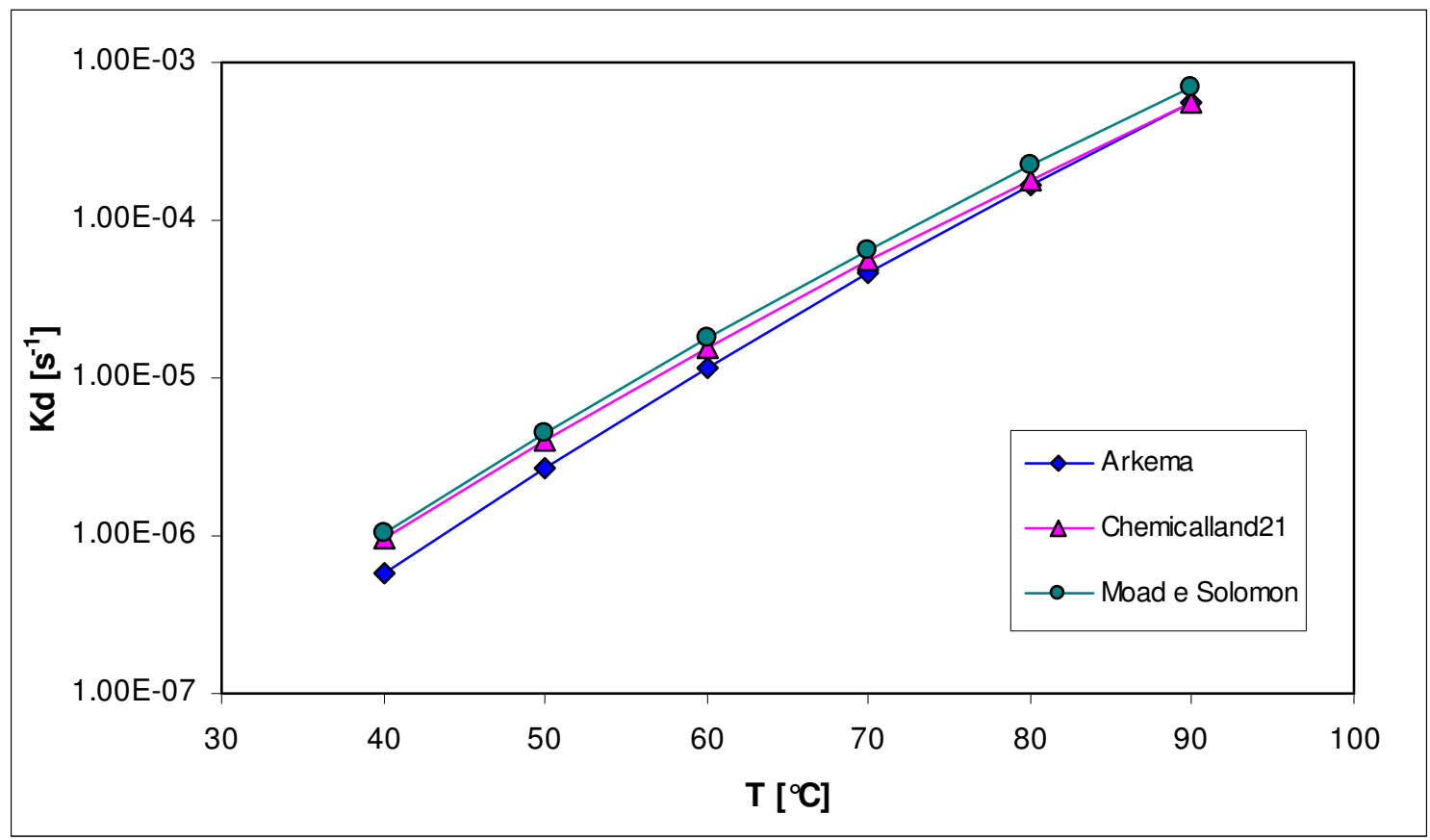

Figura 24 - Comparação entre as constantes cinéticas de decomposição do LPO.

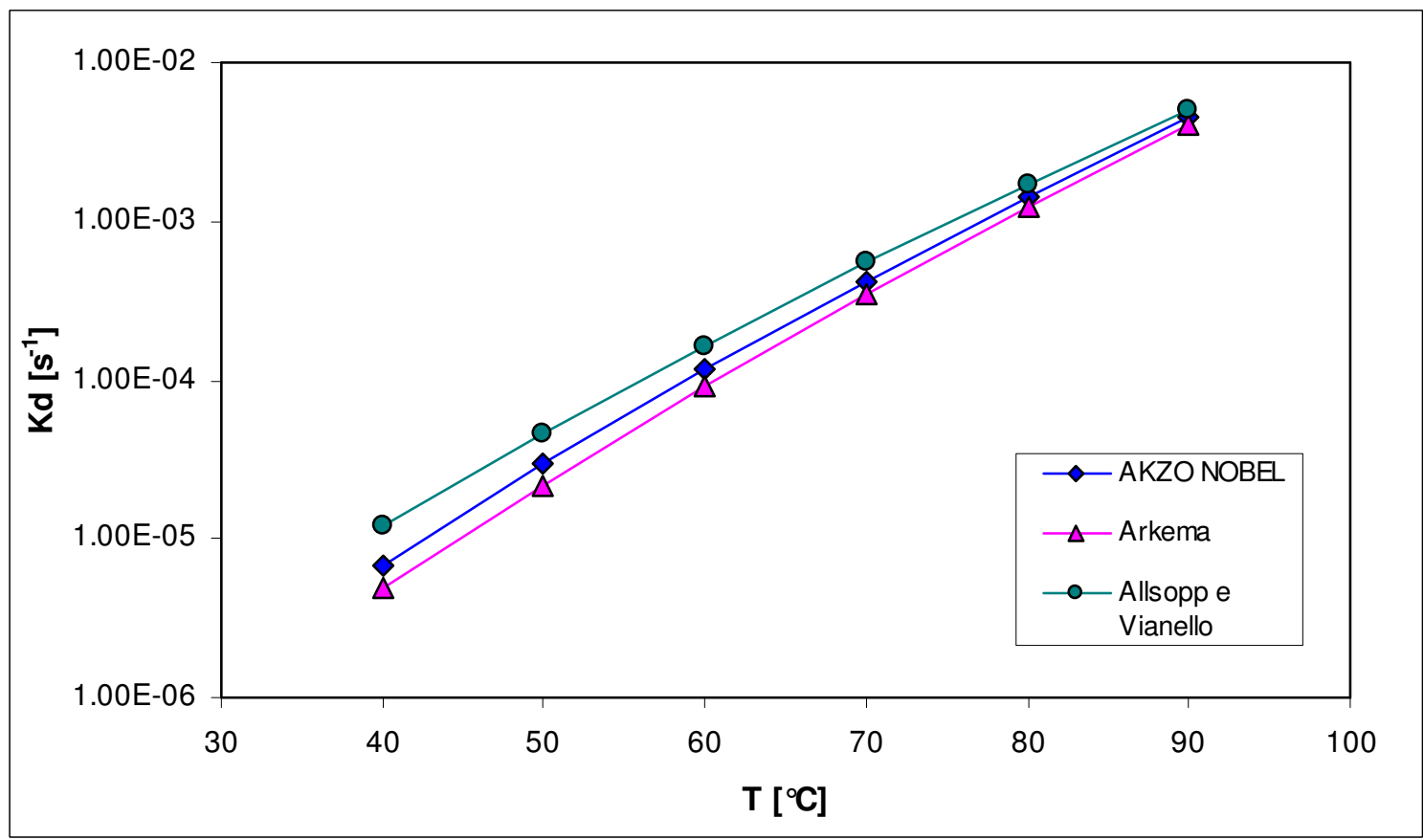

Figura 25 - Comparação entre as constantes cinéticas de decomposição do PDEH. 


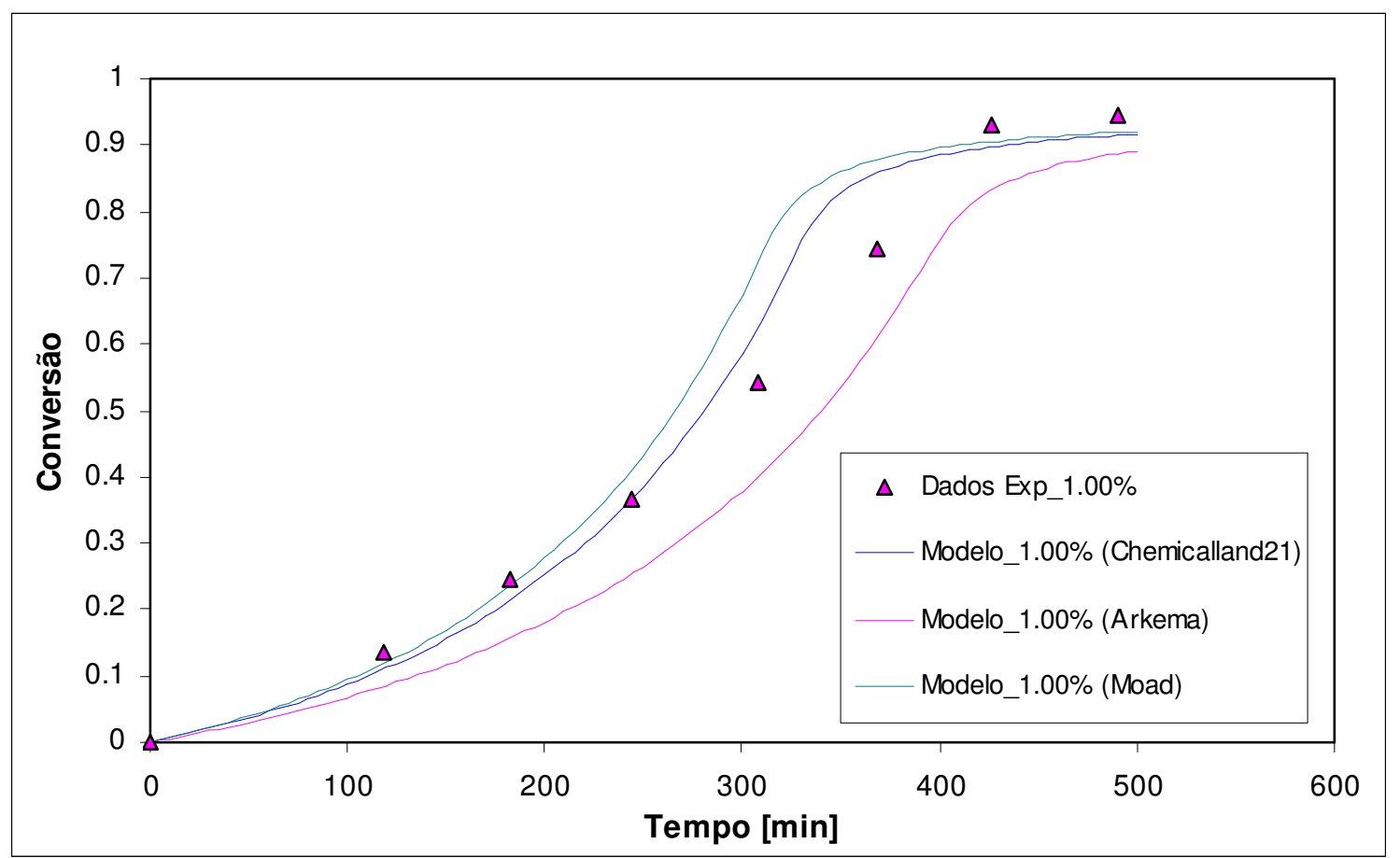

Figura 26 - Simulação do modelo utilizando diferentes valores de constante de decomposição do LPO.

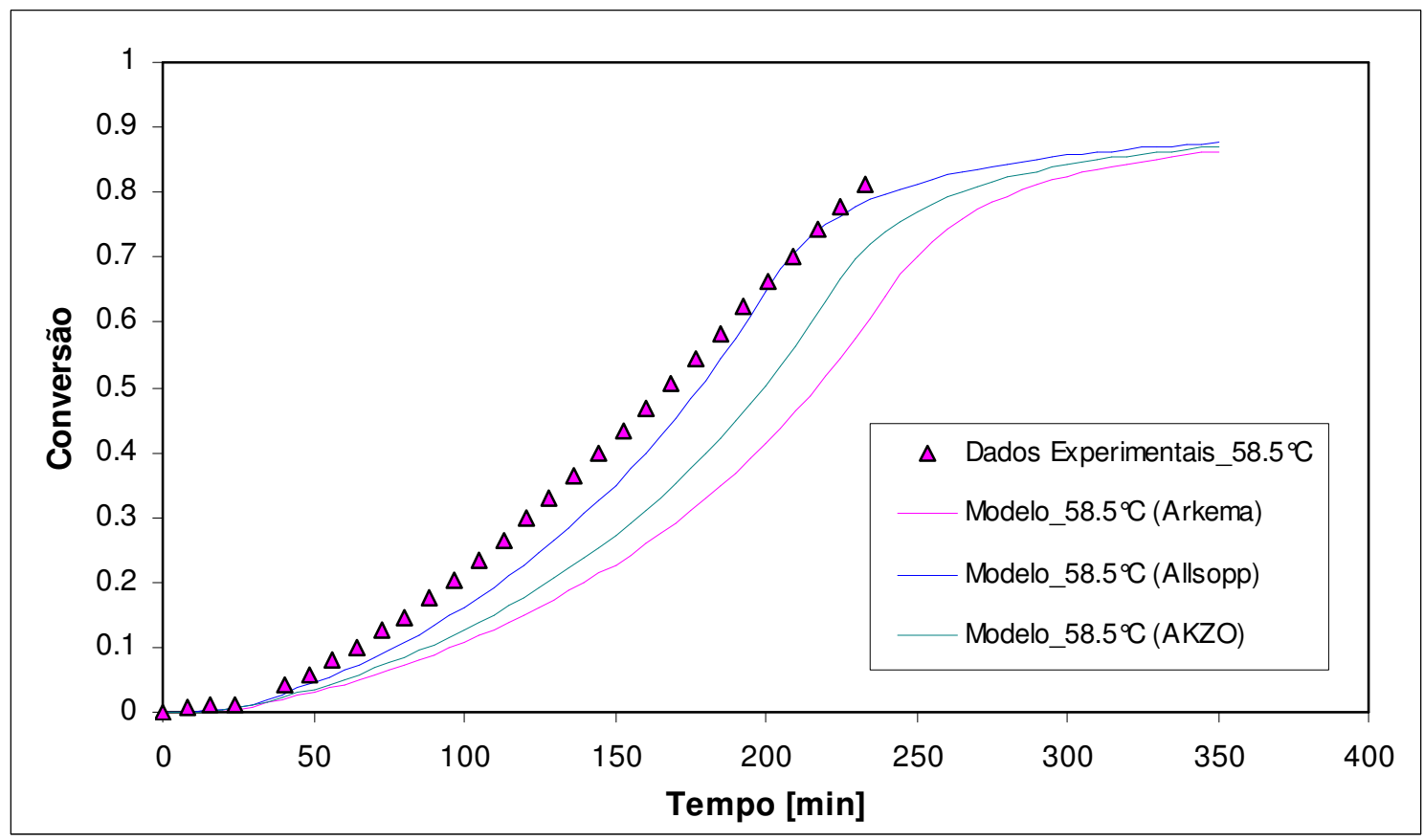

Figura 27 - Simulação do modelo utilizando diferentes valores de constante de decomposição do PDEH. 
Os valores de $k_{d}$ adotados neste trabalho foram os obtidos em Chemicalland21, e Allsopp e Vianello (2002), para o LPO e o PDEH, respectivamente. Os resultados das simulações para estas escolhas (Figuras 20, 22 e 23) apresentaram melhores concordâncias com os dados experimentais.

Do mesmo modo outros parâmetros cinéticos podem afetar o desempenho do modelo. Por exemplo, as constantes cinéticas de propagação e de terminação $k_{p o} \mathrm{e}$ $k_{t o}$ reportadas na literatura também apresentam variações de uma fonte para outra. As Figuras 28 e 29 ilustram estas diferenças, as quais, certamente teriam impacto sobre as previsões do modelo. A Figura 30 ilustra a variação com a temperatura do grupo $k_{p o} /\left(k_{t o}\right)^{1 / 2}$, o qual, de acordo com as equações (1) a (5), influenciaria diretamente na cinética da evolução da conversão.

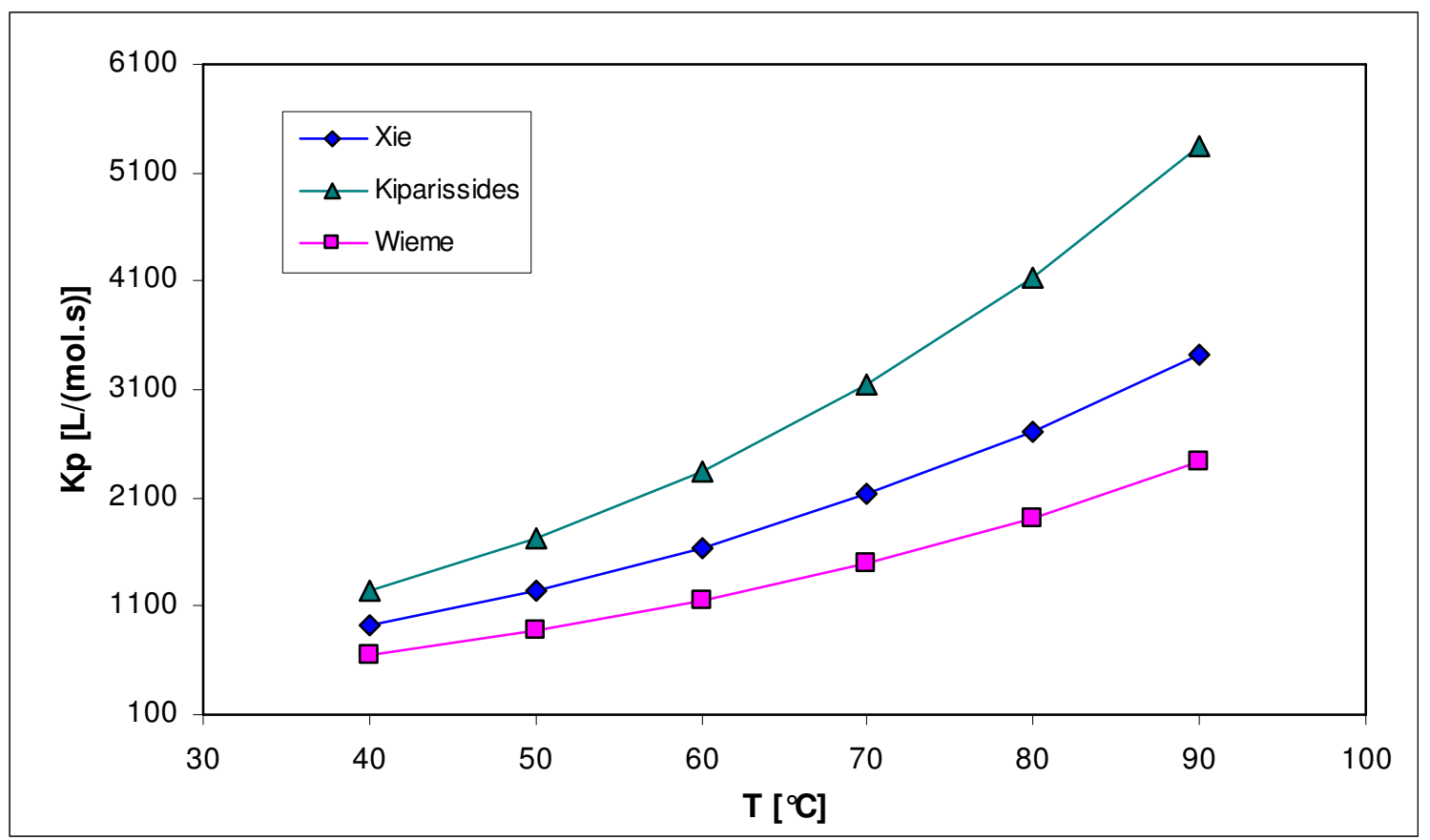

Figura 28 - Comparação entre as constantes cinéticas de propagação reportadas por diferentes autores. 


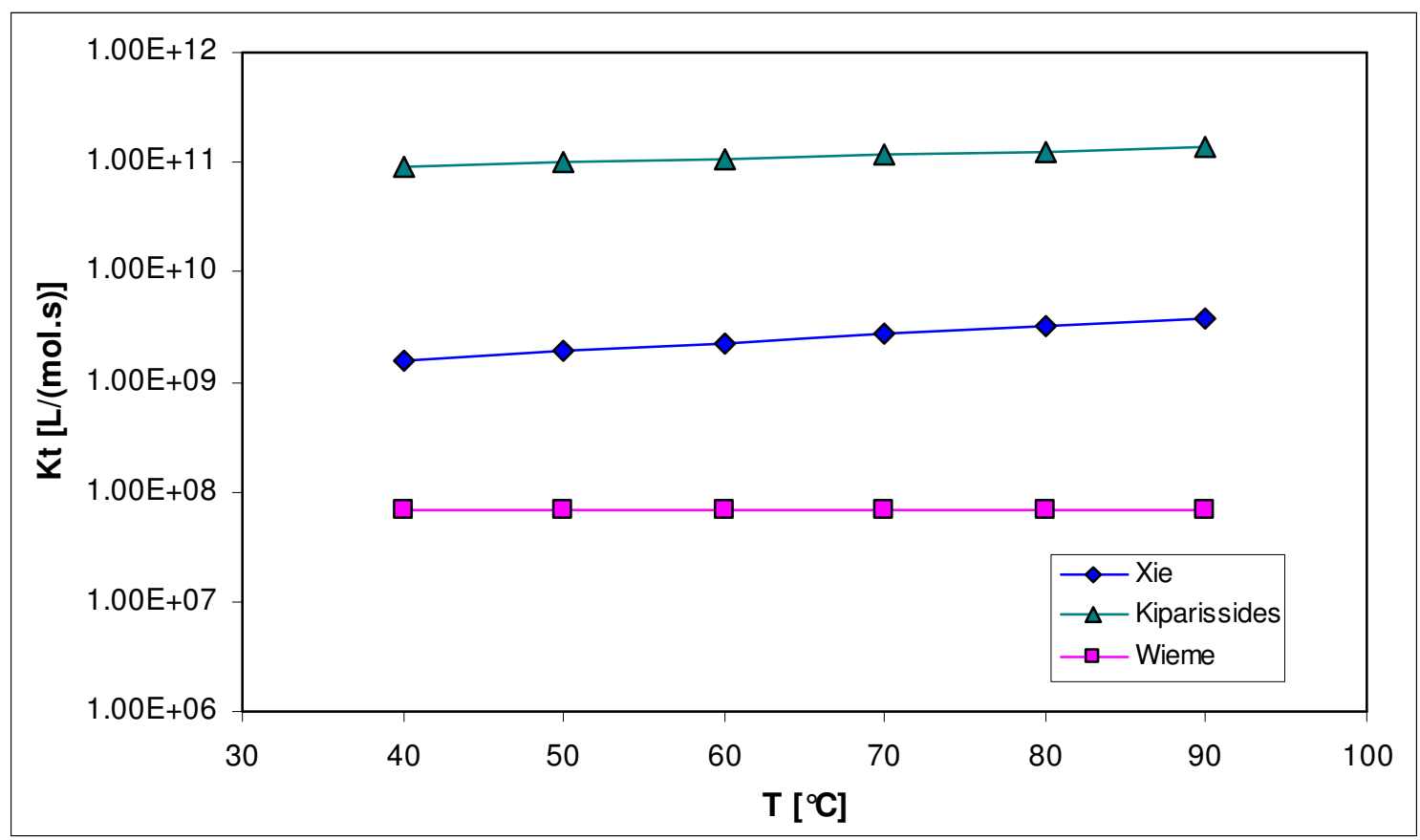

Figura 29 - Comparação entre as constantes cinéticas de terminação reportadas por diferentes autores.

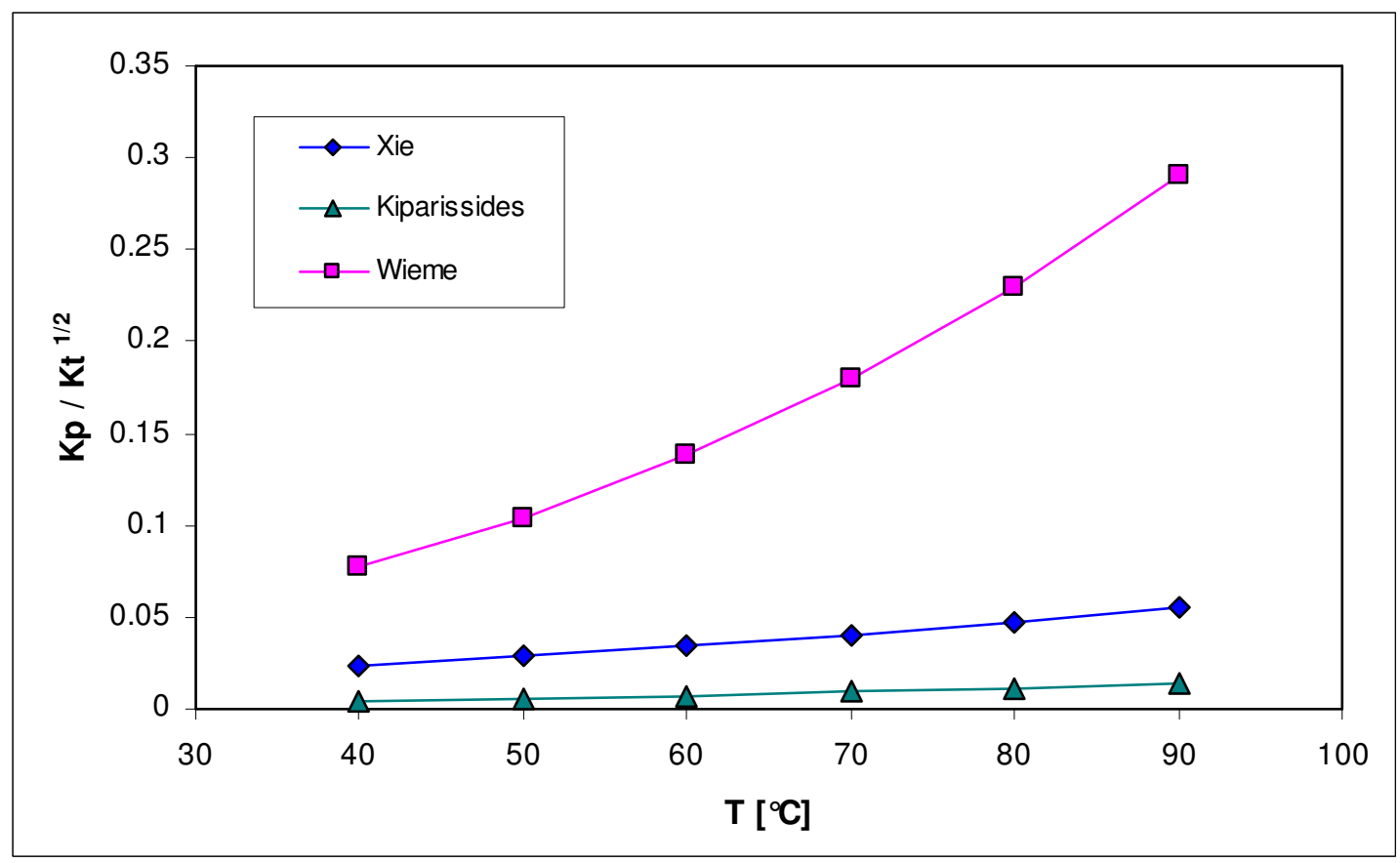

Figura 30 - Comparação entre o grupo de constantes cinéticas $k_{p d} /\left(k_{t o}\right)^{1 / 2}$ reportados por diferentes autores. 
Estas incertezas sugerem que parâmetros como os citados $\left(k_{d}, k_{p o}\right.$ e $\left.k_{t o}\right)$ poderiam, em princípio, serem incluídos entre os parâmetros ajustáveis do modelo. Entretanto, esta opção deveria ser cuidadosamente analisada uma vez que com o aumento do número de parâmetros ajustáveis, aumenta a chance de ocorrência de interação entre parâmetros, dificultando (ou mesmo inviabilizando) sua correta estimação no procedimento de regressão não-linear. Quando possível, é sempre desejável determinar cada um dos parâmetros por medições diretas e independentes. Neste sentido, poder-se-ia determinar a constante de decomposição do iniciador em meios similares ao meio reacional (p.ex. em solvente que mimetize o cloreto de vinila). Da mesma forma, já existe metodologia bem estabelecida para a determinação de constante de propagação baseada na técnica de PLP - polimerização com pulsos de laser - (Buback, 2009), muito embora ainda não tenham sido reportados resultados específicos para o monômero cloreto de vinila.

Por conta destas diferenças entre as fontes de dados, pela carência de maiores detalhes sobre os procedimentos experimentais praticados nos trabalhos de onde os dados foram obtidos, e pela relativa incerteza sobre os parâmetros fixados no modelo, pode-se considerar satisfatório o desempenho do modelo obtido na presente dissertação.

Deve-se lembrar que é importante obter um modelo suficientemente geral para o processo de polimerização em suspensão de PVC, que funcione com boa confiabilidade para diferentes tipos de iniciadores. Este tipo de modelo é necessário quando se quer otimizar o processo de polimerização. Para o aumento da produção de polímero em uma dada unidade industrial, é necessário reduzir ao máximo o tempo para completar cada batelada. Tipicamente, a limitação para isso ocorrer em processos industriais recai sobre a capacidade de troca de calor do reator de polimerização. As polimerizações são feitas isotermicamente de modo a garantir um dado peso molecular médio desejado constante ao longo da polimerização, bem como uma distribuição estreita de massas molares. O sistema de resfriamento do reator foi projetado para uma dada capacidade máxima de troca de calor, a qual não é usada em sua plenitude durante toda a batelada. Quando se usa um único iniciador, a curva de conversão versus tempo apresenta tipicamente uma concavidade para cima, e a velocidade de 
polimerização não é constante, como se pode observar nas figuras apresentadas neste Capítulo (tanto os dados experimentais como o modelo). Isto significa que apenas no instante em que a velocidade de polimerização é máxima, o sistema de resfriamento estará sendo usado em sua plena capacidade.

Um modo eficaz e muito usado para aumentar a produtividade de processos de polimerização de cloreto de vinila é o uso de "coquetel" de iniciadores, mistura de diferentes iniciadores capaz de modular a taxa de polimerização tornando-a, idealmente, constante (e a máxima permitida pelo sistema de resfriamento do reator) durante o processo. Desta forma, a batelada é completada em menor tempo possível, maximizando a produtividade do processo.

Trata-se de uma estratégia interessante para a produção de PVC uma vez que sua massa molar é dependente, principalmente, da temperatura e não das concentrações de iniciadores, permitindo estudar quais iniciadores e concentrações resultam na melhor opção de operação, sem alterar as propriedades finais (massa molar) do polímero produzido.

Para a correta determinação da mistura "ótima" de iniciadores, é necessário resolver um problema de otimização, o qual utiliza o modelo do processo para prever o desempenho de cada formulação do coquetel de iniciadores. Este modelo deverá, tanto quanto possível, ser capaz de prever a evolução da conversão versus tempo (e também de variáveis de qualidade do polímero, como o peso molecular) para diferentes iniciadores, e para misturas de iniciadores.

Os resultados obtidos no presente trabalho se inserem neste esforço de obter um modelo suficientemente geral para este processo. O modelo aqui estudado está ainda limitado à previsão da curva conversão versus tempo, mas poderá incorporar em etapas futuras, outras previsões importantes, tais como as massas moleculares médias mássica e numérica, e o índice de polidispersidade.

Da mesma maneira, o modelo poderá ser validado com dados experimentais de polimerizações com iniciadores bifuncionais. O mecanismo cinético envolvido para estes iniciadores foi apresentado no Capítulo 3 e o equacionamento correspondente está descrito no Apêndice B, seguindo o trabalho de Krallis et al. (2004). A vantagem apresentada na utilização de um iniciador do tipo bifuncional está no fato de, por 
possuir dois grupos peróxidos, eles são capazes de gerar mais radicais por molécula de iniciador. Além disso, esses iniciadores podem gerar diradicais possibilitando o crescimento da cadeia em dois sentidos, em princípio permitindo obter polímeros com maiores massas moleculares.

As constantes cinéticas de decomposição desses grupos podem ser diferentes quando o iniciador se apresentar de forma assimétrica. Esta situação pode ser interessante no caso de uma otimização, uma vez que a geração de radicais em momentos diferentes possibilita a continuidade da reação por mais tempo. 


\section{CONCLUSÕES E RECOMENDAÇÕES}

Um modelo cinético de polimerização em suspensão do cloreto de vinila via radicais livres, baseado no modelo proposto por Xie et al. (1991a), foi testado. Parâmetros foram ajustados e então o modelo foi simulado a fim de proceder a uma comparação com os dados experimentais obtidos na literatura para faixas relativamente amplas de temperatura $\left(45\right.$ a $\left.70^{\circ} \mathrm{C}\right)$, concentração de iniciador $(0,0262$ a $4,21 \% \mathrm{em}$ relação ao monômero) e seis diferentes tipos de iniciadores. Foram discutidos os efeitos de incertezas existentes sobre alguns parâmetros cinéticos sobre as previsões do modelo.

Do exposto ao longo deste trabalho, pode-se concluir:

- O modelo foi capaz de representar adequadamente todos os dados experimentais testados quando ajustado individualmente para cada ensaio.

- Quando aplicada uma correlação generalizada para os parâmetros A e B, o modelo representou de forma satisfatória, tanto qualitativa como quantitativamente, a maioria dos dados experimentais.

Dois outros modelos com diferentes equacionamentos de limitações difusionais foram testados e não apresentaram boa capacidade de representação dos dados experimentais aqui utilizados.

Como recomendações para a continuidade de trabalho, sugerem-se os seguintes pontos:

- Análise crítica das constantes cinéticas de propagação e terminação, que neste trabalho foram obtidas na literatura, mas que também poderiam sofrer ajustes, tendo em vista que foram encontradas divergências na determinação destas 
constantes, entre alguns autores estudados (Xie et al. ,1991a, Kiparissides et al., 1997, Wieme et al., 2007).

- Análise crítica das constantes cinéticas de decomposição dos iniciadores, dadas as divergências discutidas no Capítulo 4, bem como de outros parâmetros fixados no modelo, tais como o coeficiente de partição de iniciador.

- Estudos de outros modelos de correções das constantes cinéticas de terminação e propagação por efeitos de limitações difusionais (efeito gel e efeito vítreo, respectivamente).

- Considerar no modelo, além das correções das constantes de propagação e terminação, a correção da eficiência (efeito gaiola).

- Testar os modelos para uma maior gama de dados experimentais e para faixas de temperatura e concentração mais amplas.

- Incorporar ao modelo, juntamente com a previsão da conversão ao longo do tempo, a determinação de características estruturais do polímero produzido, tais como as massas moleculares médias mássica e numérica, e o índice de polidispersidade.

- Acrescentar ao modelo cinético a iniciação por iniciadores bifuncionais.

- Estudo sobre otimização da reação de polimerização do cloreto de vinila através da utilização de uma mistura de iniciadores, baseado nas análises de Pinto e Giudici (2001). 


\section{REFERÊNCIAS}

Abdel-Alim, A. H.; Hamielec, A. E. Bulk polymerization of vinyl chloride. Journal of Applied Polymer Science, 16, 783 - 799. (1972).

Achilias, D. S.; Kiparissides, C. Development of general mathematical framework for modeling diffusion-controlled free-radical polymerization reactions. Macromolecules, 25, 3739-3750. (1992).

AKZO NOBEL - Initiators for High Polymers. Disponível em: <http://www.akzonobelpolymerchemicals.com/NR/rdonlyres/C2D64A96-B539-4769-A688-

2447258D3DCA/0/InitiatorsforHighPolymersAkzoNobel2006.pdf>. Acesso em: $27 \mathrm{Jul}$, 2007.

Alexopoulos, A. H.; Kiparissides, C. On the prediction of internal particle morphology in suspension polymerization of vinyl chloride. Part I: The effect of primary particle size distribution. Chemical Engineering Science, 62, 3970-3983. (2007).

Andrade, M. Braskem vai duplicar unidade de PVC em Alagoas. Disponível em: <http://milenaandrade.wordpress.com/>. Acesso em: 27 Ago 2008.

Arkema - Organic Peroxide Half-life Selection Guide. Disponível em: <http://www.arkema-inc.com/pdf/HalfLife.xls>. Acesso em: 30 Jul, 2007.

Buback, M. II. Fundamentals of free-radical polymerization propagation kinetics in radical polymerization studied via pulsed laser techniques. Macromolecular Symposia, 275-276, 90-101 (2009).

Cebollada, A. F.; Schmidt, M. J.; Farber, N. J.; Capiati, N. J.; Vallés, E. M. Suspension polymerization of vinyl chloride. I. Influence of viscosity of suspension medium on resin properties. Journal of Applied Polymer Science, 37, 145 - 166. (1989).

Chemicalland21 - Disponível em:

<http://chemicalland21.com/specialtychem/NH/LAUROYL\%20PEROXIDE.htm>. Acesso em: 26 Fev, 2009. 
Chiu, W.Y.; Carrat, G.M.; Soong, D.S. A computer model for the gel effect in free-radical polymerization. Macromolecules, 16, 348-357. (1983).

Crosato-Arnaldi, A.; Gasparini, P.; Talamini, G. The bulk and suspension polymerization of vinyl chloride. Die Makromolekulare Chemie, 117 (1),140-152. (1968).

De Roo, T.; Wieme, J.; Heynderickx, G. J.; Marin, G. B. Estimation of intrinsic rate coefficients in vinyl chloride suspension polymerization. Polymer, 46, 8340 - 8354. (2005).

Dhib, R.; Al-Nidawy, N. Modelling of free radical polymerization of ethylene using difunctional initiators. Chemical Engineering Science, 57, 2735-2746. (2002).

Estenoz, D. A.; Leal, G. P.; Lopez, Y. R.; Oliva, H. M.; Meira, G. R. Bulk polymerization of styrene in the presence of polybutadiene. The use of bifunctional initiators. Journal of Applied Polymer, 62, 917-939. (1996).

Giudici, R. Polymerization reaction engineering: a personal overview of the state-of-art, Latin American Applied Research, 30, 351-356. (2000).

González, I. M.; Meira, G. R.; Oliva, H. M. Synthesis of polystyrene with mixtures of mono- and bifunctional initiators. Journal of Applied Polymer, 59, 1015-1026. (1996).

Hamielec, A. E.; Tobita, H. Polymerization Processes. Ullmann's Encyclopedia of Industrial Chemistry, vol. A21, 305-428. (1992).

Instituto do PVC. Disponível em:

<http://www.institutodopvc.org/publico/?a=conteudo\&canal_id=39\&subcanal_id=40>. Acesso em: 20 Ago, 2007.

Kim, K. J.; Choi, K. Y. Modeling of free radical polymerization of styrene catalyzed by unsymmetrical bifunctional initiators. Chemical Engineering Science, 44 (2), 297-312. (1989).

Kiparissides, C. Polymerization reactor modeling: a review of recent developments and future directions. Chemical Engineering Science, 51 (10), 1637-1659. (1996). 
Kiparissides, C., Daskalakis, G., Achilias, D. S., Sidiropoulos, E. Dynamic simulation of industrial poly(vinyl chloride) batch suspension polymerization reactors. Industrial Engineering and Chemical Research, 36, 1253-1267. (1997).

Krallis, A., Kotoulas, C., Papadopoulos, S., Kiparissides, C., Bousquet, J., Bonardi, C. A comprehensive kinetic model for free-radical polymerization of vinyl chloride in the presence of monofunctional and bifunctional Initiators. Industrial and Engineering Chemistry Research, 43 (20), 6382-6399. (2004).

Kuchanov, S. I.; Bort, D. N. Kinetics and mechanism of bulk polymerization of vinyl chloride. Polymer Science, USSR, A15, 2712-2736. (1973).

Kumar, V. R.; Gupta, S. K. Optimal parameter estimation for methyl methacrylate polymerization. Polymer, 32 (17), 3233-3243. (1990).

Marten, F.L.; Hamielec A.E. High conversion diffusion-controlled polymerization. ACS Symposium Series. 104, 43-70. (1979).

Moad, G.; Solomon, D. H. The chemistry of free-radical polymerization. $1^{\text {a }}$ edição, Oxford, U. K. Pergamon Elsevier Science LTD. (1995).

Pinto, J. M., Giudici, R. Optimization of a cocktail of initiators for suspension polymerization of vinyl chloride in batch reactors. Chemical Engineering Science, 56, 1021-1028. (2001).

Ray, W. H. On the mathematical modeling of polymerization reactors. Journal of Macromolecular Science, C8(1), 1-56. (1972).

Revista Plástico Moderno - Disponível em: $<$ http://www.plasticomoderno.com.br/revista/pm316/pvc2.htm>. Acesso em: $28 \mathrm{Fev}$ 2009.

Rodolfo Jr., A.; Nunes, L. R.; Ormanji, W. Tecnologia do PVC, $2^{\mathrm{a}}$ edição; ProEditores Associados Ltda., Brasil. (2006).

Saeki, Y.; Emura, T. Technical progress for PVC production. Progresse in Polymer Science, 27, 2055-2131. (2002). 
Sidiropoulou, E., Kiparissides, C. Mathematical modeling of PVC suspension polymerization: a unifying approach and some new results. Journal of Macromolecular Science - Chem. A27(3), 257-288. (1990).

Starnes, W. H., Jr.; Zaikov, V. G.; Chung, H. T.; Wojciechowski, B. J. Intramolecular hydrogen transfer in vinyl chloride polymerization: routes to doubly branched structures and internal double bonds. Macromolecules, 31, 1508-1517. (1998).

Starnes, W. H., Jr. Structural and mechanistic aspects of the thermal degradation of poly(vinyl chloride). Progress in Polymer Science, 27, 2133-2170. (2002).

Villalobos, M. A.; Hamielec, A. E.; Wood, P. E. Kinetic model for short-cycle bulk Styrene polymerization through bifunctional initiators. Journal of Applied Polymer Science, 42, 629 -641. (1991).

Villalobos, M. A.; Hamielec, A. E.; Wood, P. E. Bulk and suspension polymerization of styrene in the presence of $n$-pentane. An evaluation of monofunctional and bifunctional initiation. Journal of Applied Polymer, 50, 327-343. (1993).

Wen M.; Mc-Cormick, A. Y. A kinetic model for radical trapping in photopolymerization of multifunctional monomers. Macromolecules, 33, 9247-9254. (2000).

Wieme, J.; De Roo, T.; Marin, G. B.; Heynderickx, G. J. Process design and control simulation of pilot- and industrial-scale vinyl chloride batch suspension polymerization reactors. Industrial Engineering Chemical Research, 46, 4, 1179-1196. (2007).

Xie, T. Y., Hamielec, A.E., Wood, P.E., Woods, D. R. Experimental investigation of vinyl chloride polymerization at high conversion - temperature/ pressure/ conversion and monomer phase distribution relationships. Journal of Applied Polymer Science, 34, 1749 -1766. (1987).

Xie, T. Y.; Hamielec, A. E.; Wood, P. E.; Woods, D. R. Experimental investigation of vinyl chloride polymerization at high conversion - mechanism, kinetics and modelling. Polymer, 32 (3), 537 - 557. (1991a).

Xie, T. Y.; Hamielec, A. E.; Wood, P. E.; Woods, D. R. Experimental investigation of vinyl chloride polymerization at high conversion - semi-batch reactor modelling. Polymer, 32 (11), 2087 - 2095. (1991b). 
Xie, T. Y.; Hamielec, A. E.; Wood, P. E.; Woods, D. R. Suspension, bulk and emulsion polymerization of vinyl chloride - mechanism, kinetics, and reactor modeling. Journal of Vinyl Technology, 13 (1), 2-25. (1991c). 


\section{APÊNDICE A}

Em uma tentativa de melhorar o modelo utilizado neste trabalho, foram testados outros exemplos de correções de constantes cinéticas devido às limitações difusionais.

Uma das alternativas estudadas foi o modelo proposto por Wen e McCormick (2000) para a polimerização de monômeros multifuncionais, no caso o diacrilato e o dimetacrilato. As expressões das constantes cinéticas utilizadas neste modelo estão descritas abaixo:

$k_{p 1}=\frac{k_{p 0}}{1+e^{A_{p}\left(1 / V_{f m}-1 / V_{f c p}\right)}}$

$k_{p 2}=\frac{k_{p 0}}{1+e^{A_{p}\left(1 / V_{f}-1 / V_{f c p}\right)}}$

$k_{t 1}=k_{t 0}\left(1+\frac{1}{\frac{R D k_{p}\left[M_{1}\right]}{k_{t 0}}+e^{A_{t}\left(1 / V_{f m}-1 / V_{f c t}\right)}}\right)^{-1}$

$k_{t 2}=k_{t 0}\left(1+\frac{1}{\frac{R D k_{p}\left[M_{2}\right]}{k_{t 0}}+e^{A_{t}\left(1 / V_{f}-1 / V_{f c t}\right)}}\right)^{-1}$ 


$$
f=\left[1-\left(1-\frac{1}{f_{0}}\right) e^{A_{i}\left(1 / V_{f}-1 / V_{f 0}\right)}\right]^{-1}
$$

sendo:

$k_{p 0}$ e $k_{t 0}$ representam as constantes de propagação e terminação, respectivamente, na ausência de limitações difusionais;

$f_{0}$ indica a eficiência, para esta mesma condição;

$\left[M_{1}\right]$ e $\left[M_{2}\right]$ são as concentrações de monômero nas fases 1 e 2, respectivamente; $R D$ é um parâmetro de difusão por reação ("reaction-difusion") e neste trabalho foi fixado em 1.

Ao se utilizar este modelo, os parâmetros que passaram por um teste de ajuste foram: $A_{p}, A_{t}$ e $A_{i}$, parâmetro este que governa a que taxa a eficiência do iniciador decai no período no qual as reações são controladas por difusão. De forma análoga, os outros dois estão relacionados à diminuição das constantes de propagação e de terminação, respectivamente.

Além destes, outros dois parâmetros também passaram por ajustes: $V_{f c p}$ e $V_{f c t}$. Eles representam a fração de volume livre característico no qual a resistência difusional iguala-se à resistência intrínseca à reação.

A tentativa de ajuste do modelo através da estimativa destes parâmetros não resultou em bons resultados.

Um outro modelo estudado foi proposto por Kumar e Gupta (1990) para a polimerização do metacrilato de metila e para a produção do poliestireno.

As equações das correções das constantes cinéticas de terminação e propagação são mostradas a seguir: 


$$
\begin{array}{ll}
\frac{1}{k_{t j}}=\frac{1}{k_{t 0}}+\theta_{t} \frac{\left\lfloor R_{j}\right\rfloor}{\exp \left[\frac{2,303 \phi_{m j}}{A+B \phi_{m j}}\right]} \quad \text { para } \mathrm{j}=1,2 \\
\frac{1}{k_{p j}}=\frac{1}{k_{p 0}}+\theta_{p} \frac{\left\lfloor R_{j}\right\rfloor}{\exp \left[\frac{2,303 \phi_{m j}}{A+B \phi_{m j}}\right]} \quad \text { para } \mathrm{j}=1,2
\end{array}
$$

sendo:

$\left\lfloor R_{j}\right\rfloor$ a concentração total dos radicais na fase $\mathrm{j}$;

$\phi_{m j}$ a fração volumétrica de monômero na fase j $\left(\phi_{m 1}=1\right)$.

Para este modelo, os parâmetros que passaram por ajustes foram $A, B, \theta_{t}$ e $\theta_{p}$. Também para este modelo os ajustes obtidos não foram satisfatórios. 


\section{APÊNDICE B}

As reações a seguir foram elaboradas tendo em vista a eventual utilização de iniciadores bifuncionais na reação de polimerização do VCM.

A estrutura molecular de um iniciador bifuncional assimétrico pode ser representada do seguinte modo (Krallis et al., 2004):

$$
R_{1}-\frac{O-O}{A}-R_{3}-R_{4}-\frac{O-O}{B}-R_{2}
$$

em que $R_{1}, R_{2}, R_{3}$ e $R_{4}$ representam diferentes ligantes hidrocarbonetos e a ligação entre os átomos de oxigênio, a presença do grupo peróxido. Ele pode sofrer dois tipos de decomposição:

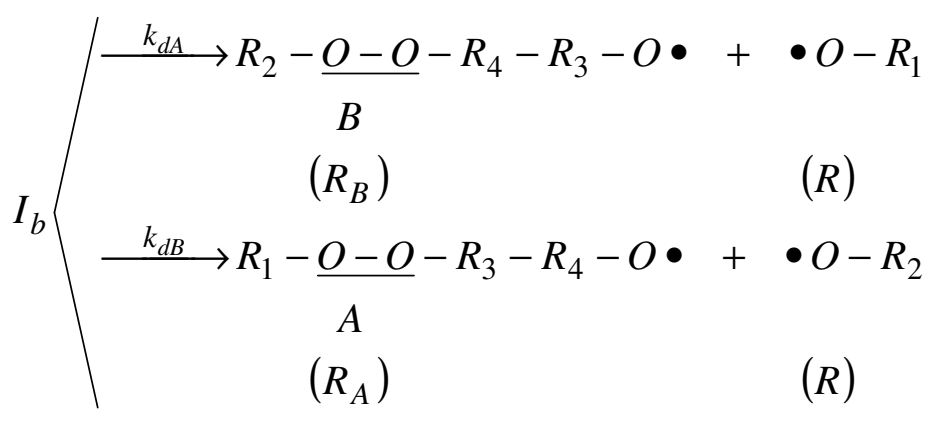

em que $k_{d A}$ e $k_{d B}$ representam as taxas de decomposição dos grupos peróxidos tipo A e tipo $B$, respectivamente.

Observa-se no esquema de decomposição do iniciador bifuncional assimétrico a formação de três tipos diferentes de radicais primários, sendo eles $R_{A}, R_{B}$ e $R$. Nota-se que os radicais primários $R_{A}$ e $R_{B}$ ainda possuem em sua estrutura um grupo peróxido 
passível de sofrer decomposição e gerar novos radicais. Esta decomposição pode ser assim representada:

$$
\begin{aligned}
& R_{A} \stackrel{k_{d A}}{\longrightarrow} \bullet O-R_{3}-R_{4}-O \bullet+\bullet O-R_{1} \\
& \left(R^{\prime}\right) \\
& R_{B} \stackrel{k_{d B}}{\longrightarrow} \bullet O-R_{4}-R_{3}-O \bullet+\bullet O-R_{2} \\
& \left(R^{\prime}\right)
\end{aligned}
$$

em que $R$ ' indica uma molécula de diradical primário.

A partir das reações esquematizadas anteriormente no Capítulo 3, pode-se efetuar o balanço de massa, combinando as taxas de formação e consumo das espécies envolvidas na reação.

As possíveis reações que acontecem na fase j (rica em monômero, j = 1 e rica em polímero, j = 2) podem ser assim descritas (Krallis et al., 2004):

\section{- Balanço de massa para cadeias de polímero vivo de comprimento n}

$$
\begin{aligned}
& \frac{1}{V^{j}} \frac{d\left(P_{n}^{j} V^{j}\right)}{d t}=\left(k_{p}^{j} R^{j} M^{j}+k_{f m}^{j} M^{j} \sum_{m=1}^{\infty} P_{m}^{j}+k_{f m}^{j} M^{j} \sum_{m=1}^{\infty} Q_{m}^{j}+k_{f m}^{j} M^{j} \sum_{m=1}^{\infty} S_{m}^{j}\right) \delta(n-1)+ \\
& \quad+\left(2 k_{f m}^{j} M^{j} \sum_{m=1}^{\infty} T_{m}^{j}\right) \delta(n-1)+f_{i r} k_{d A}^{2} U_{n} \frac{V}{V^{j}}(j-1)+f_{i r} k_{d B}^{2} V_{n} \frac{V}{V^{j}}(j-1)+ \\
& \quad+k_{p}^{j} M^{j}\left(P_{n-1}^{j}-P_{n}^{j}\right)-k_{f m}^{j} M^{j} P_{n}^{j}+2 k_{f m}^{j} M^{j} T_{n}^{j}- \\
& \quad-k_{t c}^{j} P_{n}^{j}\left(\sum_{m=1}^{\infty} P_{m}^{j}+\sum_{m=1}^{\infty} Q_{m}^{j}+\sum_{m=1}^{\infty} S_{m}^{j}+2 \sum_{m=1}^{\infty} T_{m}^{j}\right)+2 k_{t c}^{j} \sum_{m=1}^{n-1} P_{m}^{j} T_{n-m}^{j}- \\
& \quad-k_{t d}^{j} P_{n}^{j}\left(\sum_{m=1}^{\infty} P_{m}^{j}+\sum_{m=1}^{\infty} Q_{m}^{j}+\sum_{m=1}^{\infty} S_{m}^{j}+2 \sum_{m=1}^{\infty} T_{m}^{j}\right)+ \\
& \quad+2 k_{t d}^{j} T_{n}^{j}\left(\sum_{m=1}^{\infty} P_{m}^{j}+\sum_{m=1}^{\infty} Q_{m}^{j}+\sum_{m=1}^{\infty} S_{m}^{j}+2 \sum_{m=1}^{\infty} T_{m}^{j}\right)- \\
& \quad-k_{z}^{j} Z^{j} P_{n}^{j}+2 k_{z}^{j} Z^{j} T_{n}^{j}+\left(1-f_{i r}\right)\left(k_{d A}^{j} Q_{n}^{j}+k_{d B}^{j} S_{n}^{j}\right)
\end{aligned}
$$


em que $\delta(n-1)$ é o delta de Kronecker, o qual assume valor 1 para $n=1$ e 0 para $n \neq 1$.

O sub-índice $m$ refere-se ao tamanho da cadeia polimérica e pode assumir infinitos valores, inclusive, o mesmo valor de $n$.

$$
\begin{aligned}
& \frac{1}{V^{j}} \frac{d\left(Q_{n}^{j} V^{j}\right)}{d t}=\left(k_{p}^{j} R_{A}^{j} M^{j}\right) \delta(n-1)-k_{d A}^{j} Q_{n}^{j}+f_{i r} k_{d B}^{2} W_{n} \frac{V}{V^{j}}(j-1)+2 f_{i r} k_{d A}^{2} U^{\prime}{ }_{n} \frac{V}{V^{j}}(j-1)+ \\
& \quad+k_{p}^{j} M^{j}\left(Q_{n-1}^{j}-Q_{n}^{j}\right)-k_{f m}^{j} M^{j} Q_{n}^{j}-k_{t c}^{j} Q_{n}^{j}\left(\sum_{m=1}^{\infty} P_{m}^{j}+\sum_{m=1}^{\infty} Q_{m}^{j}+\sum_{m=1}^{\infty} S_{m}^{j}+2 \sum_{m=1}^{\infty} T_{m}^{j}\right)+ \\
& \quad+2 k_{t c}^{j} \sum_{m=1}^{n-1} Q_{m}^{j} T_{n-m}^{j}-k_{t d}^{j} Q_{n}^{j}\left(\sum_{m=1}^{\infty} P_{m}^{j}+\sum_{m=1}^{\infty} Q_{m}^{j}+\sum_{m=1}^{\infty} S_{m}^{j}+2 \sum_{m=1}^{\infty} T_{m}^{j}\right)-k_{z}^{j} Z^{j} Q_{n}^{j}
\end{aligned}
$$

$$
\begin{aligned}
& \frac{1}{V^{j}} \frac{d\left(S_{n}^{j} V^{j}\right)}{d t}=\left(k_{p}^{j} R_{B}^{j} M^{j}\right) \delta(n-1)-k_{d B}^{j} S_{n}^{j}+f_{i r} k_{d A}^{2} W_{n} \frac{V}{V^{j}}(j-1)+2 f_{i r} k_{d B}^{2} V_{n}^{\prime} \frac{V}{V^{j}}(j-1)+ \\
& \quad+k_{p}^{j} M^{j}\left(S_{n-1}^{j}-S_{n}^{j}\right)-k_{f m}^{j} M^{j} S_{n}^{j}-k_{t c}^{j} S_{n}^{j}\left(\sum_{m=1}^{\infty} P_{m}^{j}+\sum_{m=1}^{\infty} Q_{m}^{j}+\sum_{m=1}^{\infty} S_{m}^{j}+2 \sum_{m=1}^{\infty} T_{m}^{j}\right)+ \\
& \quad+2 k_{t c}^{j} \sum_{m=1}^{n-1} S_{m}^{j} T_{n-m}^{j}-k_{t d}^{j} S_{n}^{j}\left(\sum_{m=1}^{\infty} P_{m}^{j}+\sum_{m=1}^{\infty} Q_{m}^{j}+\sum_{m=1}^{\infty} S_{m}^{j}+2 \sum_{m=1}^{\infty} T_{m}^{j}\right)-k_{z}^{j} Z^{j} S_{n}^{j}
\end{aligned}
$$

$$
\begin{aligned}
& \frac{1}{V^{j}} \frac{d\left(T_{n}^{j} V^{j}\right)}{d t}=\left(2 k_{p}^{j} R^{\prime j} M^{j}\right) \delta(n-1)+f_{i r} k_{d A}^{j} Q_{n}^{j}+f_{i r} k_{d B}^{j} S_{n}^{j}+2 k_{p}^{j} M^{j}\left(T_{n-1}^{j}-T_{n}^{j}\right)- \\
& \quad-2 k_{f m}^{j} M^{j} T_{n}^{j}-2 k_{t c}^{j} T_{n}^{j}\left(\sum_{m=1}^{\infty} P_{m}^{j}+\sum_{m=1}^{\infty} Q_{m}^{j}+\sum_{m=1}^{\infty} S_{m}^{j}+2 \sum_{m=1}^{\infty} T_{m}^{j}\right)+ \\
& \quad+2 k_{t c}^{j} \sum_{m=1}^{n-1} T_{m}^{j} T_{n-m}^{j}-2 k_{t d}^{j} T_{n}^{j}\left(\sum_{m=1}^{\infty} P_{m}^{j}+\sum_{m=1}^{\infty} Q_{m}^{j}+\sum_{m=1}^{\infty} S_{m}^{j}+2 \sum_{m=1}^{\infty} T_{m}^{j}\right)-2 k_{z}^{j} Z^{j} T_{n}^{j}
\end{aligned}
$$




$$
\begin{aligned}
& \frac{1}{V} \frac{d\left(U_{n} V\right)}{d t}=-k_{d A}^{2} U_{n}+\sum_{j=1}^{2} k_{f m}^{j} M^{j} Q_{n}^{j} \frac{V^{j}}{V}+\sum_{j=1}^{2} k_{t c}^{j} \sum_{m=1}^{n-1} P_{m}^{j} Q_{n-m}^{j} \frac{V^{j}}{V}+ \\
& \quad+\sum_{j=1}^{2} k_{t d}^{j} Q_{n}^{j}\left(\sum_{m=1}^{\infty} P_{m}^{j}+\sum_{m=1}^{\infty} Q_{m}^{j}+\sum_{m=1}^{\infty} S_{m}^{j}+2 \sum_{m=1}^{\infty} T_{m}^{j}\right) \frac{V^{j}}{V}+\sum_{j=1}^{2} k_{z}^{j} Z_{n}^{j} Q_{n}^{j} \frac{V^{j}}{V}+ \\
& \quad+\left(1-f_{i r}\right)\left(k_{d B}^{2} W_{n}+2 k_{d A}^{2} U_{n}^{\prime}\right)
\end{aligned}
$$

$$
\begin{aligned}
& \frac{1}{V} \frac{d\left(V_{n} V\right)}{d t}=-k_{d B}^{2} V_{n}+\sum_{j=1}^{2} k_{f m}^{j} M^{j} S_{n}^{j} \frac{V^{j}}{V}+\sum_{j=1}^{2} k_{t c}^{j} \sum_{m=1}^{n-1} P_{m}^{j} S_{n-m}^{j} \frac{V^{j}}{V}+ \\
& \quad+\sum_{j=1}^{2} k_{t d}^{j} S_{n}^{j}\left(\sum_{m=1}^{\infty} P_{m}^{j}+\sum_{m=1}^{\infty} Q_{m}^{j}+\sum_{m=1}^{\infty} S_{m}^{j}+2 \sum_{m=1}^{\infty} T_{m}^{j}\right) \frac{V^{j}}{V}+\sum_{j=1}^{2} k_{z}^{j} Z_{n}^{j} S_{n}^{j} \frac{V^{j}}{V}+ \\
& \quad+\left(1-f_{i r}\right)\left(k_{d A}^{2} W_{n}+2 k_{d B}^{2} V_{n}^{\prime}\right)
\end{aligned}
$$

$$
\frac{1}{V} \frac{d\left(W_{n} V\right)}{d t}=-\left(k_{d A}^{2}+k_{d B}^{2}\right) W_{n}+\sum_{j=1}^{2} k_{t c}^{j} \sum_{m=1}^{n-1} Q_{m}^{j} S_{n-m}^{j} \frac{V^{j}}{V}
$$

$$
\frac{1}{V} \frac{d\left(U_{n}^{\prime} V\right)}{d t}=-2 k_{d A}^{2} U^{\prime}{ }_{n}+\frac{1}{2} \sum_{j=1}^{2} k_{t c}^{j} \sum_{m=1}^{n-1} Q_{m}^{j} Q_{n-m}^{j} \frac{V^{j}}{V}
$$

$$
\frac{1}{V} \frac{d\left(V_{n}^{\prime} V\right)}{d t}=-2 k_{d B}^{2} V_{n}^{\prime}+\frac{1}{2} \sum_{j=1}^{2} k_{t c}^{j} \sum_{m=1}^{n-1} S_{m}^{j} S_{n-m}^{j} \frac{V^{j}}{V}
$$




$$
\begin{gathered}
\frac{1}{V} \frac{d\left(D_{n} V\right)}{d t}=\sum_{j=1}^{2} k_{f m}^{j} M^{j} P_{n}^{j} \frac{V^{j}}{V}+\frac{1}{2} \sum_{j=1}^{2} k_{t c}^{j} \sum_{m=1}^{n-1} P_{m}^{j} P_{n-m}^{j} \frac{V^{j}}{V}+ \\
+\sum_{j=1}^{2} k_{t d}^{j} P_{n}^{j}\left(\sum_{m=1}^{\infty} P_{m}^{j}+\sum_{m=1}^{\infty} Q_{m}^{j}+\sum_{m=1}^{\infty} S_{m}^{j}+2 \sum_{m=1}^{\infty} T_{m}^{j}\right) \frac{V^{j}}{V}+ \\
+\sum_{j=1}^{2} k_{z}^{j} Z_{n}^{j} P_{n}^{j} \frac{V^{j}}{V}+\left(1-f_{i r}\right)\left(k_{d A}^{2} U_{n}+k_{d B}^{2} V_{n}\right)
\end{gathered}
$$

Os momentos das equações deste modelo, para as duas fases e para todas as espécies envolvidas na reação, ficam assim definidos:

$$
\begin{aligned}
& \lambda_{\xi . k}^{j}=\sum_{n=1}^{\infty} n^{k} \xi_{n}^{j} \quad \xi=P, Q, S, T ; j=1,2 \\
& \lambda_{\theta, k}=\sum_{n=1}^{\infty} n^{k} \theta_{n} \quad \theta=U, V, W, U^{\prime}, V^{\prime} \\
& \mu_{k}=\sum_{n=1}^{\infty} n^{k} D_{n}
\end{aligned}
$$

em que $k$ representa a ordem dos momentos e, neste estudo, assume valores zero, um ou dois.

Multiplicando-se cada termo das expressões de balanço da massa por $n^{k} \mathrm{e}$ somando-se as expressões resultantes para toda a variação de $n$, obtêm-se as funções de momentos.

Nessas equações de momento aparecerão ainda as simplificações abaixo: 


$$
\begin{aligned}
& \frac{1}{V^{j}} \frac{d\left(V^{j} \lambda_{\xi . k}^{j}\right)}{d t}=r_{\lambda_{\xi . k}^{j}}, \quad j=1,2 \\
& \frac{1}{V^{2}} \frac{d\left(V^{2} \lambda_{\theta . k}^{2}\right)}{d t}=r_{\lambda_{\theta . k}^{2}} \\
& \frac{1}{V^{2}} \frac{d\left(V^{2} \lambda_{\mu . k}^{2}\right)}{d t}=r_{\lambda_{\mu . k}^{2}}
\end{aligned}
$$

ratificando a hipótese da existência de cadeias inativas apenas na fase rica em polímero $(j=2)$, devido a sua baixa solubilidade no monômero.

\section{- Equações de momentos para cadeias de polímeros vivos}

$$
\begin{aligned}
& r_{\lambda_{P, k}^{j}}=k_{p}^{j} R^{j} M^{j}+f_{i r} k_{d A}^{2} \lambda_{U, k} \frac{V}{V^{2}}(j-1)+f_{i r} k_{d B}^{2} \lambda_{V, k} \frac{V}{V^{2}}(j-1)+ \\
& +k_{p}^{j} M^{j}\left[\sum_{r=0}^{k}\left(\begin{array}{l}
k \\
r
\end{array}\right) \lambda_{P, r}^{j}-\lambda_{P, k}^{j}\right]+k_{f m}^{j} M^{j}\left(\lambda_{P, 0}^{j}+\lambda_{Q, 0}^{j}+\lambda_{S, 0}^{j}+2 \lambda_{T, 0}^{j}\right)- \\
& -k_{f m}^{j} M^{j}\left(\lambda_{P, k}^{j}-2 \lambda_{T, k}^{j}\right)-k_{t c}^{j} \lambda_{P, k}^{j}\left(\lambda_{P, 0}^{j}+\lambda_{Q, 0}^{j}+\lambda_{S, 0}^{j}+2 \lambda_{T, 0}^{j}\right)+ \\
& +2 k_{t c}^{j}\left[\sum_{r=0}^{k}\left(\begin{array}{l}
k \\
r
\end{array}\right) \lambda_{P, r}^{j} \lambda_{T, k-r}^{j}\right]-k_{t d}^{j} \lambda_{P, k}^{j}\left(\lambda_{P, 0}^{j}+\lambda_{Q, 0}^{j}+\lambda_{S, 0}^{j}+2 \lambda_{T, 0}^{j}\right)+ \\
& +2 k_{t d}^{j} \lambda_{T, k}^{j}\left(\lambda_{P, 0}^{j}+\lambda_{Q, 0}^{j}+\lambda_{S, 0}^{j}+2 \lambda_{T, 0}^{j}\right)- \\
& -k_{z}^{j} Z^{j} \lambda_{P, k}^{j}+2 k_{z}^{j} Z^{j} \lambda_{T, k}^{j}+\left(1-f_{i r}\right)\left(k_{d A}^{j} \lambda_{Q, k}^{j}+k_{d B}^{j} \lambda_{S, k}^{j}\right)
\end{aligned}
$$




$$
\begin{aligned}
& r_{\lambda_{Q, k}^{j}}=k_{p}^{j} R_{A}^{j} M^{j}-k_{d A}^{j} \lambda_{Q, k}^{j}+f_{i r} k_{d B}^{2} \lambda_{W, k} \frac{V}{V^{2}}(j-1)+k_{p}^{j} M^{j}\left[\sum_{r=0}^{k}\left(\begin{array}{l}
k \\
r
\end{array}\right) \lambda_{Q, r}^{j}-\lambda_{Q, k}^{j}\right]+ \\
& +2 f_{i r} k_{d A}^{2} \lambda_{U^{\prime}, k} \frac{V}{V^{2}}(j-1)-k_{f m}^{j} M^{j} \lambda_{Q, k}^{j}-k_{t c}^{j} \lambda_{Q, k}^{j}\left(\lambda_{P, 0}^{j}+\lambda_{Q, 0}^{j}+\lambda_{S, 0}^{j}+2 \lambda_{T, 0}^{j}\right)+ \\
& +2 k_{t c}^{j}\left[\sum_{r=0}^{k}\left(\begin{array}{l}
k \\
r
\end{array}\right) \lambda_{Q, r}^{j} \lambda_{T, k-r}^{j}\right]-k_{t d}^{j} \lambda_{Q, k}^{j}\left(\lambda_{P, 0}^{j}+\lambda_{Q, 0}^{j}+\lambda_{S, 0}^{j}+2 \lambda_{T, 0}^{j}\right)-k_{z}^{j} Z^{j} \lambda_{Q, k}^{j} \\
& r_{\lambda_{S, k}^{j}}=k_{p}^{j} R_{B}^{j} M^{j}-k_{d B}^{j} \lambda_{S, k}^{j}+f_{i r} k_{d A}^{2} \lambda_{W, k} \frac{V}{V^{2}}(j-1)+k_{p}^{j} M^{j}\left[\sum_{r=0}^{k}\left(\begin{array}{l}
k \\
r
\end{array}\right) \lambda_{S, r}^{j}-\lambda_{S, k}^{j}\right]+ \\
& +2 f_{i r} k_{d B}^{2} \lambda_{V^{\prime}, k} \frac{V}{V^{2}}(j-1)-k_{f m}^{j} M^{j} \lambda_{S, k}^{j}-k_{t c}^{j} \lambda_{S, k}^{j}\left(\lambda_{P, 0}^{j}+\lambda_{Q, 0}^{j}+\lambda_{S, 0}^{j}+2 \lambda_{T, 0}^{j}\right)+ \\
& +2 k_{t c}^{j}\left[\sum_{r=0}^{k}\left(\begin{array}{l}
k \\
r
\end{array}\right) \lambda_{S, r}^{j} \lambda_{T, k-r}^{j}\right]-k_{t d}^{j} \lambda_{S, k}^{j}\left(\lambda_{P, 0}^{j}+\lambda_{Q, 0}^{j}+\lambda_{S, 0}^{j}+2 \lambda_{T, 0}^{j}\right)-k_{z}^{j} Z^{j} \lambda_{S, k}^{j} \\
& r_{\lambda_{T, k}^{j}}=2 k_{p}^{j} R^{\prime j} M^{j}+f_{i r} k_{d A}^{j} \lambda_{Q, k}^{j}+f_{i r} k_{d B}^{j} \lambda_{S, k}^{j}+2 k_{p}^{j} M^{j}\left[\sum_{r=0}^{k}\left(\begin{array}{l}
k \\
r
\end{array}\right) \lambda_{T, r}^{j}-\lambda_{T, k}^{j}\right]- \\
& -2 k_{f m}^{j} M^{j} \lambda_{T, k}^{j}-2 k_{t c}^{j} \lambda_{T, k}^{j}\left(\lambda_{P, 0}^{j}+\lambda_{Q, 0}^{j}+\lambda_{S, 0}^{j}+2 \lambda_{T, 0}^{j}\right)+ \\
& +2 k_{t c}^{j}\left[\sum_{r=0}^{k}\left(\begin{array}{l}
k \\
r
\end{array}\right) \lambda_{T, r}^{j} \lambda_{T, k-r}^{j}\right]-2 k_{t d}^{j} \lambda_{T, k}^{j}\left(\lambda_{P, 0}^{j}+\lambda_{Q, 0}^{j}+\lambda_{S, 0}^{j}+2 \lambda_{T, 0}^{j}\right)-2 k_{z}^{j} Z^{j} \lambda_{T, k}^{j}
\end{aligned}
$$

\section{- Equação de momentos para as cadeias inativas}

$$
\begin{aligned}
r_{\lambda_{U, k}} & =-k_{d A}^{2} \lambda_{U, k}+\sum_{j=1}^{2} k_{f m}^{j} M^{j} \lambda_{Q, k}^{j} \frac{V^{j}}{V}+\sum_{j=1}^{2} k_{t c}^{j}\left[\sum_{r=0}^{k}\left(\begin{array}{l}
k \\
r
\end{array}\right) \lambda_{P, r}^{j} \lambda_{Q, k-r}^{j}\right] \frac{V^{j}}{V}+ \\
& +\sum_{j=1}^{2} k_{t d}^{j} \lambda_{Q, k}^{j}\left(\lambda_{P, 0}^{j}+\lambda_{Q, 0}^{j}+\lambda_{S, 0}^{j}+2 \lambda_{T, 0}^{j}\right)+\sum_{j=1}^{2} k_{z}^{j} Z^{j} \lambda_{Q, k}^{j} \frac{V^{j}}{V}+ \\
& +\left(1-f_{i r}\right)\left(k_{d B}^{2} \lambda_{W, k}+2 k_{d A}^{2} \lambda_{U^{\prime}, k}\right)
\end{aligned}
$$




$$
\begin{aligned}
r_{\lambda_{V, k}} & =-k_{d B}^{2} \lambda_{V, k}+\sum_{j=1}^{2} k_{f m}^{j} M^{j} \lambda_{S, k}^{j} \frac{V^{j}}{V}+\sum_{j=1}^{2} k_{t c}^{j}\left[\sum_{r=0}^{k}\left(\begin{array}{l}
k \\
r
\end{array}\right) \lambda_{P, r}^{j} \lambda_{S, k-r}^{j}\right] \frac{V^{j}}{V}+ \\
& +\sum_{j=1}^{2} k_{t d}^{j} \lambda_{S, k}^{j}\left(\lambda_{P, 0}^{j}+\lambda_{Q, 0}^{j}+\lambda_{S, 0}^{j}+2 \lambda_{T, 0}^{j}\right)+\sum_{j=1}^{2} k_{z}^{j} Z^{j} \lambda_{S, k}^{j} \frac{V^{j}}{V}+ \\
& +\left(1-f_{i r}\right)\left(k_{d A}^{2} \lambda_{W, k}+2 k_{d B}^{2} \lambda_{V^{\prime}, k}\right) \\
& =-\left(k_{d B}^{2}+k_{d A}^{2}\right) \lambda_{W, k}+\sum_{j=1}^{2} k_{t c}^{j}\left[\sum_{r=0}^{k}\left(\begin{array}{l}
k \\
r
\end{array}\right) \lambda_{Q, r}^{j} \lambda_{S, k-r}^{j}\right] \frac{V^{j}}{V} \\
r_{\lambda_{U^{\prime}, k}} & =-2 k_{d A}^{2} \lambda_{U^{\prime}, k}+\frac{1}{2} \sum_{j=1}^{2} k_{t c}^{j}\left[\sum_{r=0}^{k}\left(\begin{array}{l}
k \\
r
\end{array}\right) \lambda_{Q, r}^{j} \lambda_{Q, k-r}^{j}\right] \frac{V^{j}}{V} \\
r_{\lambda_{V^{\prime}, k}} & =-2 k_{d B}^{2} \lambda_{U^{\prime}, k}+\frac{1}{2} \sum_{j=1}^{2} k_{t c}^{j}\left[\sum_{r=0}^{k}\left(\begin{array}{l}
k \\
r
\end{array}\right) \lambda_{S, r}^{j} \lambda_{S, k-r}^{j}\right] \frac{V^{j}}{V}
\end{aligned}
$$

\section{- Equação de momentos para cadeia de polímero morto}

$$
\begin{aligned}
r_{\mu_{k}}= & \sum_{j=1}^{2} k_{f m}^{j} M^{j} \lambda_{P, k}^{j} \frac{V^{j}}{V}+\frac{1}{2} \sum_{j=1}^{2} k_{t c}^{j}\left[\sum_{r=0}^{k}\left(\begin{array}{l}
k \\
r
\end{array}\right) \lambda_{P, r}^{j} \lambda_{P, k-r}^{j}\right] \frac{V^{j}}{V}+ \\
& +\sum_{j=1}^{2} k_{t d}^{j} \lambda_{P, k}^{j}\left(\lambda_{P, 0}^{j}+\lambda_{Q, 0}^{j}+\lambda_{S, 0}^{j}+2 \lambda_{T, 0}^{j}\right) \frac{V^{j}}{V}+ \\
& +\sum_{j=1}^{2} k_{z}^{j} Z^{j} \lambda_{P, k}^{j} \frac{V^{j}}{V}+\left(1-f_{i r}\right)\left(k_{d A}^{2} \lambda_{U, k}+k_{d B}^{2} \lambda_{V, k}\right)
\end{aligned}
$$

